\title{
Erotic Economics: \\ Metaphysical Foundations in Three Platonic Dialogues
}

$$
\text { by }
$$

\author{
Justin Andrew Campbell
}

A thesis submitted to the Faculty of Graduate and Postdoctoral Affairs in partial fulfillment of the requirements for the degree of

Master of Arts

in

Political Science

Carleton University

Ottawa, Ontario

(C) 2015

Justin Andrew Campbell 


\section{Abstract}

Reading the arguments of the Meno, the Republic, and the Symposium within their mytho-historical context, this thesis proposes that there is an essentially economic dimension to Plato's moral and political thought. By articulating a fuller and more nuanced account of the role of property in achieving Platonic virtue, conceived of here as a kind of activity that is inherently practical in nature, this thesis suggests alternative resolutions to a number of philosophical problems, including the apparent oppositions between nature and convention, the body and the soul, the individual and the city, and the material and immaterial realms. 


\section{For}

My more valiant and intelligent other half, In whose name I have endured long and sacrificed much.

\section{Virtus Vindicat.}


What if Earth

Be but the shadow of Heav'n, and things therein Each to other like, more than on Earth is thought?

- JOHN MiLTON, Paradise Lost 


\section{Contents}

Abstract $i i$

Introduction: An Apology for the Bronze Class 1

Part I

1 The Scales of Justice

Prelude: Marcia funebre.

2 Civilization and Barbarism

Scherzo: Fuga a 3 voce.

Part II

3 The Great Forgetting

Rondo: Allegro con brio.

4 Refounding the City

Finale: Tema con variazione - Molto vivace.

Conclusion: The Moral Value of Property

Notes

Bibliography 


\section{An Apology for the Bronze Class}

At the beginning of Book IV of the Republic, Adeimantus challenges Socrates to provide an apology - a defence speech - for the particular distribution of benefits in the city that he has just finished describing in the previous two books. Despite having imposed a rigid class hierarchy upon the city that would assign to the philosophers the greatest responsibility for the pursuit of justice, Socrates nevertheless allocates to them the smallest possible share of the well-governed city's material rewards. In addition to being patently unfair, this arrangement strikes Adeimantus as completely unfeasible. "What would your apology be," he accordingly demands of Socrates, "if someone were to say that you're hardly making these men happy (eudaimonas), and further, that it's their own fault - they to whom the city in truth belongs but who enjoy nothing good from the city as do the others?"1 The austere Adeimantus, whose city in Book II is founded upon the joint pursuit of the basic necessities of life - or, in more modern terms, the collective material self-interests of its inhabitants - seems to have understood Socrates' appeal to justice as utterly dependent on the undependable altruism of good men. From this perspective, Socrates seems to expect that good men will nevertheless agree to rule the city, despite the apparent problem that doing so appears to require that they sacrifice 
their most fundamental self-interests in order to join the city in the first place. In Adeimantus' view, no such city will ever come into being.

At the heart of Adeimantus' challenge is a strikingly modern concern about the nature of all political order, which is to say the difficult but necessary question of how the pursuit of a multitude of otherwise competing interests can be organized in such a way that they align with one another and so advance the greater good of all. Socrates responds to this challenge by arguing that the city will produce two different kinds of goods, both material and immaterial, and that the rulers, as philosophers, will absolutely value the latter over the former. Although this argument succeeds in demonstrating the necessary interests of the rulers in pursuing wisdom, it also implicitly introduces a fundamental misalignment of interests between the rulers and the ruled. For how can what is best for the city that is ruled by philosophy also be best for the non-philosophers who are to be ruled by it? In the following pages, I argue that we can only answer this question by undertaking a more detailed analysis of the economic realities of the ideal city and, in particular, its distribution of benefits; and yet as soon as we begin to do so we quickly find that the argument for justice in the Republic is radically incomplete in one highly specific sense: it lacks a comprehensive account of the city's producing class, without which it is impossible to show how the city's multitude of interests can be reconciled to one another. Until we have a more comprehensive account of the Bronze class, therefore, we will be unable to demonstrate how the interests of the rulers can be made compatible with the competing interests of the ruled without at the same time undermining the privileged position of wisdom that is necessary to justify the rule of philosophy in the first place. This thesis aims to provide the necessary framework for such an account. 
Let us begin by considering in detail how Socrates answers Adeimantus:

It wouldn't be surprising if these men, as they are, are also happiest. However, in founding the city we are not looking to the exceptional happiness of any one group among us but, as far as possible, that of the city as a whole. We supposed we would find justice most in such a city, and injustice, in its turn, in the worst-governed one, ... [since] we're fashioning the happy city - a whole city, not setting apart a happy few and putting them in it. $^{2}$

By framing his apology in this way, Socrates immediately calls into question two of the basic premises upon which Adeimantus launches his challenge. First, he disputes that the overall interests of the well-governed city, even one in which material goods are distributed on unequal terms, would necessarily be at odds with the most fundamental self-interest of its rulers. After all, both the ruled and the rulers alike share a common interest in being part of a well-governed city. In this respect, Socrates argues, achieving the individual happiness of the rulers requires that they first look after the happiness of the city as a whole. The good of the whole both dominates and defines the interests of the individual parts simply because the good of the parts can only be realized insofar as they participate in the greater whole. In other words, there is, almost by definition, a necessary alignment of interests in the well-governed city.

Needless to say, on its own this would hardly be a satisfying defence. For the problem Adeimantus has identified is not whether a well-governed city would be good for its inhabitants - an empty tautology - but rather the question of why the rulers should willingly accept a smaller share in the city's material rewards when they could easily use their political power to take more. Moreover, they are presumably already motivated to do precisely such a thing, since, according to Adeimantus, their desire for material goods is the very reason they have agreed to be part of the city in the first place. ${ }^{3}$ Hence 
Socrates calls into question a second basic premise by suggesting that the good of the rulers - their own self-interests - cannot ultimately be given in material terms. When Socrates supposes that "it wouldn't be surprising if these men... are also happiest,"4 he is challenging the very definition of happiness from which Adeimantus is reasoning and upon which the entire culture of Classical Athens was founded. This makes much of the subsequent argument a radical proposition. In the course of the discussion that follows, through the rest of Book IV up to the end of Book VII, Socrates makes it clear that wisdom alone is essential to the happiness of the rulers and so, by extension, the happiness of the city as a whole. Such an argument depends on a division between material and immaterial goods, and necessarily categorizes wisdom among the latter kind. And if wisdom and the happiness it entails are ultimately immaterial in nature, then the self-interest of the rulers can no longer be defined in Adeimantus' strictly material terms. The original question of how the city will distribute its material rewards therefore becomes a question of what kind of goods the city will distribute and to whom.

How does Socrates' argument answer such a reinterpretation of Adeimantus' challenge? Here we might tentatively consider the theme of wages that periodically recurs throughout the dialogue, beginning in Book I. Late in his exchange with Thrasymachus, Socrates willingly admits the necessity of instituting a system of wages that will compel the best men to rule the city in such a way that their own good and the good of the city become one and the same. "There must be wages for those who are going to rule," Socrates somewhat abruptly announces, "either money, honor, or a penalty if he should not rule." But since the best men - the true philosophers - will not want to rule for the sake of either money or honour, Socrates argues that they will only be brought to 
rule if they are made to suffer the "penalty" of living under a worse regime than they themselves would be capable of instituting. This point proves to be a foreshadow of a broader argument Socrates will later intimate in his apology to Adeimantus, when he argues that the rulers will perhaps be able to achieve the greatest measure of happiness after all, since they will attain wisdom by ruling the city. In this later variation of the theme he first introduces in Book I, then, Socrates has allocated to the rulers a more proper kind of wage. For now that he must demonstrate not only that the philosophers are most qualified to rule but that the well-ordered city will be capable of allocating to them an adequate wage to compensate them for their labours, Socrates transforms what had previously been a penalty under the unjust regime into the wage of wisdom under the just regime. Only in this way can he overcome Adeimantus' objection that the distribution of the just city's benefits is itself unjust. In other words, the philosophers will ultimately agree to rule the city because they desire immaterial, rather than material, goods. Indeed, with the advent of the Beautiful City (Callipolis) in Book VII, Socrates strongly hints at precisely such a wage: "Here alone will the really rich rule," he declares, "rich not in gold but in those riches required by the happy man, rich in a good and prudent life."6

Although the precise details of such a system of distribution nevertheless remain obscure at this point in the analysis, what appears to be the case is that a just distribution of benefits in the ideal city is to be achieved by means of something like a system of parallel "currencies." To the few, whose task of ruling consists in the pursuit of the immaterial Good, Socrates allocates the unconventional wage of wisdom. Such a wage is consistent with Socrates' characterization of the rulers as the "deliberative" part of the city. ${ }^{7}$ To the many, whose task consists in the production of material goods, Socrates 
allocates the more conventional wage of money or gold. This, too, is consistent with Socrates' characterization of the many as the "money-making" part of the city. ${ }^{8}$

Furthermore, such an interpretation of the distribution problem has the added benefit of agreeing with the account of the essential natures of each class of labourer, which manifests in the performance of their particular kind of work. When Socrates reintroduces the question of pleasure (eros) into the dialogue in Book IX, for instance, he identifies three distinct categories of desire. The highest of these, love of wisdom (philosophia), he sensibly attributes to the philosophers, while the lowest category, love of profit (philochermaton), he attributes, equally sensibly, to the city's producers. On this basis, then, we may surmise that the distribution of benefits within the just city will itself ultimately prove to be just because the city allocates to each kind of labour and labourer alike benefits of the most appropriate kind. ${ }^{9}$

Notice, however, that such an argument is still insufficient to justify the unequal distribution of either kind of good - a problem which becomes more complicated still when, in Book II, Glaucon's reformulation of the argument for injustice will specifically require Socrates to prove the superiority of justice by "dismissing its wages." ${ }^{10}$ Still, Socrates' apology implies that the city's overall distribution of goods, both material and immaterial, will nevertheless be just because the rulers, in taking a smaller share of the material kind, will effectively be compensated for their preference by receiving a greater share of the immaterial kind. For this arrangement to work, trade-offs would seem to be involved. Yet while it might be reasonable to suppose that ordinary citizens would be compelled to choose between competing goods in this way - there is no such thing as a free banquet - such constraints clearly do not apply to the rulers, who are uniquely 
positioned to seize whatever they may desire from those over whom they rule. This raises the further question of why they should not simply take a greater share of both. How are their interests served by taking less of the city's material goods, and how are they harmed by taking more? Thus it is evident that the only reason the rulers can have for accepting a smaller share of the city's strictly material goods is if their doing so somehow undermines their own more fundamental interests in pursuing wisdom. Socrates' apology on behalf of the rulers therefore cannot succeed simply by introducing a division between material and immaterial goods; it must further assert an essential opposition between these two things.

This, too, is consistent with what we find elsewhere in the text. Take, for instance, the repeated treatment of the moral value of property. A whole series of passages appear throughout the Republic where Socrates quite distinctly suggests that property is somehow corruptive of human virtue. At the conclusion of Book III, for instance, Socrates darkly warns Glaucon that "many unholy things have been done for the sake of the currency of the many"11 - a warning the terms of which invert the language he will later use in announcing the advent of the Beautiful City which distributes wisdom among the rulers as though it were the currency of the few. ${ }^{12}$ The rest of the dialogue seems to confirm this same basic message. In subsequent discussions, most notably in Book V, Socrates and his interlocutors formalize the principle that wealth and private property are to be restricted among the ranks of the ruling classes. ${ }^{13}$ This agreement is particularly significant, given that the achievement of the personal virtues of the ruling elite is imperative for the greater achievement and preservation of justice as a whole under the 
ideal regime. Indeed, it is only after the principle is implemented that Socrates then declares the advent of the Beautiful City.

Moreover, the converse appears to hold equally true. With each new phase of the city's degeneration into ever greater states of injustice in Books VIII and IX, the corruptive allure of private property steadily grows, not just among the ruling classes, but among all classes as a rule. Thus with the city's decline into oligarchy - the pivotal and therefore symbolic middle regime - Socrates puts the point most sharply of all, perhaps, when he asks Adeimantus, "Isn't virtue in tension with wealth, as though each were lying in the scale of a balance, always inclining in opposite directions?" ${ }^{14}$ Finally, with the city's ultimate collapse into the worst of all possible regimes, we come to what may well be the weightiest piece of evidence of all. For the tyrant, whose nature has been most thoroughly and completely corrupted, is also the most voracious consumer of material things. So then does the discussion about the nature of justice, which originally began in Book I with the challenge put to Socrates by Thrasymachus demanding to know why happiness (eudaimonia) does not consist simply in "tak[ing] away what belongs to others, both what is sacred and profane, private and public, not bit by bit, but all at once," 15 fittingly conclude with the image of the tyrant who does precisely these things, and at the necessary expense of his own happiness.

Yet there is an ironic problem here. To the extent that these passages confirm an essential division between material and immaterial goods, they also undermine Socrates' apology to Adeimantus. In order to justify the exclusion of private property from among the ranks of the ruling classes, thus to explain why they will not simply seize the material wealth of their fellow citizens, as Thrasymachus would have them do, Socrates has had to 
argue that the very possession of such material wealth runs contrary to the pursuit of wisdom. In terms of the two parallel currencies through which the city's system of distributing all kinds of benefits operates, then, the prohibition on private property among the ruling classes implies that the two kinds of goods, and the currencies that represent their value, are effectively "inconvertible." The pursuit of one cannot be achieved through the possession or use of the other. Socrates himself seems to leave little doubt as to the veracity of this point when he argues that the rulers will necessarily prefer the possession of wisdom to the pursuit of material gain, recognizing that the former is not only qualitatively better than the latter but that it is infinitely more valuable. This, indeed, is the only reason why the rulers will consistently prefer a greater share of wisdom over an increase in their material wealth. Yet if we agree with Socrates that wisdom is the only truly valuable commodity in the city - and it is difficult to see how we can object to this claim - then it seems we are also bound to accept that the vast majority of the city's inhabitants participate in an economy where the wages they receive for their labours are absolutely devalued. The many, it would seem, are to be paid in fool's gold, which is to say that their wealth will prove to be, at best, utterly worthless, and, at worst, outright harmful to their own pursuit of virtue. Given such a conclusion, why should the many ever agree to be ruled by the few who will institute a regime that, in the end, appears only to serve their own interests? ${ }^{16}$

That the ideal regime should now appear strikingly reminiscent of Thrasymachus' conception of justice makes is the best evidence of all that Socrates has simply skirted the original distribution problem that Adeimantus identifies at the outset of Book IV. In doing so, he ironically undermines the basis of his own argument by precisely inverting 
the original terms of the challenge that Adeimantus has put to him. If it is the case, as Socrates argues, that the philosophers will be brought to rule because they desire wisdom, and that, furthermore, they will desire wisdom above all else because it is infinitely more valuable than material wealth, then how can it also be the case that their good as philosophers aligns with the good of the rest of the city? Now it appears that the greatest possible fraction of the city will be allocated the smallest possible share of the city's immaterial rewards. What is good for the few seems not to be good for the many, and vice versa. Not only does this cast doubt upon the idea that the virtues are universal, it also causes considerable problems for the notion that there exists a single allencompassing Good from which they may be derived. ${ }^{17}$

Even worse, there would seem to be no straightforward way of resolving these difficulties while also maintaining the overall consistency of the text. Consider the following possibilities. One option might be to accept that the many contribute nothing meaningful to the cause of justice, in which case it would indeed be just that they not partake in any of its real benefits. Yet this position clearly runs contrary to the account of the founding of the city in Book II, which initially begins on the basis of Adeimantus' joint pursuit of material well-being and is therefore a prerequisite for the later emergence of philosophy. ${ }^{18}$ While we might dispute the extent of their contribution, it seems clear that the many at least contribute something tangible to the city. A second option might be to assert that the many, because they are incapable of philosophizing, ${ }^{19}$ are also incapable of achieving virtue as a result. In that case, it would not be possible for their natures to be corrupted by material wealth in the same way that the natures of the philosophers can be. According to this view, the many would effectively become an amoral multitude. While 
there may be some support for this position in the fact that Socrates never specifically assigns any unique set of virtues to the non-ruling classes, it nevertheless runs contrary to the formal discussion of the cardinal virtues in Book IV, which holds that the many and the few alike will at least have to exercise the common virtues of justice and moderation..$^{20}$ As a third option, we might simply posit that there is no adequate way of reconciling these passages to each other, concluding perhaps that Plato has written the Republic in an ironic or satirical way, or that certain problematic passages of the text should be assigned varying degrees of importance in relation to others. In any of these cases, however, we are left with the problem of a seemingly contradictory text. ${ }^{21}$

These interpretive shortcomings ultimately arise from a single common origin: we simply have no adequate account of the Bronze class or their particular set of virtues. For what, indeed, does Plato have Socrates tell us about the natures and qualities of the ruled as opposed to the rulers? What do we already know about the Bronze class as a distinct class? The answer is surprisingly little. In only a handful of passages - those which we have already cited above - does Socrates even mention the members of the Bronze class, never mind formulate a complete and comprehensive account of it. Thus the problems we have identified above all lead back to one inescapable fact: the account of the city that Socrates provides us in the Republic is radically incomplete. Despite the fact that the Bronze class comprises the great majority of the citizenry, we know very little about the kinds of lives they will lead and how these lives will contribute to the pursuit of justice. There is an irony here, too, for these concerns are also distinctly political. Since the philosopher-king is to rule over precisely this part of the city, he must surely have some understanding of their natures and qualities if he is to rule over them justly, which is to 
say to direct them toward their own proper good. Unless we ourselves can articulate these dimensions of justice, then, our own understanding of the philosopher-king as a concept will also prove to be incomplete. As such, an essential political dimension of the text is obscured as a result of the incompleteness of the account of the city as it is given in the dialogue, and specifically the incompleteness of its economic organization. Furthermore, the obscuring of this political dimension to the text presents a very practical problem not simply a theoretical one - for understanding the fuller nature of the art of ruling, and therefore the fuller nature of virtue itself. To understand the contribution of the Bronze class to the cause of justice necessarily means to understand the role of the ruling classes in bringing it about under the ideal regime.

As Glaucon observes at the outset of Book II about the preceding exchange between Socrates and Thrasymachus, so it would seem that Adeimantus, too, "has been charmed more quickly than he should have been." ${ }^{, 22}$ Let us therefore restore Adeimantus' challenge and demand of Socrates anew: "What would your apology be," we might ask, “if someone were to say that you're hardly making these men happy, and further, that it's their own fault - they who have laboured to produce the material foundations of the city from which philosophy can emerge but who enjoy nothing good from it as do the rulers?"23 In order to answer such a challenge, we will need to elaborate a fuller account of the city, and specifically the part of the city that exists beyond the palisades of the "military camp" that rules over it. ${ }^{24}$ We will need to develop a more comprehensive theory of the moral value of property, one that entails a more nuanced account of the ways in which its production, possession, and use can either contribute to or detract from the proper ordering of the city under the ideal regime. Most of all, we will need to 
describe in detail the nature of the relationship between the two halves of the city - its material and immaterial parts - such that the pursuit of the goods most proper to each one can be reconciled to the greater nature of the complete whole. In short, what we need is an economic account of the city; what we need is an apology for the Bronze class.

That is no simple task, however. The greatest challenge in providing such an apology is finding a sufficiently broad textual basis within the Republic upon which to erect a more comprehensive account of the Bronze class. In this respect, what might otherwise be the merely symbolic departure of Cephalus from the stage of the dialogue so early on in the discussion soon presents a unique set of philosophical and methodological problems. That the only participant in the dialogue who can readily be identified as a member of the Bronze class should be made to leave the discussion before the question of justice has even been adequately formulated, never mind answered, may initially appear to refute our contention that the moral and political arguments of the dialogue are radically incomplete. It would certainly seem to be the case that, in philosophical terms at least, Cephalus' early departure amounts to Plato himself specifically declining to assign any role to the Bronze class in the task of defining the requirements of justice. Moreover, that Cephalus participates in the discussion only up to the point where the traditional definitions of justice that had been articulated by the poets he reveres are demonstrated to be either contradictory or lacking only underscores his own non-philosophic nature and thus, at the same, the necessity of the strictly philosophical conversation that ensues as a result. The standard reading of Cephalus' departure as the symbolic passing away of the old order would, in this respect, seem merely to militate against one of the basic premises of this thesis. ${ }^{25}$ 
Yet it is nevertheless equally clear, as we have already shown, that the Bronze class plays an essential role in the practice of justice, even if we accept that its members, like Cephalus, have no legitimate role in defining it in theory. There remains, then, the practical consideration of how their distinctive activities contribute to the cause of justice. Put another way, their virtues remain largely undefined. Cephalus' departure is therefore methodologically significant insofar as it leads Socrates to tailor his own subsequent arguments to the particular natures of his remaining interlocutors. Indeed, that Socrates regularly speaks to the specific concerns of his interlocutors, as opposed to treating his subjects in a more comprehensive fashion, is one of the distinctive characteristics of the Platonic dialogue as a literary form, not to mention one of its great virtues. Scholars have often identified Glaucon, whose interests tend more toward the metaphysical, as a natural member of the Gold class, and Adeimantus, whose interests tend more toward the practical considerations of governing, as a natural member of the Silver class. The thematic considerations that emerge throughout the dialogue and so, by extension, our own understanding of it, tend as a result to gravitate toward these categories of ideas. But that both Glaucon and Adeimantus exhibit many of the moral qualities of the ideal city's would-be rulers means that the course of the conversation in which they participate is necessarily biased in this respect. To the extent that it focuses on the concerns of Glaucon and Adeimantus, the vast majority of the scholarship tends to reproduce the very same bias. That is not on its own a problem per se, yet we must be prepared to acknowledge that such a focus comes at the necessary expense of attention to the Bronze class and its specific functions within the ideal city. Even if one were to suppose, therefore, that the 
dialogue itself is indeed complete, it certainly cannot refute the objection that our own academic discourse has yet to exhaust its possibilities.

One of the immediate methodological consequences that arises from reading the dramatic context of the Republic in this way is that the arguments about the nature of justice that Socrates presents in the dialogue assume a markedly less general form than we might otherwise suppose, despite their philosophical presentation. Because Socrates' account of virtue is directed not just toward a particular audience but toward a particular part of the city, we must be careful to interpret it in more qualified terms, with reference specifically to the ruling classes. Put another way, the emphasis on the art of ruling cannot but de-emphasize the related qualities of those who are ruled. In this respect, it is wholly unsurprising that the Bronze class does not feature prominently in the Republic, despite being a crucial part of the city. But this also means that we cannot simply apply wholesale Socrates' arguments about justice to the rest of the city without adapting them to serve such a purpose. If we are to understand the moral and political contributions of the non-ruling classes to the cause of justice, then, we will first need to elaborate a more general account of virtue as such and then tailor it to the particular context of the Bronze class, much as Socrates himself tailors his own arguments in the dialogues. In other words, if we are to articulate an apology for the Bronze class, we need to develop a new approach to reading the text.

In the course of the argument that follows, I approach Plato specifically as a mythological thinker, for two distinct reasons. First, the absence of Cephalus from the dialogue during the entire course of the overtly philosophical conversation and the resulting dearth of passages that can be said to apply directly to the Bronze class suggests 
that we will need to look elsewhere in the text to develop a more detailed account of that class. Yet there is also something of an irony here. Despite his early departure, Cephalus nevertheless directs our attention to the importance of the literary, dramatic, and mythological dimensions of Plato's text. Having ostensibly left in order to "look after the sacrifices, ${ }^{26}$ Cephalus' religious piety underscores the persuasive power of the traditional Greek myths - and the nature of those over whom they hold the greatest sway. In drawing our attention to this fact, subtly at first in Book I and then much more explicitly in Book X, Plato clearly suggests that the rewriting of those very same myths will be necessary if the Bronze class is to achieve their own virtues. The implication of having included any myths at all in the Republic, being directed as the dialogue is toward the rulers as opposed to the ruled, is that, despite their distinctly non-philosophical form, they may nevertheless be able to convey deeply philosophical truths. For this reason, I have read Plato's myths as a direct and popular appeal to the Bronze class which can, as a result, tell us something about the nature of its members that we cannot find in the dialogue's explicit arguments.

The second reason for approaching Plato in this way is that many of the myths he has Socrates present take the form of a comprehensive description of the entire cosmos. This is particularly true in the case of the Myth of Er, which explicitly details the inherently ordered nature of the universe in order to present it as a model for the wellordered city and the well-ordered soul alike. ${ }^{27}$ A number of methodological implications arise as a result of such a portrayal, foremost among which is what would seem to be additional confirmation that the so-called City-Soul Analogy is not only meant seriously but that it may have been a widely-accepted, if culturally distinct, mode of reasoning 
about moral questions. As a further result of having first articulated a more general account of the virtues, then, the cosmological myths provide us with something of a guideline for reasoning about the Bronze class on the basis of analogies derived from the philosophical discussion that Socrates carries on with Glaucon and Adeimantus as wouldbe rulers of the just city. Moreover, since these myths are presented in a more deliberate literary style, I have approached my own interpretation of them using a corresponding style of reasoning, which is to say one that is less strictly logical and more symbolic in nature. In this way, I have argued that we may trace the literary implications of specific sets of symbols in an effort to determine their philosophical meaning with reference specifically to the members of the Bronze class. In other words, we ought to undertake to understand these myths precisely as the members of the Bronze class would themselves understand them - with of course the difference that our resulting understanding will then be given a more deliberately philosophical expression.

Adopting such a method of interpretation, then, I have organized the four chapters that constitute the argument of this thesis into two equal halves. In Part I, I consider the mytho-historical context in which Plato wrote the Republic in order to develop an interpretive framework for understanding the philosophical role of myth in the dialogues. Taking up Eric Voegelin's premise that the first line of the Republic is an allusion to Odysseus' descent into the underworld, I argue that Plato's invocation of one of his culture's founding myths serves to establish an extensive series of literary parallels between Socrates and the hero of Homer's Odyssey. One of the implications that follows is that the philosophical arguments of Plato's dialogue come to be framed in terms of the fundamental distinction between the earthly and heavenly realms. In Plato's hands, 
however, the more traditional version of the dichotomy is subverted insofar as it traces precisely to Plato's own distinction between the material realm of physical objects and the immaterial realm of the Forms. Arguing that Voegelin's explanation for the meaning of this particular symbolic parallel ultimately proves inadequate because of the seemingly contradictory ways in which Plato deploys the same themes and symbols at the end of the dialogue in the Myth of Er, I propose an alternative methodological framework for making sense of Plato's complex use of traditional mythological concepts. The chapter concludes by showing that the philosophical implications that arise from such literary parallels cannot be coherently integrated into the rest of Plato's text without a much broader analysis of the original Homeric context itself.

That is the task to which I turn in Chapter Two. Here, I consider the mythohistorical dichotomy between the Greeks and the so-called barbarians that is fundamental to the Homeric myths in particular, arguing that Plato has Socrates adapt it as analogous to the dichotomy between virtue and vice. The analogy proves significant to the philosophical arguments of the Republic because the Homeric half of the reference is ultimately rooted in a quasi-moral difference of economic organization. Whereas the Greek city-state (polis) is characterized by rigid but legitimate political hierarchies that were made possible by the specialization of tasks, which in turn was made possible by the proliferation and therefore production of specialized forms of property, the barbarian order is instead characterized by a radical political equality that is premised upon the use of violence alone to seize, rather than to produce, material goods. Taking all of this together, it becomes clear that property assumes an implicit moral importance in the arguments of the Republic because the mythological context establishes it as the 
distinguishing element dividing civilization from savagery. Transposed to the Platonic context, property becomes the means of transforming vice into virtue. It permits the overcoming of a barbarian nature, it allows for the civilizing of what might otherwise be barbarian dispositions toward violence within the city. Part II concludes with the proposition that the use and production of property is essential to a new conception of citizenship that Socrates argues must be rooted in virtue.

In Part II, I apply the conclusions I have drawn from my analysis of the mythohistorical context in Part I to develop a new interpretation of the overtly philosophical arguments of the Republic in order to demonstrate how they can be articulated with reference to the Bronze class more specifically. To that end, I have read the Republic within the context of two other dialogues, the Meno and the Symposium. In Chapter Three, I argue that the standard characterization of the Meno as one of Plato's so-called "aporetic" dialogues overlooks the more profound argument that its dramatic action is suggesting about the nature of virtue. Much of the meaning of the dialogue hinges on how we understand the central claim that "virtue is knowledge," which I interpret to mean that virtue is a specific kind of knowledge that implies an element of practical activity. If this is true, then the possibilities for achieving virtue will necessarily depend on the material conditions in which we live. The point becomes all the more important as soon as we recognize that the merely apparent failure of the dialogue to reach any conclusions about the nature of virtue as such stems from a false dichotomy upon which the whole discussion between Socrates and Meno has been premised. When we read the Meno in the context of the Republic, we find that the discussion fails only because it fails to account for the possibility that not all men ought to be taught the same things about 
virtue, since not all men have the same range of natural talents. What I call the "particularization of virtue" that results thus further implies the crucial moral function of property as the "means of recollection" of the knowledge that is virtue, since the use of different forms of property is what allows for the specialization of human activity and therefore the achievement of virtue.

Finally, in Chapter Four I reconsider some of the economic implications for the refounding of the city in Book II of the Republic in light of the more general account of virtue that I have elaborated in the previous chapter as well as the more profound moral arguments that appear in the Symposium. Here I argue that eros is the principal and ultimate means of transcending the dichotomy between the earthly and heavenly planes, which is to say the material and immaterial realms, and that the essential role of property in achieving that result implies a distinct form of economic organization. If man is to build the Beautiful City that will stretch from the material foundations of this earth unto the immaterial heavens, he may do so only insofar as the economic activity of the city is organized in such a way that men's irrepressible erotic desires are brought into alignment with, and merged into, the labours they perform, each as fellow citizens of a fully unified city. When labour is divided not on the basis of necessity or gain but instead according to men's natural talents, each man will by nature desire to develop the virtues that are most suited to his own soul. Both the material and the immaterial prosperity of the city therefore become a direct function of the extent to which the city itself facilitates the erotic harmonizing of these otherwise radically different halves of human nature.

We already know the political conditions under which the ideal regime comes into existence: only when philosophers become kings and kings become philosophers can the 
city as a whole be unified in its orientation toward the Good, and thus, free from faction, justice will prevail. We already know the moral conditions: man must achieve the virtues most proper to his nature by looking to the good of his own soul. The question now before us is this: what are the material conditions that are necessary for the triumph of justice? Our ultimate conclusion is as counter-intuitive as most conclusions reached on the basis of economic reasoning tend to be. When men join with one another and look to the immaterial, they prosper materially; when they look to the beautiful, they fulfill their necessities; and when they look to the erotic desires of the soul, they fulfill the insufficiencies of the body. In each of these respects, property is the indispensable means of achieving the unity of the individual soul and the various parts of the city as a whole. The task before the philosopher-king, therefore, is to refound the city upon a thoroughly erotic economics. For when at last he has knowledge of this royal art, he will have come to possess the skill of the moral alchemist, and with it the ability to transform not iron into gold but that which is absolutely worthless into that which is absolutely valuable. By the persuasive and compulsive power of economics, he will have acquired the ability to transform mass ignorance into widespread wisdom. 


\section{Part I}




\section{$-1-$ \\ The Scales of Justice \\ $\infty$ Prelude: Marcia funebre. $\propto$ \\ Jove sets the beam; in either scale he lays \\ The champions' fate, and each exactly weighs. \\ On this side, life and lucky chance ascends; \\ Loaded with death, that other scale descends.}

-VIRGIL,

The Aeneid

I.

The Republic famously begins with the utterance of a single word in which Plato masterfully foreshadows the philosopher's eventual return to the Cave: "I went down" (katēben). Somewhat less famously, with that very same first word he also initiates a long series of interconnected dichotomies. Having initially set the high against the low, Plato further implicitly sets the future against the past, the spoken against the silent, the eternal against the ephemeral, and, albeit more distantly, the well-ordered against the chaotic. It quickly becomes apparent on the basis of these dichotomies that with Socrates' descent specifically into the Piraeus, which scholars have long recognized as the symbolic "stronghold of the [ancient Athenian] democracy," Plato distinctly evokes the terrible political history of his age: the rise of timocratic Sparta, the fall of democratic Athens, and the establishment of the Thirty Tyrants in the wake of the Peloponnesian War. Writing about the horrors of the plague that so devastated Athens in only the second year 
of what was to become a protracted, decades-long conflict, Thucydides observed with resignation that no "human art or science [was] of any help at all. Equally useless were the prayers made in the temples, consultation of the oracles, and so forth; indeed, in the end people were so overcome by their sufferings that they paid no further attention to such things. "2 Like a prophecy inspired by the Muses, Thucydides' words would prove to be an accurate description not just of the past as it had been, nor even of the present as it then was, but also of the future that was yet to be, one in which the struggle for Greece would ultimately wreak a profound moral catastrophe upon the very soul of Athens itself.

Tracing the theme of death throughout the first book of the Republic, Mark Gifford remarks that this is indeed a "haunted setting." Certainly Plato's peculiar choice of characters contributes much to the eerie atmosphere that permeates the dialogue. For with the defeat of Athens at the hands of Sparta and the city's subsequent plunge into tyranny, at least two of the men who are present for the discussion of justice, Polemarchus and Niceratus, would later be executed, while a third man, Lysias, would be forced to flee Athens, only just barely escaping with his life. ${ }^{4}$ There is some debate as well surrounding the exact significance of the figure of Cephalus, whose historical namesake died some time between 420 and 415 BCE. ${ }^{5}$ Depending on how we decide upon the dramatic date of the dialogue, then, which scholars have traditionally located somewhere within the range of 424 to 408 , Socrates' grandfatherly host could be either the simple personification of the death of the old order, or else a very literal wandering ghost haunting Plato's stage in the fashion of William Shakespeare's King Hamlet. ${ }^{6}$ And of course we need hardly add the obvious about Socrates himself, whose execution looms large over the entire Platonic corpus. Despite, if not indeed because of, the virtues of 
these men, therefore, their very appearance within the Republic casts upon the scene a dark and disquieting sense of historical inevitability.

As the Athenians seemed then to be, are we too the mere captives of history, no more than macabre marionettes animated by the whims and caprices of the Fates? As one scholar notes, we are throughout the dialogue made to "breathe the air of the new and the strange - of decay." And if that is true, then the essence of the Republic carries with it the undeniable stench of death. What then would history be, if not the ongoing process of decay, of death - of descent? Plato has, after all, chosen to set his greatest dialogue against an overwhelmingly tragic historical backdrop, painted as it is with the broad strokes of death and destruction, if not outright despair. In doing so, he gives us cause to contemplate, much as Thucydides had a generation before him, whether there is not in all human endeavour rather more than a slight tinge of the futile. "Now the hour to part has come," Socrates declares at the conclusion of the Apology, before defiantly adding, "I go to die, you go to live. Which of us goes to the better lot is known to no one, except the god." ${ }^{\prime 8}$ So it would likewise seem from the outset of the Republic, therefore, if it is indeed "the true Apology of Socrates" as has been famously said of it, ${ }^{9}$ that the very ideal of justice has already been condemned to the darkened abyss of oblivion, that the Fates have already decreed that a whole host of evils shall triumph among humankind, that the destiny of the city has already been decided - and all before Socrates can even pronounce his immensely fraught first word: katēben.

And yet—still he goes down.

That simple dramatic fact may well pose the central interpretive problem of the entire Republic. Particularly because of the preponderance of death in Book I, some 
scholars have read the initial katēben in terms of the Greek mythological convention of the hero's descent (katabasis) into the underworld. The canonical myths of Orpheus, Theseus, Heracles, and Odysseus, for example, all centre upon descents that, in the interpretation of classicist José Luis Calvo Martínez, employ the same "simple protostructure according to which the hero transcends the insurmountable barrier between this and the other world in order to bring back with him something or someone - a purpose which he is not always able to accomplish." ${ }^{10}$ Still, despite the well-established formula, Martínez nevertheless notes that "this heroic feat is not a very common one." ${ }^{11}$ Only the greatest of heroes, it would seem, even dare to attempt such an arduous undertaking. By choosing to begin the Republic with a carefully crafted katabasis scene of his own, therefore, Plato unmistakably situates his dialogue within the very same, and highly specific, subgenre of the Greek mythological tradition. In doing so, he hints at the enormity of the task that lay ahead while also implicitly, perhaps even subversively, promoting Socrates to the pantheon of his culture's greatest heroes.

Among those scholars who read the initial katēben in this way, Eric Voegelin recognizes a close narrative resemblance between the katabasis of Plato's Socrates and that of Homer's Odysseus in particular. ${ }^{12}$ Many others have since affirmed the same in the wake of Voegelin's arguments about the Republic, ${ }^{13}$ and it is easy enough to see why. For Odysseus is the man of endless toil, the man who routinely favours the use of persuasion - or deception - over force, the man who descends into Hades only reluctantly and only because the pursuit of knowledge demands it. In these respects, Odysseus is indeed a fitting patron hero for Socratic philosophy. Thus Voegelin hears in the initial katēben a distinct echo from Book XXIII of the Odyssey, when Odysseus, having finally 
returned home to Ithaca, begins to tell his faithful wife Penelope of all that he has endured in the course of his epic homecoming: "I went down (katēben) into Hades to inquire about the return of myself and my friends..."14

The resemblance is indeed striking. Whereas Odysseus descends into Hades, Socrates descends into the Piraeus, and thus we are right to suspect, literally from the dialogue's first word, that the harbour of Athens is being prepared as a symbol of the underworld. Much as the familiarity of home steadily recedes in proportion to the distance one travels away from it, further evidence accumulates rapidly and ever more overtly as the dialogue begins to unfold. We learn, for example, that Socrates has gone down to pray to Bendis, a new and strange deity who, like the more traditional Olympian goddess Artemis, was held to be responsible for shepherding the recently departed ghosts of the dead into Hades. ${ }^{15}$ And no sooner have we witnessed the festival processions held in honour of the goddess than we encounter the ghostly Cephalus, a man whose preoccupations with death and the afterlife at last turn the conversation explicitly toward the subject that has already been implicit in the dialogue from its very beginning. Given the wider symbolic context, there is surely more than simple courtesy at work in Cephalus' friendly greeting to Socrates. "You don't come down (katabainon) to us in the Piraeus very often," ${ }^{16}$ Cephalus laments, and with those carefully chosen words Plato both implies the extraordinary quality of Socrates' descent while at the same time hailing its completion. At last the meaning of the dialogue's ever so fraught first word becomes apparent: we have arrived in the Kingdom of the Dead. 
II.

As is ever the case with Plato, however, the completion of the image only complicates its apparent meaning. For just as the katabasis of Socrates echoes the katabasis of Odysseus, so does it anticipate a third descent, that which is undertaken by Er at the conclusion of the dialogue. For Voegelin, the obvious thematic continuity between the two scenes requires that any analysis of their meaning "must explore the symbolism of the descent" ${ }^{\prime 17}$ - but this not simply within the narrow context of each scene read in isolation from the other, but in more abstract terms. For while the underlying structure of the Republic organizes the general discussion of the problems it articulates, nowhere does Plato ever directly or explicitly resolve the problems he invokes. That is not, of course, to say that such problems are never resolved within the text itself. On the contrary, we must always keep in mind the complex interplay between the form of a piece of writing and the content it expresses. 18 "The great problems of Plato," Voegelin reminds us, "are not blocks of meaning locked up in the subdivisions of [a given dialogue's parts], but are lines of meaning winding their intricate way through the whole work." ${ }^{\prime 19}$ His more general point is especially apropos in the case of the opening and concluding scenes of the Republic, which are dominated not by any explicit arguments but rather by complex and ambiguous symbols. Thus invoking a distinctly literary interpretation of the Platonic katabasis, Voegelin argues that "the full weight of the brief opening chapter deliberately balanc[es] the descent into the underworld at the end." ${ }^{20}$ Yet Voegelin's argument suffers for its lack of conceptual clarity as well as the lack of precision with which Voegelin articulates it. The only explicit statement Voegelin ever offers to explain the more theoretical literary relationship between these two scenes 
and, even more unfortunately, here he uses the most crucial term in his entire analysis "balance" - without actually defining what it means specifically in this context. If we are to evaluate the validity of Voegelin's logic and the soundness of his conclusions, we must first submit Voegelin's argument to a minimal amount of exegetical interpretation in order to grasp his meaning. When we approach Voegelin in this way, it becomes clear that he is reasoning on the basis of at least two kinds of balance. The first kind is strictly formal. Although Voegelin never states this point explicitly in his analysis of the two descent scenes, it nevertheless becomes clear from the rest of his more general arguments about the structure of the dialogue overall that he has a formal kind of balance in mind. ${ }^{21}$ Voegelin argues that there is a tripartite division of the more overt sections of Socrates' arguments in the Republic, which he traces from the founding of the city in Book II at 396b until the final degeneration of the city and the soul into tyranny in Book IX at 576b. Dividing the dialogue in this way, Voegelin draws particular attention to the interruption in Socrates' discourse that occurs at the outset of Book V with the famous "re-arresting" scene, when Polemarchus accuses Socrates of "robbing" him and the rest of the company of a crucial part of the argument in defence of justice. At this point in the dialogue, Socrates has concluded the discussion treating the founding of the city and is about to move on to a discussion of its degeneration. Voegelin designates everything preceding the interruption as Part I. The interruption itself, which takes the form of an apparent digression on the nature of philosophic wisdom, Voegelin designates as Part II. The continuation of the original line of argument prior to the interruption at the outset of Book $\mathrm{V}$, which goes on to treat the four declining forms of government, Voegelin designates as Part III. Significantly, Voegelin's division of the text in this way depends as 
much upon a close consideration of the dramatic cues within the text itself as well as the dominant themes that such cues implicitly serve to group together. In this respect, the rearresting of Socrates proves particularly important, since it draws a sharper break in the text than would otherwise have been the case. ${ }^{22}$

Having divided Socrates' argument into these three parts, Voegelin then proceeds to argue that the discussion within each part is organized according to a common form comprising two distinct sections. Each part begins with what Voegelin terms the "dialectical" section, where a question or problem is raised that leads to a conflict of some kind. The conflict itself, along with the attempts of Socrates and his interlocutors to resolve it, propels the discussion into the lengthier "analytical" section. Thus, in Part I, the founding of the city gives rise to the dialectical conflict between, on the one hand, the Austere City and its chief proponent, Adeimantus, and, on the other hand, its alternative conception in the form of the Feverish City, which is favoured by Glaucon. Glaucon's objections unleash forces within the city that necessitate the various classes and the hierarchies that gradually emerge between them, which then expands into a discussion of the greater question of the proper ordering of the city's diverse specialized parts. The resolution of Part I is achieved once agreement is reached that philosophy must rule. Likewise, in Part II, the dialectics of the Three Waves that result from the re-arresting of Socrates leads directly into the analytical section concerning the nature of philosophy and philosophic wisdom, and culminates in the Allegory of the Cave and the eventual resolution that the philosophers will have to return to its shadows. Finally, in Part III, which begins with the dialectical proposition that even the most perfectly just regime will inevitably decay initiates a comprehensive analysis of the process of the city's 
degeneration into tyranny, and the resolution that the tyrannical soul is the most perfectly unjust. Voegelin's argument therefore maintains that these three parts balance each other in that all three exhibit the same abstract "parallelism" of form, this despite what are nevertheless at times rather stark contrasts in terms of their substantive content. ${ }^{23}$

As we have already noted, Voegelin never specifically invokes this kind of formal balance in his analysis of the two descent scenes and their relationship to each other. Nevertheless, the premisses of his argument imply that the same kind of formal balance is in play between the two descent scenes. Whereas Voegelin reads both descents as katabasis type-scenes, we can infer that he has conceived of the relationship between them in terms of a similar formal "parallelism." The conventions of the type-scene therefore serve a similar function as the dialectical and analytical sections within each of the three parts of Socrates' overt arguments. This interpretation of Voegelin's argument is consistent both with the way in which Voegelin discusses each of the two descent scenes, as well as Martínez's observation that the katabasis type-scene is in general highly formulaic in the sense that it is structured according to a very particular set of conventions. To the extent that most of these conventions are directly tied to the element of transcendence, the scene itself functions as an explicit demonstration of heroism. Martínez argues that such a demonstration of heroism implies that the hero possesses a "dual nature," since he is able to move freely between two very different worlds: that of the divine and the eternal, on the one hand, and that of earthly men on the other. By going down into Hades and, even more importantly, returning to the world above, the hero distinguishes himself not just from all other mortals but from all other beings, both earthly and divine. Whereas all mortal men must go down into Hades precisely once, 
upon their deaths, and never return, neither do the gods ever go down. To the extent that the hero alone transcends these otherwise rigid categories by means of his descent, the mere act of the katabasis serves as a conventional aspect of what Martínez calls the "heroic biography." The act itself therefore distinguishes the hero from all other mortals and marks him as an extraordinary being. ${ }^{24}$

At this point it becomes evident just how much Voegelin's argument suffers as a result of its insufficiently explicit articulation of its own premisses and the exact logic according to which Voegelin derives his specific conclusions. Both scenes fit the general mould of the katabasis type-scene as a descent into and return from the underworld; and yet as soon as we read the two scenes in terms of the general type-scene's more specific mythological conventions, it quickly becomes apparent that Socrates' descent adheres closely to these conventions while the opposite holds in the case of Er's descent. The crucial point that Voegelin overlooks in his analysis is that Er's descent into Hades is not at all heroic. Indeed, Er's descent contrasts not just with that which Socrates undertakes in Book I, but with every other katabatic myth in the whole of the Greek tradition, and this in one crucial respect: Er goes down into Hades because he is actually dead. That Er arrives in the underworld in the same way as any other mortal strongly militates against any reading of his character in terms of the usual mythological conventions of the semidivine figure, just as the fact that he receives his sacred commission to become a messenger to humankind only after having entered Hades likewise militates against any interpretation of his descent as an heroic act. Unlike the great heroes of legend and lore, Er does not go down in pursuit of any particular goal, nor does he return to the world of the living by means of anything like his own cunning or sheer force of will. On the 
contrary, his extraordinary journey through the underworld is undertaken only by order of the Judges of the Dead, and its fulfilment is achieved only at the subsequent command of the Fates. In each of these respects, Plato masterfully defies all of the usual conventions of the katabasis, not just as a highly structured type-scene but as a traditional mythological concept more generally. Indeed, Er's descent into the underworld amounts to nothing less than a radical departure in the very nature of the concept itself. ${ }^{25}$

The resulting interpretive dilemma appears to be inescapable. Voegelin has implicitly invoked the traditional concept of the katabasis in order to argue, in effect, that there exists a formal balance between the opening scene in the Piraeus and the concluding scene in Hades. That the two scenes share the common a mythological typology is, equally implicitly, held to be the basis upon which a balance is struck between them. Yet the irony, of course, is that Voegelin's argument appears only to have proven the exact opposite conclusion that he himself has drawn. Since the structure of the type-scene implies certain conventions according to which the meaning of its symbolism is organized, the type-scene necessarily shapes or constrains the meaning of the scene overall. Thus we might be inclined to infer that the common form between the two scenes would further imply that they will express similar substantive meanings, yet now we find that the opposite appears to be the case. Despite the formal balance between the two scenes, their common form instead highlights what are in fact very stark differences. That Plato so carefully observes all of the usual conventions in the case of Socrates' descent implicitly distinguishes the hero of the Republic as an exceptional mortal, while in the case of Er's descent, because it defies these same conventions, he seems to be suggesting exactly the opposite: Er is not a hero but an anti-hero, an ordinary mortal caught up in 
extraordinary circumstances, to be sure, but still yet an ordinary mortal nonetheless. The contrast is both stark and fundamental.

By implicitly asserting the existence of a strictly formal balance between the two descent scenes, Voegelin's argument has in fact served only to identify a larger and more troubling substantive imbalance between the apparent meaning of the two scenes. The interpretive dilemma is that the two scenes do not balance each other in any obvious way unless we read both specifically as instances of the more general katabasis type-scene, and yet reading them in this way undermines precisely the balance that it is supposed to reveal. Even worse, since Voegelin is so inexplicit in his own process and method of reasoning, he seems not to notice the dilemma at all. Much less does he himself provide any straightforward resolution to the paradox into which he has unwittingly stumbled.

\section{III.}

Does Voegelin's argument not then collapse immediately into utter incoherence, and, what is more, under the weight of its very own ill-examined premisses? Such may well appear to be the case, were we to consider only Voegelin's specific analysis of the two descent scenes themselves. Reading Voegelin in this way would certainly be a mistake, however, as Voegelin's broader arguments about the dialogue are much more robust than this particular oversight would otherwise seem to suggest. We must therefore interpret his meaning in the same way we would interpret Plato's, which is to say within the context of the greater whole of which it is but a part.

In his more explicit reasoning about the overall structure of the Republic, Voegelin identifies a second kind of balance that relates more directly to the substantive meaning of the text itself. Having divided Socrates' overt argument about justice into 
three distinct parts, Voegelin then goes on to argue not only that there exists a formal balance between these parts, but that their common form reveals the "complementarity" that exists at the deeper level of their substantive content. For instance, Parts I and III, which respectively treat the genesis and decay of the city, strike a complementary balance between themselves in the sense that they together provide a comprehensive theory of the five possible forms of government. Similarly, Parts I and II balance each other as complements in the sense that they describe the fundamental nature of the city in terms of its material and immaterial dimensions. Finally, Parts II and III similarly balance each other in the sense that they describe the process by which the good political order of the city comes to embody the Forms as well as the process according to which they inevitably come to be "disembodied." Read together in this way, each pair of Parts provides a fuller view of a greater conceptual whole. According to Voegelin, the complementary quality of this second kind of balance establishes a deeper thematic continuity that runs throughout the entire dialogue, since it allows the three broad parts of the argument to "interlock" with each other, not only despite the strong contrasts in terms of their substantive content but precisely because of them. In this regard, the formal balance according to which the content of the three Parts is organized proves crucial, since it facilitates a more substantive complementary balance between them. ${ }^{26}$

When Voegelin argues that the dialogue's first word "assembles symbols that recur in its course ... [and] sounds the great theme that runs through it to its end," ${ }^{27}$ he is effectively making the very same point, if somewhat more ambiguously. Just as the twopart structure of each of the three broad Parts of Socrates' argument illuminate complementary aspects of the greater whole that is the dialogue itself, here Voegelin is 
suggesting that the two descent scenes must be read together because each one, read in isolation of the other, reveals only a partial glimpse of the larger philosophical point that Plato is making. But because Plato offers no explicit arguments in either of these two scenes, Voegelin elaborates the nature of their complementarity in terms of their common literary symbols. In doing so, he argues that they employ a common set of symbols that centre upon the same sub-theme of political egalitarianism. This sub-theme manifests most obviously in the scene in the Piraeus, with the Festival of Bendis and the rival processions of foreign-born Thracians and native-born Athenians. Despite the important distinction in their civic status, these two groups are nevertheless afforded equal rights in the festival.

Thus Voegelin focuses in particular on Socrates' assessment of the two processions - that of "the native inhabitants was fine; but the one the Thracians conducted was no less fitting a show" ${ }^{28}$ - arguing that the basic equality between and among the different classes of participants underscores what is an essentially political point. ${ }^{29}$ The festival highlights not just the equality of men in the Piraeus, but also the ethnic diversity that is at the heart of the political ideal it represents. The Piraeus is characterized by a great diversity of inhabitants that extends well beyond the categories of Athenians and Thracians. Indeed, it is a veritable melting pot of peoples and cultures that have flocked to the port of Athens from all across the ancient world. The egalitarian politics that emerges out of the particular historical circumstances in which Plato situates the Piraeus of the Republic is therefore a natural extension of its cosmopolitan culture. This Plato dramatizes more specifically, and thereby emphasizes more strongly, in the Festival of Bendis. $^{30}$ 
Tracing in this way the meaning of the literary symbols in Book I and the greater philosophical concerns that appear throughout the rest of the dialogue and to which they are inextricably linked, Voegelin notices that a similar set of symbols "recurs" in the concluding descent scene. Noting, for example, the particular significance that Plato should have Socrates identify Er specifically as a Pamphylian, Voegelin keenly observes that this has the effect of literally designating Er, as the messenger to all humankind, as a man "of all tribes" (pan phyle). ${ }^{31}$ Plato therefore subtly ascribes to Er's character the very same kind of racial diversity that he features much more prominently in the scene in the Piraeus. But even more significant than the immediate meaning of any of the particular symbols in either scene is the point that their comparative emphases are distinctly different. Whereas the scene in the Piraeus emphasizes the culture of the city, it necessarily has a more distinctly political connotation. By way of contrast, the scene in the Hades of Book X, being told through the eyes of a single universal "Everyman," has instead a more distinctly moral tone. Although Voegelin, of course, never develops his own analysis in quite this way. Nevertheless, it clearly follows from his own reasoning, particularly when it is read against his own more explicit interpretive statements, that there is indeed something of a complementarity between the two descent scenes. The potential for such complementarity is rooted in the relationship between the individual citizen on the one hand, understood as innately moral, and the political community on the other, understood as a conventional construct of which the individual citizen is a necessary constituent part. $^{32}$

Yet the original problem for Voegelin's argument still remains unresolved. Our own analysis has so far succeeded only in demonstrating the possibility that the two 
descent scenes could be read as a complementary pair. What is missing from our own analysis is that we have yet to establish any exact grounds on which this actually proves to be the case, and particularly so with respect to the troubling point about heroism. For despite the potential complementarity between the two scenes, read in effect as similar accounts emphasizing different aspects of the relationship between the city and the individual citizen, it is not at all obvious how - or even whether - it can resolve the polarity between the heroism that characterizes Socrates' descent into the underworld of the Piraeus and the anti-heroism that characterizes Er's descent into Hades. In other words, it would appear that Voegelin's explicit interpretive framework, and specifically the two kinds of balance that he enumerates therein, are still insufficient to resolve the fundamental problem that Voegelin has overlooked.

When we compare Voegelin's analysis to his own explicit statements, however, we discover that one of the problems with Voegelin's overall argument is that the former outstrips the latter. Rather than suggesting a broader philosophical concept that can incorporate both heroic and non-heroic dimensions, as Voegelin's consideration of the thematic structure of the three central Parts of the dialogue would lead us to expect, Voegelin instead goes on to argue that the common symbols that recur throughout the two descent scenes ultimately "blend" together. Although Voegelin again fails to specify the exact nature of his meaning, he appears to be suggesting that the recurrence of specific symbols throughout the dialogue implies that they must be read not simply one alongside the other, but directly in terms of each other. ${ }^{33}$

Voegelin accordingly argues, for example, and quite explicitly we might add, that the recurring theme of "pamphylism" that Plato elaborates with reference to both Er and 
the Piraeus signals that these symbols blend into each other. The "man of all tribes" balances what is, in effect, the city of all tribes. In this respect, Er represents not simply the universal man but the very personification of the spirit of the Piraeus, since it is home to all men. The symbolic relationship works both ways. Just as we can read the character of Er in terms of the symbolism that is expressed more overtly in the scene in the Piraeus, so too can we read the meaning of the symbolism of the Piraeus in terms of the character of Er. Voegelin does this both implicitly and explicitly. Looking at the Festival of Bendis, for instance, he finds great significance in the fact that it takes place not on the upper plane of Athens but on the lower plane of the Piraeus, understood as a symbol for the underworld. That the festival brings together both foreigners and Athenians suggests that hordes of Athenian citizens have also gone down into the Piraeus in order to participate in the festival. According to Voegelin, there is a clear correspondence between the exodus of Athenian citizens, who descend en masse into the underworld of the Piraeus, and the figure of Er, who goes down into Hades not as a hero but as an ordinary mortal man. On this basis, Voegelin concludes that the blending of common symbols implies that the festival dramatizes not simply death as an abstract concept - although it does this too - but more specifically the "death of Athens" as a well-ordered political community. That Er goes down into Hades because he has actually died can therefore be read, in parallel terms, as a corresponding symbol for the death of the body politic of Athens. Just as Er can be read in terms of the spirit of the Piraeus, so too can the Piraeus be read as a macrocosm of Er's essential mortality. ${ }^{34}$

Two tentative conclusions follow directly from such a reading of Plato’s symbolism. The first is that Voegelin ironically succeeds in resolving - even if 
inadvertently - the original dilemma concerning the apparent opposition between the two scenes on the point of heroism. In the blending of Er with the Piraeus, the former comes to assume the political dimensions of the latter. As a result, not only does Er's descent not contradict the essential nature of the katabasis type-scene, but it is in fact exactly what we ought to have expected upon further consideration. Being the personification of political egalitarianism, Er exhibits in his descent what must inevitably be a certain antagonism toward the very concept of heroism, rooted as it is in the suggestion, as Martínez notes, that certain individuals possess unique or distinct natures that necessarily set them apart from all other mortals. The katabasis as a concept thus implies at least an elementary moral hierarchy, and one that, moreover, is rooted not in the conventions of the city and its temporal power but in nature itself. To the extent that democracy is and must be premised upon a widespread conviction in the essential equality of all men, it simply cannot abide such a suggestion, nor can it abide the underlying idea that there exists a natural order over which the city can assert no authority of its own. Thus Er fittingly does not exhibit any of the usual heroic attributes precisely because these would undermine Plato's presentation of his character in terms of the universal man. Notwithstanding the usual mythological conventions, therefore, Er descends into Hades not as a hero but as an anti-hero, precisely because he is cast as an ordinary mortal.

\footnotetext{
* We should keep in mind that the anti-heroic aspect of the Myth of Er makes it highly subversive of the katabasis as a traditional mythological concept. Above all, the myth distinctly suggests that the knowledge of the cosmic order with which Er returns, ordinarily inaccessible only to the heroic few, can potentially be made available to the otherwise un-heroic many, at least under certain circumstances. Although this potential does not necessarily rule out the need of heroes to play a pivotal role in bringing about such a result - the just rule of the philosopher-king obviously comes to mind - it clearly complicates the analysis of democracy in Book VIII. By casting an anti-heroic barbarian in the descent scene of Book X, Plato may well be suggesting that the katabasis as a concept both can and must be democratized so as to encompass all humanity. The contrast with what Martínez calls the "closed catalogue" of traditional katabatic heroes is indeed stark ("The Katábasis of the Hero," paragraph 2).
} 
The second conclusion, however, immediately undermines the soundness of the first. For it is equally clear that such an interpretation of Plato's text cannot be supported by the two kinds of balance that Voegelin has explicitly articulated; or, at the very least, that it cannot be supported by these two alone. Voegelin argues, for instance, that the interplay of common symbolism in the two descent scenes serves to establish a series of philosophical "parallels" between them, thus invoking the terminology he has set out in describing the first kind of balance. But this would seem to be a clear a misapplication of his own concept, which Voegelin has already explicitly argued applies only to the strictly formal dimensions of the text. Yet now he is arguing, just as explicitly, that the two scenes are instead to be read in terms of what he takes to be their substantive similarities. Not only does such a reading confuse the theoretical underpinnings of the first kind of balance but, even worse, it contradicts outright Voegelin's own explicit articulation of the second kind. Complementarity, it would seem, has been abandoned in favour of an alternative principle asserting the essential similarity of the two descent scenes. What, then, are the further consequences for Voegelin's interpretation of the overall dialogue,

Plato's apparent suggestion adds an entirely new dimension to Leo Strauss's analysis of the relationship between the Myth of the Metals, the degeneration of the city in Books VIII and IX, and the apparent correspondence between democracy as the fourth declining form of government and Hesiod's "race of heroes" as the fourth in a line of five declining races in Works and Days (Strauss, "Plato," 1963, in An Introduction to Political Philosophy: Ten Essays, ed. Hilal Gilden [Detroit: Wayne State University Press, 1989], p. 208; Hesiod, lines 106-201). What is the philosophical significance of the symbolic connection? Is the advent of democracy the beginning of a new age of katabatic heroes? Is Socrates the first of many such heroes? Is heroism itself to be democratized?

However we choose to answer such questions, Strauss's analysis raises a distinct objection as to whether Er's descent into Hades is in fact so anti-heroic after all. On the other hand, Plato may be suggesting something much narrower than Strauss seems to suppose, for it could be the case that only the results of the katabasis are to be democratized. On this reading, the knowledge of the cosmic order that is achieved by the few can and must be shared among the many - perhaps it must even be compelled - not despite the inability of the many to achieve a similarly heroic feat for themselves but precisely because of that inability. Given especially the argument I present in Chapter Four, this alternative explanation seems to me to be the stronger of the two, not least because it also sheds a great deal more light on the reasons Plato may have had for framing Socrates' descent into the Piraeus in such deliberately heroic terms in the first place. 
premised as it is on the carefully delineated relationship between the formal similarities of the three Parts and the complementary themes that emerge from them as a result? Are we to conclude that the various parts of the Republic balance each other in fundamentally different ways? It would appear that the balance between the descent of Socrates and the descent of Er is at odds with the overall balance of the dialogue as a whole - to say nothing of Voegelin's own interpretation of it. ${ }^{35}$

\section{IV.}

Voegelin's argument that there is a careful balance between the two descent scenes with which the Republic begins and ends therefore raises more problems than it solves. At the heart of its interpretive confusion lay two specific problems. The first is that Voegelin has a tendency to equivocate between the two kinds of balance he himself has explicitly set out. For example, having related the two scenes to each other in terms of their essential similarities by arguing that the character of Er blends into the scene in the Piraeus in Book I and, further, taking this to imply a substantive "parallel between the underworlds of Socrates and Er,"36 he then goes on to conclude that "the Descent [of Socrates] formulates a problem and the judgment [the Myth of Er] provides a resolution." ${ }^{37}$ However, this conclusion is, quite simply, utterly enigmatic. If the two underworlds are substantively the same, how can we read the first as a question and the second as an answer? To read the relationship between the two scenes in this way implies that their meanings are in some sense complementary, which would seem to be irreconcilably at odds with the claim that they also run in "parallel." For how can a question answer itself? Moreover, what would be the point of even asking such a question? Or answering it? 
Alternatively, if instead Voegelin means by this statement that the two scenes assume only the form, as opposed to the substance, of a question and an answer, then they cannot balance each other in the way that Voegelin supposes they do, which is to say specifically as katabasis type-scenes, since this claim depends on their literary forms being essentially the same. Even worse, in the absence of such a formal resemblance, what reason could we even have to identify the first scene as a question and the second as its answer? Might not the tale of Gyges in Book II, for example, provide an equally justifiable "answer" in this respect? ${ }^{\dagger}$ Thus we once again find ourselves entrapped within an increasingly familiar interpretive dilemma, but it is one wherein the ultimate cause is that Voegelin's first set of claims simply confuse the principle of similarity that is tied to the first kind of formal balance by mistakenly applying it to the substantive dimensions of the text, which in the rest of his argument Voegelin more consistently interprets according to the principle of complementarity. To the extent that Voegelin's ultimate conclusions about the Republic depend on the inconsistent application of his own interpretive principles, therefore, those conclusions will necessarily be deeply flawed.

\footnotetext{
$\dagger$ We ought to take this question seriously, for three reasons. First, as John Evan Seery notes, the story of the Ring of Gyges exhibits all of the conventional attributes of the katabasis type-scene ("Politics as Ironic Community: On the Themes of Descent and Return in Plato's Republic," Political Theory 16, no. 2 [May 1988]: p. 250 n. 15). Going down into the earth, Gyges witnesses many "quite wonderful things" (359d) before returning up above with the fabled ring. Compared to the descent of Er, the story exhibits a more pronounced theme of heroism, at least initially, since Gyges' descent and return are undertaken at his own initiative, will, and desire. Yet there is also a distinctly anti-heroic quality about Gyges' character, since he is ultimately corrupted by the power of the ring that he brings back with himself into the realm of mortal men. Is this a warning akin to the myth of Daedalus about the risks of transgressing boundaries the meaning of which exceed one's capacity to comprehend? If so, why is Er not similarly corrupted by the vision he beholds in Book X? Second, the episode adds further support to Voegelin's argument that the theme of descent runs through the entire dialogue. At the same time, it also illuminates a somewhat Nietzschean dimension to the theme itself: Why ought any of the katabatic heroes, whose superior natures set them apart from the rest of humanity, use the supernatural powers they acquire in the other realm to benefit humanity as a whole rather than themselves alone? Significantly, that question never arises in any of the traditional myths, and yet Plato is implying it to be a potential problem here in one of his own. Third and finally, given both the deceptions of Book I and the fact that Glaucon introduces the story at the beginning of Book II in his restatement of the original question about the nature and value of justice, we must ask whether Glaucon is not in effect proposing a darker counter-example to the Socratic katabasis.
} 
The second problem is that there is an ironic imbalance between Voegelin's explicit interpretive statements and his application of them in the specific case of his analysis of the two descent scenes. Whereas Voegelin argues that the substantive balance between the dialogue's three broad Parts is defined according to the way in which the content of each one "interlocks" with that of the other two, in the case of the two descent scenes he advances a much stronger claim by arguing that their content "blends" together. Contrary to what Voegelin seems to think, however, these claims are in fact disanalogous. In the first case, Voegelin argues that Parts I and III, for instance, provide a complete theory of the five possible regime types. The two Parts must accordingly be read together because the meaning of each one augments that of the other. Yet in the second case, Voegelin's language suggests what his subsequent arguments already imply: that the two descent scenes merge together because their substantive meaning is essentially the same. The logic underwriting this claim would be equivalent to arguing that the mere suggestion of a relationship between the four degenerate forms of government in Part III and the ideal regime in Part I means that all five are therefore in essence the same - a claim that is much more obviously false.

Still, despite the flawed logic that is at the root of this second problem, the error itself sheds greater light on the causes of the first. In the absence of a more complete theoretical framework with which to interpret the Republic, Voegelin's analysis inevitably strays beyond the point of its own theoretical support, thus lapsing into ambiguity and equivocation as a result. That Voegelin never defines his terms clearly and precisely only creates further difficulties, since it masks the troubled nature of his exact 
sequence of reasoning. In the domain of philosophical discourse, explicitness surely is a virtue.

We therefore have two options for resolving the imbalance between the applied analysis and the theoretical framework that together constitute Voegelin's interpretation of the two descent scenes: either we pare down the analysis or we extend the theory. The first option is clearly unsatisfactory, since it would lead us back to the intermediate claim that the two scenes only potentially balance each other as complements, without actually demonstrating how this in fact proves to be the case. As a result, it would necessarily reverse the substantive parallel Voegelin finds between the character of Er and the political culture of the Piraeus, thus leading us back into the original dilemma on the point of heroism. Paring down Voegelin's analysis would therefore lead to the ultimate conclusion that the two scenes simply provide irreconcilable accounts of the katabasis, meaning, in other words, that they fail to reach a substantive balance because they are inherently opposed to each other. Not only would the rest of Voegelin's analysis unravel, we would also apparently have to conclude that Plato seems to have been a sloppy artist in his composition of the Republic. Since this is clearly an uncharitable interpretation, not just of Voegelin but of Plato himself, we ought to prefer the option of paring down Voegelin's applied analysis only in the event that the alternative produces worse results.

How then can we extend Voegelin's theoretical framework? One way we can make sense of his argument is by introducing a third kind of balance into our own interpretation of it. When Voegelin argues that the descent of Socrates into the Piraeus at the beginning of the Republic poses a question that is ultimately answered by Er's descent into Hades at the end of it, he appears to be suggesting the existence of a 
dialectical relationship between the two scenes. The dialectical quality emerges out of three specific elements that are already present in Voegelin's argument: first, the formal resemblance of the two descents to each other, each read as katabasis type-scenes; ${ }^{38}$ second, their symmetrical position within the overall structure of the dialogue, one read as the beginning and the other read as the end $;^{39}$ and third, the complementarity of the subject matter they present. ${ }^{40}$ In this last respect, the original problem that arises as a result of Er's anti-heroism proves fundamental to our conception of this third kind of balance, since it only emerges as a genuine philosophical problem once we have already recognized the significance of the formal "parallelism" that exists between the two scenes. Their apparent substantive opposition on the point of heroism thus initiates a dialectical process that is driven by the need to reconcile the contrasts in content between them - one that is not entirely unlike the way in which a world dominated by shadows compels a closer consideration of the relationship between light and darkness. In this way we become aware of the need to articulate a distinctively Platonic conception of the katabasis as such. The resolution of that problem thus brings the two scenes into a dialectical balance in the sense that the process will have illuminated the fundamental unity of a concept that Plato only partially articulates in either scene. ${ }^{41}$

The notion of a dialectical balance emerging out of the implied relationship between the two descent scenes shifts Voegelin's argument into the realm of esotericism, ${ }^{\ddagger}$ thus exposing it to a common objection. By maintaining that a given set of

\footnotetext{
$\$$ Given the exceedingly controversial history of esotericism - some of it deserved, some of it not - I want to be as explicit as possible as to what I mean by my own use of the term here. I am not suggesting that Voegelin's "real" argument is hidden somewhere between the lines of his own writing, nor that Voegelin himself is reading Plato in this way, nor that I am reading either one in such a fashion in the analysis that follows or, for that matter, in the analysis that has already gone before. I am not insinuating anything about persecution or Leo Strauss. Instead, the kind of esotericism I have in mind is much more general: a text will prove to be "esoteric" to the extent that its full meaning cannot be reduced to a simple function of the
} 
symbols balance each other in both complementary and dialectical terms, are we not simply attributing contradictory meanings to the text itself? Or, to put the same objection more bluntly, how can it logically be the case that the heroism of Socrates' descent is not fundamentally opposed to the anti-heroism of Er's? Indeed, we are not maintaining here that Er's descent is anti-heroic in its outward appearance only, but that it really is antiheroic in its very essence. Nor are we maintaining that the essential anti-heroism of Er's descent ultimately "resolves" in some way into a deeper heroic aspect as a result of the myth's dialectical relationship to the heroic descent of Socrates. On the contrary, what we are suggesting is that these dichotomous categories that emerge as a result of our analysis of the two descent scenes ultimately prove to be complementary, rather than contradictory, precisely because each scene constitutes one half of a greater whole. In this respect, the dialectical balance that is achieved between them is neither heroic nor antiheroic. Instead, the conceptual unity that is revealed in the process of bringing the two scenes into a dialectical balance with each other transcends altogether the very dichotomy itself.

In this respect, the anti-esoteric objection is useful because it draws our attention to the likely inevitability that every text must to some extent consist of multiple levels of meaning. This is particularly so, and most obviously true, in the case of literary texts, which deliberately employ symbols specifically to suggest a meaning that is not and cannot be itself contained within those symbols themselves. This, indeed, is the very definition of symbolism. The essential literary aspect of all such symbolism, and

immediate meaning of the words and phrases that constitute it. In such cases, the surface meaning of the text will always be but the beginning, rather than the end, of any inquiry into its ultimate meaning. Thus James Joyce's Finnegans Wake qualifies as impenetrably esoteric; the list of ingredients on the side of a soda can as pedantically exoteric. 
particularly as it applies to the dialogues of Plato, raises a question that has frequently troubled many analytically-inclined philosophers: Why does Plato not simply articulate explicitly what he means to convey with Socrates' descent into the Piraeus? In other words, why does he not simply write as clearly and methodically as Aristotle? The simple answer is that he has done so as explicitly as it is possible to do without altering the meaning of the ideas that are conveyed in and by his writing. When Voegelin emphasizes the interpretive imperative of approaching Plato as a philosophical artist, he is arguing the very same point, which is that the Platonic dialogue as a form of art necessarily shapes the essential meaning of the content it contains. And if that is true, then it will never be possible to rearticulate precisely the meaning of a given piece of writing without altering the ideas it expresses. Furthermore, if there exist multiple levels of meaning in a given piece of writing that are expressed in different ways, then it is likely that some of the meaning found at any particular level may not be directly translatable to the unique expressive context of another. Hence we fully ought to expect that there will be a variety of meanings in any piece of writing, never mind one as complex and as profound as the Republic. $^{42}$

The irony of Voegelin's position, of course, is that he himself fails to distinguish in his own argument these various levels of Plato's text and, even more importantly, the ways in which his various conceptions of balance apply to each of them. Thus when he equivocates in his application of the principles that he attributes to the formal and substantive kinds of balance when he implicitly argues in different contexts that both kinds can variously be characterized either by similarity or by complementarity, his more fundamental mistake is that he confuses the different levels of Plato's text and so, too, the 
interpretive principles that apply to them. Let us therefore distinguish more deliberately each of these levels and the principles according to which their content can be understood. At the most basic level of the text is its structural form, or what we may refer to as the subtext. It is at the level of the subtext that Plato invokes the conventions of the katabasis type-scene. Inasmuch as these conventions necessarily constrain, and therefore shape, the possible range of meanings that may be expressed in the more substantive content that a given passage of text contains, the content of the type-scene itself functions as a kind of meta-content for that passage. The principle of similarity governs the formal balance between scenes that share the same subtext precisely because the subtext, and therefore the meta-content, is the same. For this reason Voegelin is right to conclude that Socrates' descent into the Piraeus and Er's descent into Hades in the Myth of Er are inextricably tied to each other, for they are already implicitly related because they employ a common form.

Somewhat non-intuitively, the formal balance that exists at the level of the subtext of the two descent scenes makes possible the expression of substantive ideas that need not be identical. This expression occurs at the level of what we may refer to as the exoteric text. But because only the range of meaning, rather than any specific details of that meaning itself, is constrained by the underlying structure, Plato is able to employ an identical subtext in each of the two scenes in order to articulate ideas that fall at opposite extremes of the range of meanings that are possible. At the level of the exoteric text, therefore, the two scenes appear to be opposed to each other, thus giving rise to the original conflict between the heroism of Socrates' descent and the anti-heroism of Er's. Yet already we have good reason to think that the meanings that Plato expresses in these 
two scenes will ultimately prove to be complementary rather than contradictory, since they necessarily share a common form at the level of the subtext, and therefore their meta-content is the same. In this respect, they already balance each other, if only in an elementary way. The greater dialectical balance emerges only at a third level of the text, or what we may refer to as the esoteric text. It is at this level that the unstated implications of the ideas and concepts that are expressed more or less overtly at the other two levels are brought into a dialectical relationship with each other and, as a result of that relationship, ultimately illuminate the existence of a conceptual unity that transcends the narrower terms of their initial exoteric expressions.

The problem that Voegelin's argument raises but never resolves is the apparent paradox that the substantive meaning of the two descent scenes can be both similar and yet also different, depending on the level of the text at which we read them. This is why he stumbles into the evidently dubious pair of claims that the underworld of the Piraeus can be essentially the same as the underworld of Er's Hades while also maintaining that the former poses a question to which the latter provides an answer. Does this selfcontradictory pair of claims not therefore vindicate the common objection against esotericism? It should by now be clear that this is not necessarily so. For the cause of the apparent paradox in Voegelin's argument is not that all multi-level texts are simply and inherently contradictory, but only that Voegelin himself never specifies the nature of the logic that governs the multi-level relationships that Plato has implicitly established between the two descent scenes. As a result of this interpretive omission, Voegelin fails to specify whether the pair of claims he would assert are true at the same level of the text. 
Thus it is Voegelin's incomplete articulation of the argument, rather than the nature of the argument itself, that proves to be problematic.

The interpretive reasoning that is implicit in Voegelin's analysis shares a number of striking parallels with the compositional techniques of musical counterpoint in general and the form of the fugue in particular. As a compositional form, the fugue is built entirely around a single theme, called the subject, which recurs in various guises throughout the piece. Everything in the piece centres upon, and emerges out of, various statements and restatements of the same musical idea that is first expressed in the initial statement of the subject. In this regard, the subject itself quite literally permeates every single measure of the composition. There is a distinct resemblance between the function of the subject in a fugue and Voegelin's own basic premise that the initial katében "sounds the great theme that runs through [the dialogue] to its end." 43 Every fugue begins in the same way that Voegelin understands the beginning of the Republic.

In the fugue, the initial statement of the subject is then immediately restated in a different key. This restatement is called the answer. In musical terms, the subject and its answer are transpositionally equivalent, meaning that the sequence of intervals in which they consist are precisely the same, even though the notes themselves are not. In this regard, there exists a formal balance between the subject and the answer, just as the common theme of the katabasis establishes a formal balance between the descent of Socrates into the Piraeus and the descent of Er into Hades, even though both the characters and the scene are different. Despite the difference in their exoteric expressions, read as the loose equivalent of different keys, the two descent scenes are nevertheless as recognizable as the answer in the fugue is recognizable as an echo of the subject. Yet 
there is also a certain complementarity between the subject and the answer, since the keys in which they are given are as a rule closely related. There is a correspondence here with the subtext, which organizes the expression of the substantive ideas that are given in the exoteric text by imposing a pre-existing set of relationships upon them. That the same essential set of ideas are expressed in complementary forms opens up the possibility for a more complex relationship between them. The dialectical balance that this makes possible corresponds to the musical harmonies that emerge in the course of the fugue. In this respect, the subject and its answer form two halves of the greater musical whole in which they participate.

It is important to note, however, that the harmonic qualities of the fugue emerge neither spontaneously nor arbitrarily from the composition. On the contrary, the sequence of harmonic progressions are carefully calculated and controlled by the composer. Moreover, the complex rules of counterpoint impose a wide range of conditions upon what is and is not an acceptable subject of a fugue: the innate relationships that exist between the different keys in which the subject and its answer may be stated and restated, as well as the particular sequence of intervals in which they consist - all of these factors constrain not only the structure of the music but its range of expression. In this sense, the harmonies that emerge are already implied in the subject itself, before it ever comes into a dialectical relationship with its answer, and thus the function of the episodic section is merely to realize more explicitly the potential that already exists within the subject itself. The very same kind of logic is at work in Voegelin's analysis - not explicitly, and not always consistently, and yet it is there. When he argues that the two descent scenes "blend" together, he is loosely suggesting that the descent of Socrates - read as the 
subject of the fugue - must be sounded together with the descent of Er - read as the answer. In both cases a dialectical balance emerges at a more esoteric level that expresses a meaning that simply does not exist at the level of any of its constituent parts. The harmonies of music transcend the form of their melodies, just as the philosophy of Plato as expressed in the Republic transcends the ideas that are articulated at the level of its exoteric text.

\section{V.}

Voegelin takes this reasoning to its ultimate apparent conclusion by arguing that each of the exoteric analogues within the two descent scenes blend into each other. Thus the Er who goes down into Hades in Book X blends into the Socrates who goes down into the Piraeus in Book I. In making this argument, Voegelin draws our attention to the way in which Plato has Socrates frame the narrative of the Myth of Er:

And thus, Glaucon, a tale was saved and not lost; and it could save us, if we were persuaded by it, and we shall make a good crossing of the river of Lethe and not defile our soul. But if we are persuaded by me, holding that soul is immortal and capable of bearing all evils and all goods, we shall always keep to the upper road and practice justice with prudence... ${ }^{44}$

In this passage, Voegelin notices that Socrates subtly displaces Er as the protagonist of the myth. Having concluded with the question of whether we will be persuaded by the myth itself, Socrates then goes on to elaborate the moral consequences of our being persuaded by him. According to Voegelin, one way in which we can read the meaning of the narrative displacement is to understand Er and Socrates as being in some sense the same person: the final result of the dialectical balance between the two scenes is our realization that the two descents are not in themselves different, but only different 
expressions of the same event. In other words, Voegelin's argument proposes that the Myth of Er is ultimately a mythological retelling of the descent of Socrates into the Piraeus at the beginning of the Republic. ${ }^{45}$

Yet the scales of justice are not so easily balanced. Although Voegelin's suggested conclusion is certainly an elegant one, it is also easily refuted. For if Socrates blends into Er, and if Er blends into the underworld of the Piraeus, then simple transitive logic demonstrates that the combined persona of Socrates-Er must also blend into the underworld of Hades-Piraeus. Yet this is obviously false, since Socrates' descent into the Piraeus serves to illuminate the absence of justice by contrasting it with the idea that he brings back down with himself into the Piraeus. The mere act of the founding of the city in Book II according to principles that are more just than those that are manifest in the existing political order of the Piraeus makes this point quite plain. Not only does Voegelin's conclusion indirectly undermine the traditional reading of Socrates' descent as a return to the shadow world of the Cave, it also contradicts outright the dialogue's most basic philosophical premise.

Despite the validity of Voegelin's abstract reasoning, therefore, his particular conclusions cannot be right, since they undermine the very premises upon which it is built. This suggests that Voegelin's argument ultimately fails only because it has failed to account for all relevant premisses. Voegelin has attempted to strike a balance between the two descent scenes while forgetting the intimate connection that each one must have to a common third descent - that which Odysseus undertakes into Hades in Book XI of the Odyssey. The omission is profoundly ironic, considering that the resemblance Voegelin notes between the descent of Socrates and the descent of Odysseus is the fundamental 
premise that sets Voegelin's entire analysis into motion in the first place. In effect, Voegelin has misread the harmonies of the Republic and hence has mistaken its more fundamental form. It resembles a fugue not in two voices but in three. 


\section{$-2-$ \\ Civilization and Barbarism \\ $\infty$ Scherzo: Fuga a 3 voce.}

Let it come out of the ground, out of the sea's water, and from the high air make the waft of gentle gales wash over the country in full sunlight, and the seed and stream of the soil's yield and of the grazing beasts be strong and never fail our people as time goes, and make the human seed be kept alive.

-AESCHYLUS, spoken by ATHENA, The Eumenides

In much the same way that Plato himself begins the Republic, Socrates begins the Myth of Er in Book X by uttering a similarly superficially simple but nevertheless extraordinarily fraught phrase. "I will not tell you a tale of Alcinous (Alkinou)," Socrates rather offhandedly tells Glaucon, "but rather of a strong man (alkimou), Er."1 On closer consideration, it too proves to be as beguilingly complex as the initial katēben, the full depth of its meaning as equally difficult to fathom as its interpretive significance to the dialogue as a whole. Allan Bloom observes, if somewhat understatedly, that the phrase introduces "a complicated series of allusions," noting in particular the play on words as well as the hint of an apparently self-effacing joke. ${ }^{2}$ Invoking the mythical king of the Phaeacians, to whom Odysseus tells the story of his decade-long travels and travails following the Trojan War, Socrates alludes to the lengthy Homeric sub-narrative that comprises the whole of Books IX through XII of the Odyssey. By tradition, these four 
books collectively came to be known simply as The Story of Alcinous. Whereas Odysseus spends an entire night at the king's court regaling his audience with the dramatic account of his voyage, Bloom suggests that the phrase with which Socrates introduces his own mythical account had likely become, by Plato's time, a proverbial expression for a "longwinded tale." ${ }^{3}$ In this regard, the immediate meaning of the allusion is basically ironic. Since Socrates invokes the phrase only at the end, rather than the beginning, of his own lengthy argument about justice, he instantly renders moot his own promise not to tell "a tale of Alcinous." The humorous dimension to the allusion, then, is that Socrates simply has no reason to tell such a tale precisely because he has already told a much longer one over the course of the dialogue. As Odysseus concludes his own tale to the king, so now does Socrates slyly seem to be suggesting to us: "Why cover the same ground again?"4 As is so often the case with humour, however, Socrates' joke masks a more serious underlying point. Although Bloom may be correct to suggest that the reference to King Alcinous is meant at least in part proverbially, and hence that the humour it evokes is self-effacing on the part of Socrates, he appears to reach this conclusion only by excluding the possibility that the meaning of the expression might also have a more substantive significance. It is evident, for example, that Plato has carefully calculated the exact placement of the allusion, evoking the Phaeacians not at the very end of the dialogue but only at the end of the argument that has vindicated the cause of justice. Thereafter does Plato have Socrates go on to conclude with Er's mythical vision of the transmigration of souls and their ultimate return to life. In this respect, the allusion mirrors within the local context of the Republic the very same position that the Phaeacians themselves occupy within the broader narrative of the Odyssey as the 
inhabitants of the last island Odysseus visits before he returns home. That the Phaeacians are responsible for sailing Odysseus back to Ithaca underscores the thematic significance of the allusion's position within the dialogue. Moreover, that the Republic begins with Socrates' descent into the underworld of the Piraeus, where he encounters the festival procession of the Thracians, deepens the narrative parallels with Homer even further. For Odysseus, too, begins The Story of Alcinous by telling of his own departure from Troy and recounting his many landfalls, the very first of which occurs in Thrace. The obvious parallel themes and symbols of departure and return are alone sufficient to demonstrate that Plato is clearly implicating the narrative arc of the Odyssey within the compositional structure of his own Republic.

At what point, therefore, do the rich threads of the Homeric epic become definitively assimilated into Plato's own distinctive philosophy? Matters quickly become more complicated still. For the reference to Alcinous also serves a meta-literary function that is itself as fittingly long-winded as The Story of Alcinous. For Odysseus' account of his travels, as told to the Phaeacians, includes the story of his descent into the underworld in Book XI, which Odysseus then recounts to Penelope in Book XXIII - the very moment to which Plato in turn alludes when he begins the Republic by having Socrates echo the first words of Odysseus' story to Penelope. The long chain of allusions and metareferences is significant for two reasons. First, it effectively means that not only have we already heard a tale that incorporates the very substance of the original tale of Alcinous despite Socrates' ironic promise - but we have already heard precisely that tale entirely unwittingly. In the end, the joke is entirely on us, a point that assumes much greater weight given that it appears at the outset of Socrates' appeal to memory and the moral 
imperative he assigns to recollection in the pursuit of virtue. Second, that the whole series both begins and ends with Plato's Socrates - and that it begins at the end of the Republic and ends at the beginning, no less - means that it is ultimately self-referential. This has the rather paradoxical effect of suggesting an entire series of parallels with the Odyssey while also undermining them at the very same time. That Socrates promises that the Myth of Er will not be a tale of Alcinous both revokes the resemblance to Homer in the case of everything that comes after the allusion and, in doing so, implies the exact opposite of everything that has come before it. Clearly, the two works will not be so easily disentangled from each other.

After his brief introduction to the tale, Socrates goes on to describe Er's journey through the underworld. Thus we can surmise from the nature of the allusion, and in particular the fact that it indirectly references Odysseus' own descent through the underworld in Book XI of the Odyssey, that the story Socrates is about to tell about Er's own descent and journey through the underworld will not be "a tale of Alcinous" in this particular respect. The implication, of course, is that Er's description of the underworld will be different from Odysseus' description of Hades. One of the many layers of complexity to the allusion is that Socrates is about to present us an alternative rendering of Hades, one that will be set up specifically in opposition to the Homeric version. Here we find the deeper flaw in Voegelin's ultimate conclusion: whereas the allusion to the Odyssey at the beginning of the Republic serves to establish a series of parallels between Socrates and Odysseus and so, by extension, between the Piraeus and Homer's Hades, here at the end of the dialogue, Plato alludes to the very same set of concepts in order to achieve precisely the opposite result. The balance between the descent of Socrates and 
the descent of Er therefore cannot be struck in the way Voegelin argues it can be for the simple reason that neither scene, on its own, balances against the descent of Odysseus in the same way.

When Voegelin argues that "it is the pamphylism of the Piraeus that makes it Hades," he clearly implies that the symbolic significance of the Festival of Bendis is that it blurs distinctions that are ultimately rooted in differences of civic status. ${ }^{5}$ The festival, after all, entails separate processions for Athenian citizens, on the one hand, and foreignborn Thracians on the other. Yet there are at least three reasons why the blurring of distinctions between these two categories is not properly read in terms of the simple blurring of foreigners and natives as such. First, such distinctions are purely conventional rather than moral. Unlike the absolute and eternal standard of justice that is applied in the Myth of Er, the laws of citizenship are by their very nature relative and can be changed arbitrarily at any moment. Indeed, in the wake of the plague that devastated the population of Athens in $430 \mathrm{BCE}$, the city undertook precisely such a revision to its highly exclusive citizenship laws, opting to bestow the full rights of citizenship upon those born in Attica to parents of whom only one, rather than both, were themselves Athenian citizens. ${ }^{6}$ That in the scene in the Piraeus the grounds for distinctions in civic status are implied to be essentially arbitrary, whereas the moral judgments that are rendered in the Myth of Er are not, is one way in which the crowing myth of the Republic will not be, as Socrates promises, a tale of Alcinous.

Second, distinctions in civic status are not entirely meaningful within the context of Greek polytheistic religious practice. Although the cult of Bendis was first imported into the Piraeus from abroad, as Voegelin correctly notes, there is nothing at all unusual 
in this fact alone. For the Greeks routinely identified foreign deities with their own, a point which Plato himself appears to underscore by specifically declining to name "the goddess" to whom Socrates is said to offer up his prayers at the very beginning of the dialogue. ${ }^{7}$ The most likely explanation for the omission is that, regardless of whether such prayers are made in the name of the foreign goddess Bendis or the native Olympian goddess Artemis, any differences between them are essentially meaningless: for all practical purposes, they are one and the same deity. That Voegelin, as well as a handful of other commentators, ${ }^{8}$ have tended to emphasize the "strangeness" of the festival in their arguments about the moral and political implications of its symbolism is to some extent self-contradictory. For, indeed, the Greeks themselves were far more likely to have thought about their own participation in the common rituals and rites of religious festivals more in terms of the transcendence of such earthly categories, particularly so in the case of one where their own participation took place directly alongside nominal foreigners. ${ }^{9}$

Third, it ignores the nature of the implied relationships between the recurring symbols that appear at the beginning of Book I and at the end of Book X, the importance of which Voegelin's own argument insists upon. When Socrates sets Er's underworld against the underworld of the Piraeus by promising that it will not be a tale of Alcinous, he sets the two against each other in a very precise and calculated way. The movement of souls through each of these two underworlds brings the point into sharper focus. Narrating Er's descent into the underworld, Socrates describes the initial leg of the journey as having been made "in the company of many." 10 As Er joins this single group of souls and arrives with them at the gates of Hades, each member of the company is judged for the life he or she has led. As a result of the judgments that are rendered, this 
single group of souls is then divided into two separate processions. Those souls deemed to have lived just lives proceed upward through the heavens, there to receive rewards for the justice they bear within themselves; while, conversely, those souls deemed to have lived unjust lives proceed downward through Tartarus, there to receive punishments for the injustice they carry within themselves into the underworld. ${ }^{11}$

In the scene in the Piraeus, however, Plato carefully inverts the sequence of the processional symbolism. Whereas the souls in Er's Hades begin as a single group, in the Piraeus they instead begin separately. The Athenians come down into the Piraeus from Athens, which is, by implication, associated with the higher moral ground that is described in the Myth of Er; and, having come down, they are then joined by the Thracians, who arrive in the harbour from beyond the sea, which is thus implicitly associated with the lower moral ground of Tartarus. Thus beginning, initially, as two separate groups, the Athenians and the Thracians then come together on Voegelin's "common level" in the Festival of Bendis, ${ }^{12}$ whereupon they proceed - in the absence of moral judgment - to march off together toward their symbolic deaths under the shepherdlike watch of Artemis-Bendis. The calculated inversion of the recurring symbolism positions the meaning of the scene in the Piraeus in terms of the moral consequences of the earthly decay of the divine order that Socrates describes in the Myth of Er. Whereas in Er's Hades the distinctions drawn between the just and the unjust are cleanly delineated, in the Piraeus the initial distinctions between the two groups of worshippers are instead erased as a result of their participation in the festival. Yet the geographical imagery itself, importantly, remains a constant between the two scenes. That the erasing of the distinctions between the two groups in the Piraeus is limited to the political plane 
on which the Festival of Bendis takes place, without extending to the underlying landscape itself, implies that the festival serves merely to obscure differences between the two groups that nevertheless remain morally significant. ${ }^{13}$

Although Voegelin goes on to make a similar point in his own analysis of the scene, ${ }^{14}$ the fact that he does not draw the necessary distinctions quite as precisely as he ought to have means that his own argument eventually - and mistakenly - reproduces at the level of interpretation the very moral confusion that Plato implicitly attributes to the political culture of the Piraeus. The obvious problem is that this mistake then becomes the very basis upon which Voegelin concludes that the political disorder of the Piraeus is ultimately rooted in its equal treatment of citizens and foreigners alike. The symbolism of the festival processions is taken to be symptomatic of this disorder, which is to say Voegelin reads it simply as a dramatic illustration of the egalitarian attitudes that dominate the political culture the Piraeus. According to him, Socrates can find no difference in the quality of the processions precisely because the Athenian citizens who take part in one of the two have, through their participation, been brought down to the "common level" of the foreigners marching in the other. ${ }^{15}$

There is a further irony in that Polemarchus makes a similar mistake in his attempt to defend the view of justice as benefiting friends and harming enemies. In his exchange with Socrates, Polemarchus quickly runs into trouble as soon as Socrates demonstrates that Polemarchus' proposed definition cannot, on its own, distinguish between those who merely appear to be friends, but are in fact enemies, and those who merely appear to be enemies, but are in fact friends. As a result of the confusion in terms, Polemarchus is compelled to accept that his view of justice is inherently contradictory, 
since it will sometimes lead one to benefit one's enemies and to harm one's friends. ${ }^{16}$ In this regard, it is fitting that Socrates' counterarguments reveal two specific flaws that are inherent in Polemarchus' definition of justice, since they also serve to identify the flaws in Voegelin's own interpretation of the scene.

The first is that, despite having begun from the premise that "friends owe it to friends to do some good," Polemarchus nevertheless fails to specify how exactly one may recognize what is and is not good, and so, by extension, those who are in fact one's friends and enemies. ${ }^{17}$ Socrates' objection thus draws attention to the absence of moral judgment in Polemarchus' definition of justice, an omission which ultimately compels Polemarchus to accept that his definition "seems to be bad." 18 The second flaw emerges as an extension of the first. The absence of an absolute moral standard according to which one may deductively recognize one's friends by recognizing what is good leads Polemarchus to fall back upon conventional categories of friends and enemies. In other words, his definition of justice implicitly defines friends in terms of citizenship and enemies in terms of the foreign. That Polemarchus himself is not an Athenian citizen, however, but an alien resident of the Piraeus, only deepens the dramatic irony that characterizes his exchange with Socrates. For Polemarchus unwittingly identifies himself as an enemy of Socrates, who then returns the gesture by defeating Polemarchus in the argument. $^{19}$

But by defeating Polemarchus' definition of justice, Socrates is also indirectly criticizing the traditional ethos upon which it is based. Significantly, that ethos is one of the central themes of the Odyssey. Throughout his travels, Odysseus is a scrupulous observer of the code of hospitality (xenia), which constitutes the first half of 
Polemarchus' proposed definition of justice - doing good to friends. Whereas travel in the ancient world was exceedingly dangerous, safe passage necessarily depended upon the benevolence of civilized peoples. For this very reason, the code itself is essentially rooted in a series of reciprocal obligations, beginning with this one: since civilized people had to rely on each other for safe passage, hospitality was always extended to strangers as a rule partly because the generosity of the host toward his guests could then be expected in return. "Welcome the coming, speed the parting guest!" is the ethical imperative that civilized peoples everywhere observe in the Odyssey. ${ }^{20}$ Fittingly, Cephalus, who is often identified with the old order, himself exemplifies all of the qualities of a good host. ${ }^{21}$

The particular rituals associated with the code of hospitality drive home its distinctively moral dimensions. For instance, one of the unbreakable obligations that the code imposes upon the host is that he provide his guest with a parting gift. Typically the kinds of gifts that were given to meet this requirement would be objects of great value, and yet the gesture itself is less about the material value of such objects than of the deliberate connotations of civilization and civilized life that they imply. For while the objects given are both useful and valuable, they are useful and valuable in very particular ways. They are valuable in the sense that they would typically be indicators of great wealth, such as treasure and gold. When Odysseus stops on the island of Aeolia, King Aeolus gives him the gift of the winds as a parting gift. The idea here is that he gives Odysseus power of the winds so that his ship will carry him back home to Ithaca. Though unconventional in the strict sense of the code of hospitality, its symbolic power is great, for it is both useful and valuable in returning Odysseus to civilization. Yet Aeolus' gift is the exception that proves the rule. Tellingly, Odysseus' compatriots simply assume that 
the bag containing the winds is full of treasure, an assumption that implies that treasure is indeed a typical kind of parting gift. Not realizing that it contains something far more valuable - the power to return home - they open the bag of winds and the ship is blown off course once again. ${ }^{* 2}$

But the connotation of civilization arises because these kinds of gifts are not inherently valuable, but valuable only within the specific context of civilized life, as the Greeks understood it. Gold, for example, is neither useful nor valuable in wilderness; yet it assumes both of these traits within the context of the polis. It is this feature that goes to the heart of the reasons why gifts are given in this way. They are given as a mutual recognition of the civilized nature of both the giver, bestowing such gifts that are produced within his own city, and the recipient, who receives them under the assumption that they will be as useful and valuable within his own city. So there is a mutual recognition of civilization. For instance, when Odysseus' son Telemachus travels to Sparta, King Menelaus offers him the gift of a chariot and a team of horses. But Telemachus rejects the gift, saying that they would be of no use back home on Ithaca because of the island's hilly terrain. It is significant that Menelaus does not interpret Telemachus' response to his generosity as a rejection of his hospitality, or as a rejection of the connotations of civilization, but instead takes it to heart. That Telemachus would have no use for the gift is clearly understood to defeat the purpose of the giving. Thus Menelaus simply substitutes another gift that Telemachus may find more useful. ${ }^{23}$

\footnotetext{
* Anthony Edwards notes that the art of sailing seems to have particularly distinct associations with artistry (techne) in general throughout the Homeric epics. These associations help to make sense of Aeolus' angry and apparently irrational response at encountering Odysseus and his crew a second time when they return to ask for his help again. Given these associations, however, the crew's misuse of Aeolus' generous gift could rightly be taken to imply that they lack the necessary skills to use it well, and thus, by extension, that they are not so civilized as Aeolus originally believed them to be. "It proves the immortals hate you!" he screams at them, "Out_-get out!" (Odyssey X, 83; trans. Fagles, p. 233)
} 
The kind of property that is given freely to friends in observance of the code of hospitality is therefore intimately connected to the social and political hierarchies of the Greek city-state (polis) in the most specific meaning of the term. Although the theme of hospitality dominates the Odyssey, its roots are more readily found in the Iliad. In Book XVIII, Homer gives us a detailed description of the shield of Achilles that the great warrior's divine mother, Thetis, obtains for him from Hephaestus, the god of craftsmanship, to replace the armour that was stolen from him by the Trojans when Patroclus took it into battle. The passage is often cited as a classic example of ekphrasis, which is an instance in epic poetry when a particular object is used or described in a manner meant to convey a much broader narrative or even philosophical point. Achilles' shield is used to this effect in the sense that it portrays a detailed representation of the social and political hierarchies that characterize civilized life in the Greek polis; but because of its divine origin, it can be - and often is - read as a microcosm, literally a representation, writ small, of the divine order of the cosmos.

As a description of the ideal polis, the shield articulates the essential economic relationship between the city and its surrounding countryside by depicting

a king's estate where harvesters labored, reaping the ripe grain, swinging their whetted scythes. ...

And there in the midst the king, sceptre in hand at the head of the reaping-rows, stood tall in silence, rejoicing in his heart.

And off to the side, beneath a spreading oak, the heralds were setting out the harvest feast. ${ }^{24}$

The description is important because it associates clearly-defined hierarchies with the proper ordering of the polis. These hierarchies are associated with, or are taken to be illustrations of, the greater cosmic order of which they are a part. In their reflection of 
that greater order, the hierarchies of the city bring harmony to its many diverse parts; and it is through that harmony that the order they bring about is made legitimate. If we consider the king in this image on Achilles' shield, holding his sceptre aloft just as the poet does in Hesiod's Theogony, so then does his characteristic property become a symbol of the kingdom over which he rules as a natural extension of his own body. It symbolizes his moral legitimacy, his authority to rule over the city and its inhabitants.

The proper ordering of the city, and the legitimizing of it, results in the economic prosperity of the city that is also depicted on Achilles' shield. This occurs only when virtue, rather than force, is the end of politics. It implies an order where the harvesters are described as labouring toward their own ends, using their own proper tools, just as the king "labours" toward the greater end of the whole by using his practical authority, represented in his sceptre, to bring harmony to the city and its many diverse parts. In both cases, the tools involved become symbols of the practical authority of those who wield them, an authority that is consonant with their natural positions within the greater organization of the city and thus, by extension, the cosmos itself. As a result of this harmonizing with the cosmic order, the city as a whole produces material goods in abundance. This economic prosperity is also displayed on Achilles' shield: the "harvest feast" that is being set out, the typical symbol of hospitality and solidarity among friends within the Homeric world, is the result of the reciprocal duties shared between the king, who guarantees the safety and security of the city, and the labourers who are thereby empowered to perform their particular tasks. Property is the natural product of the wellordered Greek polis precisely because the social and political hierarchies that characterize it reproduce on the earthly plane the greater order of the cosmos. 
Socrates' criticism of Polemarchus' more traditional definition of justice identifies a profound paradox that is at the heart of the code of hospitality and the traditional ethos. The problem with observing the code of hospitality so religiously, in deference to the sanctity of civilization, is precisely that the world is not wholly civilized. This, too, is one of the central themes of the Odyssey. Indeed, the assumption underlying the episode with the Ciconians is that there exists something of a natural state of war between them and the returning Achaeans. Odysseus responds by immediately besieging the settlement. He lands his ships, they attack the city and drive out its inhabitants, the slaughter the men and sack the city, and then they plunder it for its wealth. The episode would be a strange one indeed were we to read it without this fundamental distinction between Greeks and barbarians, friends and enemies, in mind. For although Homer never explicitly invokes this distinction himself, he never explicitly identifies the Ciconians as barbarians, but the scene makes no sense at all unless we read it in this way. But we should also mention that one reason why Homer never draws such a distinction explicitly is simply that the distinction is already so ingrained in the Greek imagination that he has no need to do so. For Homer's audience, it would have been obvious why Odysseus behaves in such an overtly hostile manner. That these are Ciconians, understood as barbarians, would already have been accepted as a sufficient justification for the aggressive actions Odysseus takes. Both Homer and his audience, therefore, take for granted what we, approaching him from across the span of three millennia, do not. ${ }^{25}$

But in any case, the way that the episode with the Ciconians unfolds in the Odyssey leaves little doubt as to the reasons why the Greeks considered the Ciconians to be barbarians. It illuminates their particular characteristics. For Homer's description of 
them emphasizes their violent and savage nature. Once Odysseus and his compatriots raid and sack the settlement, the Ciconians return the next day to wreak their revenge upon the Achaeans. Telling his tale to King Alcinous, Odysseus describes the episode in this way:

Out of the morning mist they came against uspacked as leaves and spears that flower forth in springand Zeus presented us with disaster, me and my comrades doomed to suffer blow on mortal blow. ${ }^{26}$

The juxtaposition here between the calm beauty of flowers blooming in springtime and the utter savagery of the Ciconians is instructive, for Homer is suggesting not only that the Ciconians are uncivilized, but that their very natures are intrinsically opposed to civilization. As a result, they fall naturally into conflict with the Greeks, who are, conversely, innately disposed toward civilized life. A state of war is therefore inevitable between the two groups.

But the passage is also illuminating in another way. Odysseus and his compatriots are, of course, veterans of the Trojan War. They are battle-hardened warriors. And not only that, they have only just left their victory at Troy, where they besieged the city for ten years, and now, having attacked this lowly barbarian settlement, they are quickly repelled by the Ciconians, who easily marshal overwhelming force against them. This makes an obvious and stark contrast with the decade-long siege at Troy. Odysseus and his compatriots are beaten back in mere moments by mere barbarians, a point which goes to the symbolic force that they exert upon the Greek imagination. Homer, too, underscores this very point when he describes the Ciconians, because he mentions only one "skill" that they possess: the ability to inflict violence. This is ultimately what characterizes not just the Ciconians as a tribe, nor even the Thracians as a people, but the barbarians in general as a class. Whereas they are skilled only in the use and threat of 
violence, the suggestion is that this forms the political order upon which their society is based. $^{27}$

This introduces a new distinction in this series of dichotomies that we are tracing. The skill the barbarians possess is singular because it is a generalist skill, meaning that the possession of it disinclines the possessor from developing other more specialized skills. But if we think about skilfulness as virtue, as we should, then the levelling of the barbarian city is necessarily a moral levelling of the city; it is a reduction of skilfulness, to the ability to inflict violence only. So one of the implications that we get out of that is that this dichotomy between Greeks and barbarians, the civilized and the savage, also implies a dichotomy in terms of the basis of citizenship. This is an extension of the natural friends and natural enemies dichotomy, but this new dichotomy implies that either virtue or violence must be the foundation for citizenship, for the city itself. And there is no middle ground between them. The absence of diverse virtues requires the development of skilfulness in violence, because there are no other grounds upon which to make an a political appeal to other would-be citizens.

Their skilful use of violence is what makes the barbarians especially terrifying to the Greeks, not just because of the damage they can inflict upon the bodies of Greek soldiers but because of the political implications of such unrestrained skilfulness. The barbarians are a threat not to any particular Greek soldier nor to any particular Greek city. Rather, they represent an existential threat to the very idea and ideals of Greek civilization itself. Ultimately the barbarians are both terrifying and threatening because of their mode of politics, which is grounded in the very same kind of indiscriminate but overwhelming violence. Thus, while Homer refers to the Ciconian settlement specifically 
as a "city" (polis), ${ }^{28}$ it is clear that this is a city in name only, for it has none of the civilized qualities that are most distinctive of the more narrowly defined concept that that word would otherwise imply. ${ }^{29}$

The connection between property and political order brings us to the root of the distinction between Greeks and barbarians, which is this: the barbarians are designated as such precisely because they represent the anti-ideal of Greek political organization. As a result, they necessarily exist outside the confines of civilized life by definition, since they are the antithesis of the good political order that is emblazoned on Achilles' shield. There are a wide array of implications that follow from this simple dichotomy. Above all, just as the legitimacy of the well-ordered polis in Homer's description of Achilles' shield results in material prosperity for all, so then can we read the conspicuous absence of that same prosperity in the Ciconians as evidence of their lack of a good political order. The nature of the property that Odysseus and his compatriots plunder from the Ciconian settlement is in this regard revealing. Homer mentions only three specific kinds of goods that Odysseus and his compatriots acquire as a result of their raid upon the Ciconian settlement: sheep, cattle and wine. These do not have the same connotations of civilization that are intrinsic to the kinds of goods that are bestowed by Greeks upon each other as part of the traditional code of hospitality. They are not the kinds of goods we would expect to find within a Greek polis because they are not the kinds of goods that would be most useful there. Instead, they have a distinctly agrarian character; they are the kinds of goods that would be more readily found within the surrounding countryside. There is a hierarchical levelling within their settlements that is implied here precisely because of the absence of greater productive capacity. That the only kinds of goods that 
can be produced there are agrarian goods underscores the essential idea that the barbarians represent: the levelling of all hierarchies down to the common element of violence - the very razing of the city as a concept.

The distinction between foreigners and native-born citizens, then, simply does not align with the broader moral categories into which human life is organized in the Homeric epics. More importantly, neither does that distinction align with Socrates' subtle but no less radical revision of those categories in Book V. In a brief exchange with Glaucon, Socrates distinguishes between, “on the one hand, what is one's own and akin, and what is alien, and foreign, on the other." ${ }^{30}$ At first glance, the two categories Socrates introduces here appear to be precisely the same as those which Voegelin has already proposed. Such is not the case, however, as Socrates immediately goes on to broaden the first of the two categories while at the same time narrowing the scope of the second. As a result, kinship comes to be redefined not in terms of one's family or city of birth, as we might expect, but is given instead as a function of one's ethnic origin. "The Greek stock is with respect to itself its own and akin," Socrates argues, while "with respect to the barbaric, [it is] foreign and alien." ${ }^{31}$ Many great moral and political ramifications stem directly from the fact that Socrates so explicitly invokes this basic cultural dichotomy within the context of the philosophical arguments of the Republic. The most immediate result, however, is to reorient the basic concept of citizenship in terms of a more strictly moral, as opposed to merely conventional, definition. It is here where Socrates departs almost radically - but also, given the context of the discussion, rather fittingly - from the cultural conventions of his own time. ${ }^{32}$ 
Of course, the overtly racist tone in which Socrates introduces the distinction may initially appear only to confirm, rather than reject, the imperialist cultural mores of ancient Athens. Thus we may be tempted to dismiss it as a serious philosophical argument. But what Socrates is actually doing here is appealing to what are, however unfortunately, the merely presumed indicators of the inherent natural differences that exist between and among human beings. Despite the premise's overtly racist expression, therefore, the more abstract philosophical point it illustrates is, nevertheless, itself sound. Hence we ought to be careful not to dismiss the passage out of hand, since, in doing so, we would risk overlooking a crucial step in the overall moral argument of the Republic. For Socrates then goes on to develop the original distinction between the native and the foreign, read here as Greek versus barbarian, into something far more significant: a distinction between friends and enemies "by nature." 33 When we consider Aristotle's observation in Book II of the Politics, which he attributes to Socrates, that friendship is "the greatest good of states and what best preserves them against revolutions," now we can better understand the reasons why. ${ }^{34}$ For the alternative conception of citizenship that Socrates is suggesting here in Book V of the Republic - but which Aristotle, true to form, seems almost wilfully to go on to misread - thoroughly grounds the fundamental distinction between friends and enemies in nature rather than the conventions of the city. The concept itself, as well as the series of related distinctions upon which it is based, must therefore necessarily be more just as a result, for it will not be bound - as all conventions are, and must be - by any of the usual contingencies of time and place. ${ }^{35}$

Are we really to believe, therefore, that Socrates' observation about the competing processions is meant only as a neutral observation of fact? When Socrates 
redefines the fundamental basis for citizenship in Book $\mathrm{V}$ in terms of unchangeable differences in nature, he is suggesting something radical and, indeed, subversive of the Homeric tradition. For it is not merely that the Thracians are non-citizens, nor even that they are foreigners. These categories are, as we have noted, purely conventional. Rather, the presence of the Thracians in the Piraeus and, especially, their equal status alongside the Athenians in the Festival of Bendis ought instead to be read as the threat to the very moral foundations of the city that it is, and this for one reason above all others. That the Thracians are barbarians means that they are by nature the enemies of the civilized Athenians. By drawing our attention specifically to their presence in contradistinction to the Athenians, Socrates' observation subtly reaffirms the very kind of moral judgment that is present in the Myth of Er but which is lacking in both Polemarchus' essentially conventional arguments about justice. For despite the apparent equality between them, the most salient fact of all is that there remain, nevertheless, two processions rather than one. They are equal and yet not equal. ${ }^{36}$

Socrates' implicit moral judgment of the two processions deepens the parallels between the Odyssey and the Republic and Socrates and Odysseus. In that broader narrative parallel Plato is also evoking a typical kind of scene that dominates the action in the second half of the Odyssey. There, Odysseus frequently disguises himself as a wayward beggar in order to test the moral characters of those he encounters on the island, in preparation for the restoration of his rule over Ithaca. ${ }^{37}$ There is therefore an ironic dimension to the scene. By alluding to the Odyssey, Socrates "disguises" himself as Odysseus in order to cut through the appearances that dominate the world of the Piraeus, and for much the same reasons that Odysseus does once he returns to Ithaca. Moreover, 
in the Odyssey as well as in the Republic, the purpose of this moral judgment is fundamentally political, since it becomes a test of citizenship. The way that the subject being tested responds to a member of the underclass reveals something not just about his or her moral character but is taken to be an extension of his or her loyalty to the legitimate ruler of the kingdom of Ithaca.

Yet we would miss the real significance of the complex mytho-historical context of the Republic were we to focus only on the parallels between it and the Odyssey. As the discussion of poetry in Book X amply demonstrates, Plato's invocation of Homer is never simple and is always multifaceted. While Plato alludes to a series of literary parallels between Socrates and Odysseus in order to suggest the necessity of refounding the city upon a new and more morally worthy conception of citizenship, his appeal is not simply for a return to Homeric tradition. Indeed, by having Socrates go down into the Piraeus in Book I under the guise of Odysseus returning to Ithaca to refound the city of which he is the one legitimate ruler, Plato implies that that traditional conception of the city is lacking precisely because it has necessitated the return in the first place. That the political order of the Piraeus has decayed into a state of chaotic egalitarianism - that it has decayed quite literally into a state of barbarism - will lead Socrates to appeal to something far more fundamental than mere tradition. Rather than proposing a return to the Homeric conception of citizenship, Socrates instead argues for a return to that which precedes even this most ancient of conceptions: his appeal is for a return to nature itself.

In his arguments for the restoration of the ultimate authority of nature, Socrates will preserve the moral value of property that made possible the rise of the Greek polis that Homer so glorifies in the epics, but he will use it not to legitimate the traditional 
order but instead to overturn it. The re-establishment of a political order more fundamental than tradition, more legitimate than any possible convention, more civilized than the Greek polis itself, will take the form a city grounded in truth above all and the necessity of remembering what has long been forgotten: the ultimate and absolute authority of nature. 


\section{Part II}




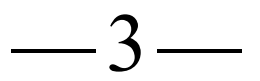

\title{
The Great Forgetting
}

ఖ Rondo: Allegro con brio. \&

\author{
The ready-spoken daughters \\ of great Zeus had this to say, \\ And gave me a staff that they had \\ plucked, a branch of flowering bay, \\ A wondrous thing! and breathed a \\ god-inspired voice in me, \\ That I might celebrate the \\ things that were and that shall be.
}

- Hesiod,

The Theogony

Like all ancient Greek poets working in the great tradition of the epic, Hesiod begins his Theogony with an invocation of the Muses. He does so in recognition of humanity's essential unfitness to behold the infinite wisdom of the gods who, by virtue of their immortal intelligence, possess all knowledge of "things that are, / Of things in future

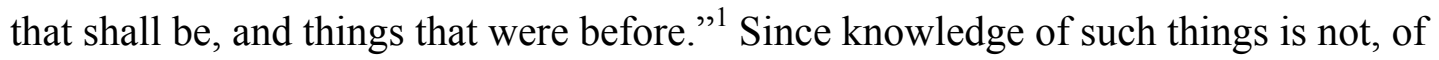
course, within the ordinary purview of mere mortals, no man can ever hope to transcend his human limitations, these the limitations of our all-too-earthly condition, in the absence of divine inspiration. But the invocation of the Muses specifically - the "goldenfilleted" daughters of Zeus, king of the gods, and Mnemosyne, goddess of Memory ${ }^{2}$ - has a special significance, for it reveals that the wisdom of the poet springs from a remembrance of "the things that were." This preternatural recollection of the past is 
ultimately what grants the poet a certain authority to speak, an authority which Hesiod symbolizes in the staff, or sceptre, that the Muses bestow upon him before he undertakes to tell of the birth of the gods and the primordial war of heaven. It is thus by means of memory that the poet comes to acquire what we may call a practical authority to exemplify his poetic virtues in activity. Just as the past flows ceaselessly into the future, so as well does one's knowledge of what once was entail knowledge of what ought to be and the power to make it so.

Rather than beginning the Republic with an appeal to Memory, Plato instead concludes with one. In the Myth of Er, Socrates relates the tale of a mere mortal man who, after passing into death, miraculously returns to life with a mandate from heaven to enlighten mankind about the nature of our moral existence. While travelling among the kingdom of the dead, he learns that the souls of all men are engaged in a constant transmigration between worlds and that each must re-enter this life with no memory of all that it has undergone, as though it were but a ship set adrift upon the vast ocean of eternity. On the broad Plain of Lethe, Er bears witness to this Great Forgetting; and because he alone has been forbidden to drink from the River of Carelessness, his memory of the momentous event is uniquely preserved. He returns to the ranks of humanity, much like the servants of Job, thus to declare: I only am escaped alone to tell thee. ${ }^{3}$ However, quite unlike either Job's servants or Job himself, or even the poet prophetically possessed of a "god-inspired voice," Er carries back into mortal life, not simply the words of a divine intelligence, but, indeed, a direct understanding of the very objects it beholds. He thereby becomes the first man to possess the most exalted form of wisdom, and this entirely because of his singular powers of recollection. "And thus," Socrates concludes, 
"a tale was saved and not lost; and it could save us, if we were persuaded by it." The salvation of humanity, Socrates suggests, lies exclusively in our ability to reverse the Great Forgetting, to remember what Er himself came to know: that which distinguishes virtue from vice, good from evil.

Therefore — speak, Memory! Tell us what you will. Tell us what manner of truth can be found in the Socratic maxim that virtue is knowledge recollected, and how it implies that all virtue consists in activity. Tell us, too, in what way the practise of virtue is inherently tied to man's material condition, and thus of the moral ends which the possession of property can be made to serve. And tell us, above all, of the state of vice in which men knowingly do ill despite their will to do good, and whether there can be any redemption for such poor souls as these - as, perhaps, they are such poor souls as ours. Speak, Memory! and tell us of these things, of truths which men have never so urgently needed to know. Speak for our time too.

Let us with Memory recall first that it is in the Meno where Socrates explicitly proposes that all virtue is wisdom, or, to employ Meno's slight variation of the same claim, that all virtue is knowledge. ${ }^{5}$ Despite the purposely uncertain context in which the maxim is first asserted and in which, over the course of the dialogue, its meaning steadily becomes more fully elaborated, it has nevertheless given rise to an apparently intractable problem of interpretation which has attained the widely-recognized status of a "paradox" in the scholarly literature on the subject. Indeed, some commentators have gone so far as to suggest, whether deliberately or not, that in the face of the many characteristically perplexing things Socrates has to say over the course of the entire Platonic corpus, the maxim that virtue is knowledge amounts to nothing less than the Socratic Paradox. ${ }^{6}$ The 
heart of the so-called paradox lies in the following question: If virtue is knowledge, then why do knowledgeable men sometimes fail to act virtuously? The question would seem to be as old as the maxim from which it is derived, ${ }^{7}$ and it has notably proved to be as enduring as the ideas of its most popular - and, in a rare historical coincidence, also its most distinguished - proponent, Aristotle.

In a thinly veiled passage of the Nicomachean Ethics, Aristotle subverts one of Plato's most privileged metaphors by arguing that certain unspecified men have a regrettable tendency to "take refuge in theory and think they are being philosophers and will become good," when, according to him, such men are merely deluding themselves by "behaving somewhat like patients who listen attentively to their doctors, but do none of the things they are ordered to do." ${ }^{, 8}$ What Aristotle has in mind is to describe the peculiar moral phenomenon known to the Greeks as akrasia, which has traditionally been rendered somewhat archaically in English as the vice of "incontinence," meaning a failure of self-command. ${ }^{9}$ In his diagnosis of the problem, Aristotle also means to suggest that no adequate explanation - much less any effective remedy - can be found for it in Platonic thought. The point about the doctor's wise yet unheeded advice, however, merely masquerades as a conveniently fatal flaw in the Platonic account of virtue inasmuch as it implicitly interprets the problem in terms of Aristotle's own essential concepts while simultaneously obscuring the nature of his criticisms behind the mask of Platonic metaphor. In effect, Aristotle alleges that the Socratic maxim incorporates only the philosophic virtues while omitting the specifically moral kind, despite the fact that Plato's Socrates never draws any such distinction of his own. 
There is, then, something of a rhetorical sleight of hand at work here. Yet despite Aristotle's slyly anti-Platonic interpretation of the problem of incontinence as being caused by a lack of moral force that ostensibly attends all purely theoretical knowledge, it has nevertheless become the standard - and thereby incredibly problematic - approach for interpreting the Socratic maxim that virtue is knowledge. As Lawrence Houlgate rightly argues in response to a number of scholars who have been casually critical of the maxim, "its patent falsity ought to make us suspicious." ${ }^{10}$ Indeed, what Houlgate seems to be warning us against is the presumption that the meaning of the terms involved is necessarily self-evident. We are, after all, confronting ideas and concepts for which we will inevitably be unable to find any precise analogues of our own. Caution is warranted. Despite his eminently reasonable warning, however, Houlgate, too, stumbles into the standard Aristotelian framework inasmuch as he tries to make sense of the relationship between right conduct and a conception of knowledge that is unreasonably restricted to its purely theoretical form. Considering that Houlgate's stated purpose is to make sense of the paradox, it is more than a little surprising to find him disclaiming at the very outset that his own analysis is "not... in any way exegetical of [Plato's] Socrates." "11 Although honesty with respect to one's methods is always admirable, Houlgate's disclaimer nevertheless betrays an evidently unselfconscious irony. By rejecting an exegetical approach, he tacitly accepts that the Socratic maxim is indeed irredeemably paradoxical even within its original context.

Given the widespread puzzlement concerning the problem, it may seem as though many scholars have drunk more than their share from the River that winds its way through the broad Plain of Lethe and have consequently forgotten to ask what should 
have been the most obvious question of all: Is there, indeed, a paradox in the Socratic maxim that virtue is knowledge, in the original sense in which Plato's Socrates meant it? If there is a paradox at all, surely it exists only in the fact that so much effort could have been expended discussing the exact meaning of the relationship between two terms, virtue and knowledge, without first establishing the essence of each term in and of itself. There has been much fretting as a result over the failings of what one scholar has termed Socratic "intellectualism," 12 by which she evidently - though unintentionally - means an oddly deflated variant of what properly ought to be a more robust Platonic idealism. These failings, however, all stem from but a single origin in their common failure to acknowledge one rather glaring fact: that in the dialogues in which the troublesome claim appears most prominently the very meaning of virtue itself is always deliberately, if not quite explicitly, thrown into question. This is most obviously true in the case of the Meno, which begins abruptly with the stark question of whether virtue can be taught. The way in which Socrates responds to that question is entirely apropos, and it ought well to draw our close attention. "If I do not know what something is," Socrates innocently tells Meno, "how could I know what qualities it possesses?"13 That the conversation between the two men nevertheless proceeds without a satisfactory answer ever being given to Socrates' more fundamental question - which is not entirely unlike the way much of our own academic discourse on the same subject has proceeded - is no minor detail. The reader, and the unwary scholar, have been forewarned.

But alas! Perhaps it is inevitable that some philosophers will behave somewhat like students who listen attentively to their teachers, but learn none of the things in which they have been instructed. What some philosophers have overlooked is that a resort to 
strict epistemology alone cannot resolve the so-called Socratic Paradox since the very paradox itself is premised on an unwarranted division between epistemology and moral theory. Yet there is a wonderfully redemptive irony in precisely such a mistake. For the dramatic centrepiece of the Meno, which consists of Socrates' demonstration of the Doctrine of Recollection through his interrogation of Meno's slave boy, serves both philosophical and literary functions. On the surface, it presents an argument about a strictly epistemological point, namely that learning is possible because all men have the capacity to recall knowledge, which is eternal. The fact that the demonstration itself concerns the subject of geometry, which is a pure abstraction, is particularly significant because the very notion of such theoretical knowledge being "recollected" also more subtly prods the familiar reader to recall what he already knows, and what Meno does not know, about the nature of Platonic virtue. It points, in other words, to a class of knowledge beyond geometry that can only be found in the other Platonic dialogues.

At the very beginning of the Meno, for instance, Socrates claims not to "remember" anything at all about virtue. ${ }^{14}$ The obvious disingenuity of his protestations, ingeniously clothed in the language of forgetfulness, steadily assumes a more profound meaning as the broader philosophical context of the dialogue, and the Doctrine it proposes, unfolds. This is true even and especially when the dialogue is read exoterically as nothing more than an account of a mere epistemological theorem. But even Meno rightly expresses incredulity in the face of Socrates' claims to ignorance, blurting out in disbelief, "but, Socrates, do you really not know what virtue is? Are we to report this to the folk back home about you?"15 His questions shrewdly anticipate the familiar reader's own objections and, more importantly, challenge him to produce evidence to the 
contrary. Is this, after all, the same Socrates of the Gorgias - a dialogue which Meno himself directly invokes ${ }^{16}$ - who very publicly advances several different arguments about what virtue is and is not? Is this Socrates of the Meno, who proposes that virtue is wisdom just before one of his accusers silently enters the dialogue,${ }^{17}$ the same Socrates of the Apology, who unrepentantly marches off to death in virtue's very name? Although the baffled Meno fails to marshal any evidence to expose Socrates' pretended ignorance, the point is well and clearly made. For no one who reads the dialogue through to the end can fail to notice that, by the time of its conclusion, a mere ignorant slave boy - not even yet a man - has recollected at least something of the truth, whereas Meno himself has recollected precisely nothing. The insinuation about the careless interlocutor, and by implication the careless reader, is clear enough.

The implicit argument lurking beneath the literary surface of the Meno holds that to possess knowledge of the Doctrine of Recollection, meaning to grasp both what it claims and the consequences that follow from it, necessarily means to put it to use. For this reason a number of scholars have been correct to emphasize the importance of the hypothetical approach on the basis of which Socrates and Meno conduct their inquiry, ${ }^{18}$ particularly since it ultimately leads them to an impasse - or shall we call it a paradox? on the original question of whether virtue can be taught. Even more importantly, it also leaves unresolved the actual truth-value of the hypothesis that virtue is knowledge, which was only tentatively granted on the basis that virtue is the cause of men being good and that knowledge is the cause of men's actions being either beneficial or harmful. In both instances, the inquiry eventually stalls because it has been conducted in the absence of an essential account of virtue itself. It fails, in other words, because of the inaccessibility of 
the conclusions Socrates draws in the arguments he has already made on previous occasions; it fails because of his apparent forgetfulness, and thus because of his failure to recollect. The Doctrine of Recollection thus itself suggests an interpretation for understanding the - as yet still hypothetical - maxim that virtue is knowledge. ${ }^{19}$

In Book VII of the Republic, Socrates argues that the hypothetical method of inquiry is but one step in the ascent to truth. Ultimately it must be succeeded by dialectic, which alone is able to "destroy hypotheses" and replace them with firm knowledge. The process of recollection is instrumental in that endeavour because its objects lie in the realm of the Forms. They can be known for certain because they consist in the essential. The deeper significance of the hypothetical method Socrates employs in the Meno, therefore, becomes fully clear only once its purpose is considered within the context of the arguments Socrates makes in the Republic. One may, accordingly, similarly undertake to "destroy" the hypotheses which arise in the Meno by interpreting their meaning within an imagined - that is to say a hypothetical - dialectical context within the greater Platonic corpus. The Doctrine of Recollection suggests its own ability to reach beyond mere hypothesis to grasp the exalted objects of knowledge insofar as it indirectly suggests that one must become a practitioner of dialectic in order to do so, or that, rendered in literary terms, the Socrates of the Meno must be placed in dialogue with the Socrates of the Republic. Thus does the single character of Plato's Socrates come to recollect, in both literary and philosophical senses, something of his "former lives" which he has supposedly forgotten in the Meno - and the reader himself does the same. The process by which one finally arrives at the conclusions which Meno is unable to discover for himself fittingly vindicates its own truth. ${ }^{20}$ 
For this reason Socrates recommends dialectic as the highest of the arts which the philosophers ought to employ "as assistants and helpers in the turning around" of the citizenry toward the Good. ${ }^{21}$ Because all knowledge (episteme), in contradistinction to true opinion (orthe doxa), implies the necessary practise of some art (techne) - as, in this case, the Doctrine of Recollection implies the practise of dialectic - the division Aristotle asserts between theoretical knowledge (episteme) and moral conduct does not in fact exist in the Platonic context. The man who knows, does; whereas the man who merely thinks he knows simply goes on believing that he knows - much as Meno, who wrongly concludes from Socrates' line of questioning that true opinion is the source of all virtue. Socrates, however, warns Meno against this opinion, likening it and all others to the transience of Daedalus' flying statues, while also, perhaps, indirectly invoking Daedalus' son, Icarus, who takes flight on makeshift wings despite being utterly "unaware / of any danger in the things he handled." 22 The esoteric reference, along with the fateful fact that Anytus, too, recollects nothing of virtue by the conclusion of the dialogue, suggests a political dimension to the Meno which is much understated. Inasmuch as dialectic is the singular art of tying down true opinion to the mind of man, thus converting it - safely into knowledge, the association Socrates draws between the master craftsmanship of Daedalus and the royal arts of the philosopher-king suggests that the Doctrine of

\footnotetext{
* We ought not to forget the crucial detail that the flight of Icarus comes to a disastrous end because Icarus flies too close to the sun - suggesting that the cause of the disaster is to be found in his grasping for wisdom that is beyond his nature to comprehend. When viewed through the lens of another Platonic dialogue, the Phaedrus, in which Socrates proposes the famous image of the winged chariot in order to "inquire into the reason why the soul loses her wings" (246d; trans. Jowett, op. cit., p. 144), the image of Icarus as a critique of the sophists comes into much sharper focus. It is fitting, therefore, that Socrates mentions Daedalus' flying statues in the Meno immediately after the discussion of sophistry. And yet here Plato introduces a surprising reversal. By pretending to defend sophistry against Anytus' just criticisms of it, Socrates himself now seems to be playing the role of Icarus - with Anytus, incredibly, assuming the position of the sun! Thus the unexpected literary reversal signals an equally curious philosophical parallel in that Socrates' evident hubris prophesies - in a temporal reversal of the Doctrine of Recollection - his own plummet to the sea. Thus Plato suggests, along with Hesiod, that to know of "the things that were" means to know of the things "that shall be."
} 
Recollection, like a beautiful flying statue, only becomes valuable once it has been securely tied to the city's political organization. There is a moral imperative, then, that this be done. ${ }^{23}$

This implied but unaddressed consideration of justice hangs over the Meno like a fog suspended in the distance, and it rightly recalls the confrontation between Socrates and Thrasymachus midway through Book I of the Republic concerning, in part, the nature of artistry. In one of his usual attempts to clamp shut a series of traps which he has meticulously set for his opponent, Socrates suggests that the fallibility of a city's rulers inevitably precipitates a paradox in Thrasymachus' proposed definition of justice as the advantage of the stronger. Indeed, there is a fitting parallel here with Aristotle's own misguided criticism of Platonic virtue as knowledge in that he and Socrates both allege that the man who is ruled does not in fact do what he thinks it is right for him to do. Under such circumstances, the justice of the Republic cannot prevail against the dominance of mere opinion, however true it may be. ${ }^{24}$ Unlike Meno, however, Thrasymachus deftly avoids sinking into the morass of opinion. Sneering back at Socrates - as perhaps we might imagine Plato sneering back at a certain overconfident student who seemingly has yet to have read to the end of Book I - Thrasymachus cleverly retorts, "Do you suppose that I call a man who makes mistakes 'stronger' at the moment when he is making mistakes?",25

And so do we, in our turn, call a man who affirms mere opinion to be a philosopher? Aristotle, evidently, did suppose Plato's Socrates to mean this. Thrasymachus, of course, does not mean this, and he goes on to argue that the man who errs in the practise of his art is a man who errs as a result of some lack of knowledge; and 
the man who lacks knowledge is in this precise respect no artisan. The distinction, of course, becomes a crucial fulcrum in Thrasymachus' own argument, which is later defeated only because he fails to recognize that the practise of any art must be undertaken not for the sake of its practitioner but for the sake of its object. ${ }^{26}$ But even though his formulation of justice is revealed to be weaker than Socrates' criticisms and so, fittingly by its own standard, unjust, it is nevertheless significant insofar as it introduces the element of "precision" into the rest of the dialogue, thereby providing a solid foundation for the division of labour in Book II and, ultimately, the formal definition of justice in Book IV as each man minding his own business. ${ }^{27}$ All three iterations of the argument each convey in a very definite way that all knowledge presupposes an element of practical activity.

To say that virtue is knowledge, then, means to say that virtue is a kind of activity which cannot occur in the absence of knowledge. In fact, the imperative to action is the inalienable purpose and final end of the educational regime of the ruling classes that Socrates outlines in Books III and VII of the Republic. In both books Socrates argues that the city's education of the Guardians must ultimately be undertaken in order that they may become "champions of war" (athletes polemon), ${ }^{28}$ a turn of phrase which distinctly suggests the execution of government as a kind of competition (athlos) and justice as a kind of prize (athlon) to be claimed in the city's name. Somewhat unexpectedly, perhaps, Aristotle himself strikingly makes the very same point in a pivotal section of Book I of the Nicomachean Ethics, when he observes that the athletes who are most worthy of victory at the Olympic Games - the champions - are not, after all, merely the strongest men, but rather those who have proven their strength in actual competition against each 
other. The observation is meant to illustrate the broader argument that the essence of all virtue is found in activity rather than any particular state, since it is only through activity that what would otherwise remain but mere dormant potential can be, and is in fact, realized. $^{29}$

Few interpreters of the so-called Socratic Paradox have emphasized the importance of this tacit distinction between the potential and the actual - or, in equivalent terms, between true opinion and knowledge - that is present in Socrates' use of language in the Republic and what it means specifically for the claim that virtue is knowledge. R. E. Allen, however, is one notable exception. Hinting at the distinction's great significance, he interprets the overly-problematized Socratic maxim to mean plainly that "the knowledge which is virtue is not merely an abstract or theoretical understanding of value, but the capacity or practical ability to exhibit understanding in action." From this he concludes, with much understatement, "if this is true, the Socratic Paradox is far less paradoxical.” Magnanimity may well be a virtue, but Allen's conclusion deserves to be stated more bluntly than he himself delivers it. For once we have defined virtue as being inherently linked to practical activity which is informed and made possible by theoretical knowledge, thus defining it in opposition to what a strictly "intellectualist" interpretation of Plato would seem to suggest, the so-called Socratic Paradox does not simply become "less" paradoxical. Indeed, it ceases to be a paradox altogether. ${ }^{30}$

In the same way that Memory has saved us from the incoherence of the Socratic Paradox by persuading us of the Doctrine of Recollection, so too might she have saved the principal discussion of the Meno if only Meno himself could have been persuaded of the same thing. Hence Socrates repeatedly emphasizes the importance of knowledge in 
making men good, going so far, in fact, as to state boldly and without any of his characteristic ambiguity: "I would contend at all costs both in word and deed as far as I could that we will be better men, braver and less idle, if we believe that one must search for the things one does not know."31 Meno, however, misinterprets the meaning of even this direct contention, finding in it not a warning against Socratic ignorance but rather proof of Socrates' conviction that virtue can indeed be taught. As a result of this misunderstanding, Meno later finds himself reduced to utter perplexity by his inability to explain how it could be that virtue should in principle be teachable when neither he nor Anytus, nor even apparently Socrates, is able to identify any profession that actually seeks to make men good by imparting to them some essential knowledge of virtue. Meno stumbles, therefore, into his own version of the Socratic Paradox. Unlike ourselves, however, he fails to escape it. ${ }^{32}$

The exact flaw in Meno's reasoning should by now be familiar. In his failure to grasp the essence of virtue, Meno necessarily fails to understand - in fact, he literally fails to recall - a crucial point which he himself has already made and, what is worse, one that he has made repeatedly. In the first part of the dialogue, Meno many times lists various examples of things he takes to be virtuous without actually giving an essential account of virtue itself. ${ }^{\dagger}$ Socrates predictably criticizes this approach, joking that "we

\footnotetext{
$\dagger$ Socrates does eventually succeed in eliciting from Meno a general definition of virtue, but even then Meno merely resorts to quoting an unnamed poet when he proposes that virtue is "to desire beautiful things and [to] have the power to acquire them" (77c; trans. G. M. A. Grube, op. cit., p. 877). The irony, of course, is that Meno's definition is almost exactly what Socrates himself will later suggest, albeit obscurely, when he disingenuously proposes that those with the best natures ought to be sequestered in the Acropolis (see below). But because Meno has once again resorted to mere opinion, he fails to grasp any of the similarities and even fewer of the implications, and Socrates inevitably rebuts his definition with the utmost skill of a sophist.

We might also note as an important aside that Meno's proposed definition of virtue provides Socrates with the perfect opportunity to introduce the concept of eros into their discussion, and that, even more importantly, doing so would have preempted Meno's subsequent counterargument (at 80d), made in
} 
have found many virtues while looking for one," meaning, in other words, that Meno's error is to have looked for the general by searching for it among particulars. ${ }^{33}$ Naturally, the lesson is lost on Meno. And now, at the conclusion of the dialogue, Meno merely inverts his same error when, with the added assistance of Anytus, he sets about to look for particulars by searching for them among the general. While looking for one virtue, now he inevitably finds none, which is a rather ominous note on which to end the dialogue. Indeed, the ultimate failure of his search forms something of a darker counterweight to the Doctrine of Recollection: a dramatic demonstration of the very concept of virtue passing into utter oblivion. ${ }^{34}$

Because Meno's forgetfulness prevents him from assimilating the essential nature of his error, he necessarily fails to realize that the theoretical understanding which makes an activity virtuous must by definition be general even while the activity itself in which virtue manifests must always be particular. One cannot, in other words, simply practise virtue as such, as Meno now seems to suppose. Rather, one can only practise it under its many different particular guises. The same principle, then, holds true as well for those who would learn to become virtuous. Hence there are no teachers of craftsmanship as such, but rather teachers of blacksmithing, teachers of carpentry, and so on. ${ }^{35}$ As Meno himself had declared at the beginning of the dialogue, albeit with unwitting insightfulness, "There is virtue for every action and every age, for every task of ours and every one of us. ${ }^{, 36}$ His words, despite their truth, are quickly forgotten, however; and

the aftermath of Socrates' apparent refutation of his proposed definition of virtue, that learning is impossible because one cannot know what one lacks. Since eros is by definition the desire for that which one lacks, it is entirely conceivable that one could erect a full account of learning upon it alone. That Socrates opts instead to pursue his discussion with Meno by resorting to the comparatively tame Doctrine of Recollection, as opposed to some version of Diotima's Ladder that he presents in the Symposium, is both greatly significant and yet altogether puzzling. 
although their meaning finds a striking parallel with a familiar verse from the Book of Ecclesiastes - "To every thing there is a season, and a time to every purpose under heaven $" 37$ - the character of their utterance is perhaps more fittingly captured by another: There is no remembrance of former things; neither shall there be any remembrance of things that are to come. ${ }^{38}$

Meno's fate, it would seem, is to be a tragically ironic figure. While according to the Myth of Er all souls drink from the River of Carelessness precisely once, at the end of the afterlife, Meno, in contrast, seems to have the grave misfortune to drink repeatedly from the River throughout the course of his mortal life. If, therefore, virtue is knowledge, then, as that most famous Socratic maxim asserts, the very beginning of all virtue must be the recognition that the only thing one can know for certain is that one knows nothing. If, furthermore, all knowledge is recollection, as Socrates argues, then to be capable of learning means above all to have become aware of having once forgotten. This is something which Meno consistently proves himself to be utterly incapable of doing. Thus the dialogue which begins with him asking whether virtue can be taught ultimately provides an answer in the affirmative only by demonstrating how Meno himself has failed to learn anything at all about it. He answers his own question without even realizing it and, moreover, does so only in the process of taking lessons from a teacher whom he fails to recognize as the very thing he claims not to be able to find. More than a simple amnesiac, Meno is indeed the very incarnation of amnesia (amnesis), the literal antithesis of recollection (anamnesis), the personification of the Great Forgetting. He represents nothing less than the very threat to man's salvation that Socrates warns us against with his final words in the Republic. 
Beneath the Meno's comedy of philosophical errors, therefore, there is something much darker at work. We have often observed that Meno is less wise than the words he utters; but to say this is also to say, as a corollary, that the meaning of his words holds a wisdom greater than even he himself is able to recognize. There is, as a result, much more to Meno's challenge to the claim that all men have an innate capacity to learn virtue than the force of his words would at first seem to admit of. Frustrated by Socrates' attempts to drive him into self-awareness of his ignorance, Meno demands of his pesky inquisitor, "How will you look for it, Socrates, when you do not know at all what it is? How will you aim to search for something you do not know at all? If you should meet with it, how will you know that this is the thing you did not know?"39 Socrates immediately goes on to demonstrate the Doctrine of Recollection in response to these very questions, thus providing the necessary theoretical refutation to Meno's objection. Yet, in the aftermath of Meno's abject failure to recollect anything himself, which is to say his failure to translate his right opinion of what is true (orthe doxa) into practical activity (techne), he in effect unwittingly advances a retroactive practical objection to Socrates' merely theoretical proof that learning is indeed possible. For if the proof is valid, why then does Meno learn nothing from the manifestation of its truth? Meno's once-benign obtuseness now seems on the verge of a reincarnation in the form of the much more potent Aristotelian rift between theory and practise.

Is the Meno, then, the true revenge of Thrasymachus wrought upon Socrates? Is Meno himself the kind of patient Aristotle has in mind when he criticizes the man who simply nods his head in agreement when profound truths are spoken, only then to reach out into the River to drink once more? Despite his decisive intellectual victory over 
Meno, Socrates still has yet to address his own, and far more significant, apparent moral failure in that he has not actually brought Meno to any real knowledge of virtue as a result of their discussion. According to the criteria of precision which Thrasymachus introduces in Book I of the Republic, and which Socrates himself directly incorporates into his own subsequent arguments, it may well seem that Socrates is in this precise respect no philosopher. That Meno's explicit objection is nothing more than an ironically memorized “debater's argument," in Socrates' apt description of it, is in fact entirely beside the point. For Meno's own deeds now pose an objection that the man himself must always have been unable even to conceive of, much less to articulate, precisely because of the objection's very nature. ${ }^{40}$

Like far-sighted Apollo, however, Socrates skilfully avoids the looming paradox, evidently anticipating the potential problem in much the same way that he eventually corners and tames Thrasymachus in Book I of the Republic. Arguing that there are many different particular virtues and that men will as a result be more apt to pursue some more than others, he cleverly turns the emerging paradox back onto Meno's own failure to grasp the essence of virtue itself. Socrates' apparent failure as a teacher thus becomes Meno's actual failure as a student, and so the element of precision that we first admitted into the Meno in order to explain the moral force of recollection in turn becomes, as it does in the Republic, the basis for the particularization of all virtue. It is, indeed, only after Anytus enters the dialogue, and only after Meno's evident bewilderment in the face of the Doctrine of Recollection, that Socrates begins speaking of particular virtues as opposed to virtue as such. Meno, as always, fails to recognize what Socrates has done in subtly shifting the ground of their discussion back toward his own initial observation that 
there is a multitude of virtues, just as Anytus, having been absent for the demonstration of the Doctrine of Recollection and who is for that reason equally incapable of recalling what has gone before, similarly fails to grasp the deeper implications of Socrates' new line of questioning. That Socrates throughout the Republic often stresses the importance of memory among the Guardians strongly suggests that he is well aware that his own virtues as a philosopher are not the virtues most proper to these men, these ever so forgetful men, of the Meno. ${ }^{41}$ As he shrewdly observes to Anytus, and with an unusual degree of circumspection for a self-confessed gadfly, we cannot blame the teacher for "the poor natural talents" of his students. ${ }^{42}$

So it is that Socrates ultimately justifies the particularization of virtue on the basis of a parallel particularization of the natural predispositions, or talents, of men. While we ought not to neglect the broader moral implications of such a justification, for they are many, neither ought we to overlook the fact that Socrates' appeal to natural talent specifically in the context of education and convention echoes the disingenuous proposal he had only just before put to Meno, who thinks he is agreeing with Socrates' actual position when he rejects it out of hand as obviously false. "If the good were so by nature," Socrates had then argued,

we would have people who knew which among the young were by nature good; we would take those whom they had pointed out and guard them in the Acropolis, sealing them up there much more carefully than gold so that no one could corrupt them, and when they reached maturity they would be useful to their cities. ${ }^{43}$

It is only now, after having conclusively trapped Meno in a logical paradox, that Socrates begins to intimate that the entire discussion he has been carrying on with his two interlocutors has in fact been premised on a wholly false dichotomy. In truth, men are not 
made good either strictly by nature or else strictly by convention. Rather, men become good only when nature and convention have been brought into harmony with each other. Meno has long wanted to know whether virtue can be taught, but he has given no thought at all to the question of whether all men ought to be taught the same things about virtue, and this for the now-familiar reason that he himself knows nothing about it. Those men who would become good, therefore, must ultimately be instructed only in such particular virtues as are consonant with their own unique individual natures.

Yet given especially the immediate context of Meno’s own persistent selfincurred ignorance, Socrates' muted revelation that there is no necessary dichotomy between nature and convention suggests that the two cannot be made to harmonize simply by means of a properly moral education alone. His seemingly outlandish proposal that the very best of the citizenry be sequestered within the Acropolis implies that at least certain specifics of their material condition will inevitably exert a formative influence upon the attainment, or alternatively upon the corruption, of the virtues that are most proper to their natures. Thus what Socrates is really suggesting when he hints at the nonexistence of the dichotomy is that his interlocutors - or, more accurately, Plato's readers - ought to consider very carefully not just the deficiencies of the soul as against those of the body, but more precisely the nature of the correspondence between the two. To the extent that we are right to claim that the materiality of the human body occupies one side of the dichotomy while the immateriality of the human soul occupies the other, the exact nature of the correspondence between the two halves is ultimately what will dictate the limitations and possibilities of bringing the conventions of the city into harmony with human nature, thus producing virtue. ${ }^{44}$ 
As part of his exposition on the education of the Guardians in Book VII of the Republic, Socrates warns Glaucon equally against ignorance and inaction. Characterizing these states as opposite poles of a single vice, he suggests that they spring from a single source and thereby implies, further, that the solution to each and to both would necessarily have to reconcile the possibilities of the soul to the limitations of the body. ${ }^{45}$ He goes on to argue that even the highest virtues of the soul, despite aiming at the perfection of what is most divine in man, nevertheless remain "somewhat close to those of the body. ${ }^{, 46}$ It is this connection that ultimately precipitates Socrates' fateful command that the Guardians be compelled to return to the Cave, not despite the virtues of their souls but because of the necessities of their bodies. The virtues of humanity are not, and never will be, the same as those of disembodied spirits capable of departing at will "to a colony on the Isles of the Blessed while they are still alive." ${ }^{, 47}$ Inasmuch as the materiality of man's body is both the primary impetus and the prime instrument of his activity, so also is it an indivisible part of virtue as such. The return to the Cave becomes an imperative, then, as much to save the soul from its forgetfulness as to preserve the body through which the soul's truths become incarnate. And as the degeneration of the city in Books VIII and IX of the Republic clearly suggest, that the soul rules the body does not at all imply that the material state of the body exerts no influence upon the ordering of the soul.

Indeed, the material conditions that prevail within the city cannot but exert a considerable influence upon the proper ordering, or alternatively the resulting disorder, of the soul. For once we accept Socrates' implicit arguments in the Meno that virtue implies an element of practical skill and that particular skills are best practised by particular 
natures, then the possible range of circumstances under which particular men may attain the virtues most proper to themselves becomes considerably more narrow than it otherwise would be. The very justice of the city becomes, in short, a function which incorporates in large part certain particulars of each citizen's individual material conditions. When Socrates argues that those with the best natures ought to be guarded "more carefully than gold," he cleverly implicates his argument within the broader imagery of the Myth of the Metals and, in so doing, indirectly suggests a political correspondence between the power of wealth to manipulate men's material conditions and the philosopher's capacity to know under which particular conditions men can be made just. The task of guarding souls would seem to imply the subordinate task of guarding wealth as well. Socrates suggests, in other words, that the moral correspondence between the body and the soul can be writ large at the level of the city, and so the harmonization of nature and convention depends critically - if not radically - upon an antecedent coincidence of knowledge with power.

The conclusion Socrates seems to be insinuating here evokes the more detailed discussion he carries on with Glaucon at the end of Book III of the Republic, where he argues more bluntly that the members of the Gold and Silver classes must ultimately be sequestered from the corruptive influence of the city's commercial activity. ${ }^{48}$ Before that can happen, however, the Guardians will have to "look out for the fairest place in the city for a military camp, from which they could most control those within," 49 by which Socrates again means the Acropolis. But here, as compared to the parallel passage in the Meno, his relative subtlety as to the exact objective only more heavily emphasizes the material means that must be employed to achieve it. His conspicuously militaristic 
imagery stresses the essential point that while a properly moral education may provide men with knowledge of the good, it does not thereby equip such men with any practical authority to exhibit the good in action, to employ Allen's phrasing. Much less does it allow them to assert their just rule over the rest of the city. Hence when a characteristically overeager Glaucon seems to suggest that the city's educational regime alone ought to suffice to bring about the triumph of justice, Socrates rebukes him with a thinly-disguised insult, telling him that an "intelligent man" would be liable to find it lacking for one crucial reason. "In addition to this education," Socrates argues, "they [the Guardians] must be provided with houses and other property such as not to prevent them from being the best possible guardians and not to rouse them up to do harm to the other citizens."

Whereas in the Meno Socrates merely alludes to the kind of power the Guardians will eventually need to acquire, here in the Republic he makes the point as explicitly as it can possibly be made: power manifests in the proper use of property. Arguing that the Guardians will not fully be able to achieve their virtues until they possess the specific material means necessary to exhibit their virtues in action, Socrates formulates a moral basis for what we may term the Property Requirement. Though virtue may well be the exclusive province of the soul, so long as its actual practise is constrained by the limitations of man's earthly materiality - as it always will be - then the very possibility of its pursuit will always be similarly constrained as well. Those who have been rightly educated, therefore, require in addition certain forms of property lest their virtues be rendered quite literally impractical, which is to say they would be utterly devoid of all capacity for praxis. And without this crucial element, which can be realized only through 
the acquisition of practical authority, the knowledge that is virtue fails to amount to anything more than the impotent theoretical abstractions that Aristotle could now rightly criticize as a state of vice, and specifically as a state of incontinence.

The difference, however, is that the exact flaw in Aristotle's criticism is now much more apparent, since he wrongly traces the origins of incontinence to a specifically moral deficiency of the soul rather than a particular material deficiency of the body. In other words, even though Aristotle correctly identifies the symptoms, he nevertheless fails to diagnose the disease. For without the extension of practical authority, meaning property, theoretical knowledge never gives rise to virtuous activity, which is to say it fails to achieve the status of virtue in the highly specific sense in which Socrates means that virtue is knowledge. The state of incontinence, then, precisely corresponds, both theoretically and practically, to a state of knowledge (episteme) deprived of practise (techne), which is to say it amounts to nothing more than mere true opinion (orthe doxa). When Socrates warns Meno that all true opinions are as transient as the flying statues of Daedalus, and that the process of recollection is analogous to tying them down in order that they may become valuable, he means that the man who would seek real knowledge may do so only by employing such property that is the proper material means to the particular immaterial end which is consonant with his own particular nature. In other words, the beautiful flying statues of the mind are secured to the soul by the body's acquisition and use of property: Property is the moral weight that secures the soul. And lacking this, man is doomed to fall back into forgetfulness. Ultimately it is the means which make - or unmake - the man. 
In addition to the establishment of a politically just regime, therefore, one further condition becomes necessary if rightly educated men are to attain their virtues, and this condition can be stated in terms of whether such men are able to acquire the necessary practical authority to exhibit their knowledge of the good in action. In other words, the question of man's ultimate attainment of virtue reduces to a function of the extent to which there exists a just distribution of the city's economic resources. The well-ordered regime cannot, as a result, long endure in the absence of an equally well-ordered economy. The vice of incontinence, which for Aristotle is unmistakably a disease of the solitary will, becomes for Plato's Socrates a general vice of the city’s overall economic organization, one that gradually compels the transformation of the moral character of the citizenry into a diabolical inversion of Mephistopheles' self-characterization in Johann Wolfgang von Goethe's Faust - to join with the part of power that wills good always but always works for evil. ${ }^{51}$ For once economic injustice becomes sufficiently widespread, it inevitably produces the seemingly paradoxical set of circumstances in which many or perhaps even most of the citizenry fail to act well despite knowing what is good, despite wanting to do good, and, even worse, despite having at their collective disposal the necessary means for all men actually to do good. Incontinence, therefore, is not simply a moral disease of the individual citizen. On the contrary, it is an outright plague upon the political economy of the agora. It is a Great Forgetting, here and now, in this mortal life of ours.

The Myth of Er, then, is less a tale about the afterlife than a warning of the perils that would threaten the salvation of man's soul in this life. Less still is the myth an account of the divine order of the cosmos than a prescription for the proper moral 
ordering of the city in which a Great Remembering may yet transpire, where men may yet learn to distinguish virtue from vice, where justice may yet prevail. But Memory has told us this much: Justice cannot prevail unless and until the city's rulers hold a proper regard for the moral value of property. For inasmuch as all men exist as material beings, their virtues will always imply an element of practical activity, the execution of which depends crucially upon the material means they have at their disposal. But since all men do not share the same natural talents and dispositions, neither, therefore, do they share the same sets of virtues. This particularization of human ends only makes men all the more dependent on whether they are able to obtain the necessary means for them to exhibit their proper virtues in action, which is to say the possibilities for their acquisition of practical authority. When the means are sufficient, men find salvation in Recollection; and when the means are insufficient, men are doomed to languish in oblivion.

Socrates has good reason, therefore, to begin his telling of the Myth of the Metals with the first reference to the Doctrine of Recollection in the Republic. Mimicking the great epic poets, Socrates' more subtle invocation of Memory suggests that he is about to communicate a profound truth or, in other words, that he is about to command a refounding of the city upon principles that are more perfectly just than those that went before. Memory speaks thus through the god-inspired voice of Socrates - to tell of how, once the Auxiliaries have been rightly educated, the city's founders must then persuade them and the entire city that "the rearing and education we gave them were like dreams; they only thought they were undergoing all that was happening to them, while, in truth, at that time they were under the earth within, being fashioned and reared themselves, and their arms and other tools being crafted." ${ }^{52}$ The Auxiliaries and Guardians have not been 
trained to be forgetful men, yet they must nevertheless be brought to a state of forgetfulness - even if it be but a contrived one - in order that they may confront their practical ignorance, thereby to recollect that, despite their education, they still yet lack the practical authority to execute their knowledge of the good in action. It remains for these men to venture forth in virtue, not only for the sake of themselves but for the sake of all men. Indeed, for the sake of humanity itself.

Much as Hesiod does at the beginning of the Theogony, Socrates too invokes Memory for no less a reason than that power may be made to coincide with knowledge through man's acquisition and proper use of property. For it is only once the city's founders "have armed these earth-born men" that the Guardians acquire the capacity to take the Acropolis of the city and establish the just rule of philosophy. ${ }^{53}$ And while the implements of war which they employ to that end exemplify only the virtues particular to the Guardians, which, as such, are not the virtues proper to all men, Socrates nevertheless distinctly suggests at the end of Book III what the basic premise of the Republic already requires. The recall of reason to the human mind that is made manifest in philosophy's reconquest of the Acropolis is but a macrocosm of the human condition itself, which is to say that it is incumbent upon all human beings to recall the authority of their own particular natures and to employ the proper implements of their own salvation. Not just the Guardians, therefore, but indeed all men and women must be armed with the material means of recollection, that they might labour at this great and noble but no less arduous a task - this the task of ours, that each and every one may yet retake the Acropolis of his own soul. 


\section{$-4-$ \\ Refounding the City}

Finale: Tema con variazione - Molto vivace. $\&$

And they said, Go to, let us build us a city and a tower, whose top may reach unto heaven; and let us make us a name, lest we be scattered abroad upon the face of the whole earth.... And the Lord said, Behold, the people is one.

-GeNESIS 11:4-6, King James Bible

In the eleventh chapter of Genesis a united mankind joins together to build the fabled Tower of Babel. The builders' aim is to escape the lowly confines of their earthly existence by ascending to the heavenly realm, but the greatness of their project threatens the eminence and supremacy of god, who as a result rains down his vengeance upon them. He destroys their tower and scatters them across the face of the earth, thus guaranteeing that man forever after will remain alienated and divided from other men. ${ }^{1}$ The ancient Greeks would have recognized the tragedy in the story of the Tower of Babel as rooted in man's hubris, that is, the willingness to challenge the divine order of the universe and the arrogant desire to seek immortality by reshaping that divine order after one's own mortal image. In the Symposium Plato offers a story that is strikingly reminiscent of the one we find in Genesis eleven. In his praise of the power of love, the Platonic Aristophanes darkly relates that in the primordial past mankind once "dared to scale heaven, and would have laid hands upon the gods," except that, in retaliation for 
this attempted affront to their dignity and power, the gods decree that men's souls are to be cut in half in order to break our unity of will and strength. ${ }^{2}$ In both stories, man's lust after divinity leads him to tragedy because the very nature of his pursuit is held to be fundamentally at odds with his own nature as an earthly - and more importantly as a mortal - creature.

It is especially significant that in both stories man's divine punishment should be wrought as a consequence of his political and moral unity, and thus in these terms, too, is his punishment inflicted. Just as the Judeo-Christian god inflicts upon mankind the confusion of tongues in order to sow among him disunion and disorder, the almighty Zeus likewise tears the unity of man's very soul asunder, thus leaving him afflicted with an eternal erotic longing for wholeness and completion. Yet it is here that we find in Plato a critical break with his contemporaries, ${ }^{3}$ and one that emerges as well in contradistinction to the Judeo-Christian tradition. For eros aims to heal the primordial injury done to us by the gods in that it ultimately seeks to restore our unified nature. In the Symposium, Socrates takes this suggestion further than Aristophanes does himself when he introduces the concept of Diotima's Ladder, which, in bridging the earthly and heavenly realms, allows man to ascend freely from one to the other. The Platonic concept, in short, amounts to a metaphysical Tower of Babel. Yet just as the Word must be made flesh and the Idea of the Good made manifest, so too must the Tower not only be conceived, therefore; it must also be built.

If for Plato the greatness of man's final end (telos) is definable in terms of the most divine elements in his nature, then the sheer humility of man's origins can only be defined in terms of his unforgiving material condition. In Book II of the Republic 
Socrates proposes that the city comes into being "because each of us isn't self-sufficient but is in need of much,"4 but his point is steeped in irony. For, like much else that Socrates has to say, it is in fact deceptively straightforward. What he no doubt has foremost in mind is man's metaphysical and ultimately moral insufficiency; but the unsuspecting Adeimantus, to whom the suggestion is directed, takes Socrates to mean, not incorrectly but nevertheless incompletely, that the simple materiality of our human bodies imposes upon us such a wide array of practical demands that no man could ever be capable of fulfilling all of them by himself alone. Here at the very beginning of the Ascent out of the shadow world of the seeming, for which the city in speech is to light the way, Socrates begins his defence of the just life with the argument that it is the economic poverty of our pre-political condition that impels us to seek community with others: the mere need to fulfill our basic earthly wants for such things as food and shelter, rather than some nobler insatiable appetite to pursue great heavenly things in common such as philosophy.

As even Socrates readily admits, each member of the community recognizes first and above all that it is more advantageous to his own private material self-interest to live among others because he may acquire many goods from them through trade. ${ }^{5}$ But the generation of wealth made possible as a result of gains from trade, and the division of labour that it implies, are mistaken by Adeimantus to be not simply the beginning of human community but its final end. The founding of the Austere City in particular culminates, with all deliberate design on Socrates' part, with the establishment of the agora, a term variously translatable as either "market" or "place of assembly" and one that, in its dual meaning, captures perfectly the emergence of the public sphere out of the 
private material pursuits of each individual citizen. ${ }^{6}$ Economic exchange thus forms both the impetus that gives rise to the city and the heart that subsequently sustains it. But for all that, economic exchange, taken on its own, nevertheless fails utterly to capture the city's true teleological essence, a point that Plato evidently wants to emphasize with the failure of Adeimantus to find either justice or injustice in the city that he himself helped to establish. Adeimantus' failure proves to be foreboding, for the absence of justice, which alone can unite the city, renders any guarantee of the citizenry's material wellbeing an exercise in political and moral futility. ${ }^{7}$

In the shadow of the Enlightenment Socrates' economic account of the origin of the city may strike us as self-evident, if not, for that reason, entirely uninteresting. Indeed, its familiarity almost makes it seem to have been the model for the state of nature out of which thinkers like John Locke have devised their own political philosophies. ${ }^{8}$ To the extent that this is the case, the nature of Glaucon's objection that the Austere City lacks "relishes" only becomes all the more significant, for at the heart of his objection is the charge that the city lacks anything at all of the beautiful. "If you were providing for a city of sows," he rather saucily complains to Socrates, "on what else would you fatten them than this?"10 Glaucon finds in the Austere City a moral, as opposed to an economic, failing in that it aims merely at survival rather than the greatness and flourishing of which human beings are capable; it defines man according to his necessities rather than his potentialities. This criticism, for Glaucon, renders the Austere City entirely unfit for human habitation. To him it is a sty, not a city.

What justly has not escaped the attention of many commentators on the Republic is the role Glaucon assumes throughout the dialogue as the "erotic man"; ${ }^{11}$ and so neither 
ought we to fail to notice that Plato makes a point of having him, the voice of eros, not merely object to but outright interrupt Socrates' account to Adeimantus regarding the simple way of life that will prevail in the Austere City. ${ }^{12}$ With his interruption Glaucon signals that the materially self-sufficient city is nevertheless morally insufficient. For eros, like Glaucon himself, has no presence in the initial founding of the city, as Socrates implies in his strictly economic account of the city's origin. It is not, after all, for the love of wisdom, or for any other kind of love, that the city initially comes into being, but only for the alleviation of the brutal compulsion of our original material circumstances. For Adeimantus, and especially for Socrates, it is a product of necessity. Until men's bodies are fed, the pangs of hunger in their souls can neither be felt nor, for that reason, satisfied.

The founding of the city upon the rock of necessity rather than love's tenderness evokes a central point in Agathon's speech in the Symposium. Challenging Phaedrus' view that Eros must be among the oldest of the gods, ${ }^{13}$ Agathon instead argues the opposite: "those old stories Hesiod and Parmenides tell about the gods - those things happened under Necessity, not Love, if what they say is true. For not one of all those violent deeds would have been done - no castrations, no imprisonments - if Love had been present among them. There would have been peace and brotherhood instead, as there has been now as long as Love has been king of the gods." ${ }^{14}$ So it is that the newly triumphant dramatist dresses the players in his speech with the masks of the gods in order to divide primordial time between the Age of Necessity and the Age of Love. In doing so he insinuates that eros cannot exist outside the city because, in the absence of economic exchange and its attendant promise of material self-sufficiency, men will be unable to recognize even the concept of beauty, being condemned instead, like the brutish sows 
that so trouble Glaucon, to consume themselves with the always-immediate question of their own survival. It is not insignificant, either, that the kinds of violence Agathon mentions suggest both the impossibility of erotic union - castration - as well as the Cave - imprisonment.

In such details we find an undeniable hint of darkness in Agathon's otherwise rather optimistic speech. His allegorical musings about the violence and treachery that must prevail among men when the survival of each and all is at stake - I hesitate to describe such circumstances as a "war of all against all" - as well as his implied point that such violence, perhaps always lurking just beneath the surface of human nature, must inevitably be unleashed in the absence of Eros can only be taken as a definite warning to those men among him who would be statesmen that the neglect of eros presages the destruction of the city. His warning proves to be ironically prophetic, considering that Alcibiades, the one man in the Symposium who most ought to have heard and understood it, still has yet to make his boisterous entrance onto the stage of the dialogue and therefore fails to hear Agathon's warning. Yet this particularly dark moment does not define Agathon's speech overall, for, indeed, we might well take him to be espousing a most hopeful view of humankind's great potential, not to mention the great need, to redeem the animalistic side of our nature. With his division of primordial time into two ages, Agathon suggests in particular that the first leads inexorably into the second; for him we are not merely animals although we wear the mere masks of mortals over our more divine souls. Eros is born of the Age of Necessity in order to free us from its tyranny. 
The theme is one that Socrates, following Agathon's performance, cleverly develops in his own speech. In it he provides an explicit myth detailing the birth of Eros to his parents, Penia, literally meaning "poverty", and Poros, literally meaning "resource":

When Aphrodite was born, the gods held a celebration. Poros, the son of Metis, was there among them. When they had feasted, Penia came begging, as poverty does when there's a party, and stayed by the gates. Now Poros got drunk on nectar (there was no wine yet, you see) and, feeling drowsy, went into the garden of Zeus, where he fell asleep. Then Penia schemed up a plan to relieve her lack of resources: she would get [poieasthai] a child from Poros. So she lay beside him and got pregnant with Love. ${ }^{15}$

In Socrates' myth, Penia becomes the personification of man's implied pre-social condition in the Republic. Alone and wandering in the wilderness, she is drawn to the community of gods, whose overflowing abundance strikingly contrasts with her own state of deprivation. Yet she cannot alleviate her want simply by joining with the gods, who have wisely locked the gates to their halls. For as Socrates notes in the Republic, poverty is one of the two basic threats (along with war) against which even the Austere City will need to remain ever vigilant, an obvious corollary of the city having been founded upon the promise of economic exchange to produce wealth. ${ }^{16}$ Thus barred from the gods' table of plenty, it may seem that Penia, and thus perhaps also all of humankind, is condemned to an eternally brutish existence - a sow among gods.

We ought not to overlook the significance of the particular occasion of the gods' celebration, however. For the birth of Aphrodite, the goddess of beauty, signals the beginning of a new age, one that is to be characterized by a related phenomenon over which she too presides: procreation. Despite Penia long having been a beggar - by 
Socrates' account she seems to have acquired somewhat of a reputation for attempting to crash divine dinner parties - on the day of Aphrodite's birth she suddenly becomes endowed with the power to create, to "bring forth" (poieasthai) out of her own body. Immediately she has intercourse with Poros, the object of her want, in order to multiply the "resources" that are available to her. Importantly, she seeks to multiply not herself but the object of her want. In her procreative, and therefore sexual, act she herself becomes resourceful, meaning quite literally - this is not philosophy for the prudish - full of Resource, but not, it must be noted, because of some love she has for Poros but rather because of the mundane need she has of him. Her "scheming" actions are governed by pure necessity, which may well recall Adeimantus' words to Socrates that the elusive justice of his Austere City seems only to be vaguely definable in terms of "some need these men have of one another."17

As the product of the union between poverty and resource, Eros becomes in his own turn the personification of Necessity Vanquished, or, to put it more precisely, the means uniting an object's material cause with its final end. There is somewhat of a paradox here. For erotic desire manifests as the self-reflective awareness of our insufficiencies, but also, for that reason, of the means by which they are to be alleviated: counter-intuitively, it is both the cause of and solution to our experience of want. Thus Socrates aptly describes Eros as a "spirit" that is constantly springing into existence and subsequently fading away, each state always spawning the other. ${ }^{18}$ Because of this peculiar quality, eros rather fittingly proves to be the greatest resource that man could ever have at his disposal. Its efficacy in propelling man toward his final end makes it at least a requisite element of prudence (phronesis), which suggests a close necessary 
relationship between eros and virtue in general. And yet, importantly, eros cannot imply the whole of prudence. As Socrates notes in the Republic, the truly prudent man must be able to see and love the light of truth by which he becomes prudent, and thereby able to attain the particular ends that he desires. Prudence proper is only prudence as such when man's eros is guided by reason and wisdom. ${ }^{19}$

By itself, then, eros is perhaps but a shadow of prudence, and left to its own devices it may work either for good or for ill - and more likely the latter. The city therefore neglects man's erotic drives at its own great cost and peril. This is entirely because eros can never be exiled from the city, being virtually synonymous with the city itself for the following reason: man himself conceives and gives birth to Eros when he "schemes" with other men to join with them together in one city, when he realizes that he has need of others in precisely the same way that Penia has need of Poros. The partnership that founds the city is man's first sexual and procreative act, and eros is his first-born. Thus we find that Socrates' tale of the conception of Eros in the Symposium not only coincides with but is directly analogous to the founding of the city in the Republic. Man's “bringing forth” (poieasthai) of human community becomes the hinge upon which turns Agathon's two-fold division of primordial time.

There is, perhaps, also a darker analogue to the founding of the city: the opening of Pandora's box. With the advent of the Age of Love man finds himself suddenly transformed into a fully moral creature in that he assumes a new capacity to make choices about the objects of his wants that are qualitatively different than they were under Necessity. Now, man chooses between good and evil, rather than merely yielding to the necessary, and as a result, as Hesiod says of the post-Pandora world, "troubles that are 
numberless wander among mankind." ${ }^{20}$ Because man cannot be ignorant of his own hunger, for instance, he cannot by nature fail to have the urge to seek food. Nature herself impels him toward a requisite element, albeit a very small one, of his final end, without his ever having to make any deliberate choice to do so. He need not have knowledge of what is good for himself, but only merely to do as his body dictates. By way of contrast, man can of course be ignorant of the attributes that make non-necessary objects good or evil. Whereas the materiality of his body ensures that he will always feel a want of necessities, only the proper ordering of his soul can compel him to feel a want of good and beautiful things. As Diotima tells Socrates, "herein lies the evil of ignorance: that he who is neither good nor wise is nevertheless satisfied with himself; he has no desire for that of which he feels no want."21 A man's failure to recognize truly the goodness of wisdom, or any other virtue, means that he will never feel himself to be in want of it. He will therefore never feel the compulsion of an erotic longing to pursue it in the way that his body slavishly compels him to pursue materially necessary things.

In his speech in the Symposium, Pausanias frames the elementary yet crucial distinction between good and evil as a matter of erotic orientation. He argues that an earthly-oriented eros desires its objects only for their materiality and, ultimately, for the pleasure that it brings to the lover. "Base is that vulgar lover who loves the body rather than the soul," Pausanias argues, "inasmuch as he is not even stable, because he loves a thing that is in itself unstable, and therefore when the bloom of youth that he was desiring is over, he 'takes wing and flies away,' dishonouring all his words and promises.",22 Whereas earthly eros renders itself transient by the materiality of its objects and the constant movement from one thing to another that their innate impermanence 
necessitates, so does the lover himself come to assume the instability of his beloved.

When man loves what is impermanent, he implicitly devotes his life to those things which have no enduring value, which in Platonic terms is to say that they have no real value at all. Consequently, such a man reduces his own life to a chaotic enterprise the ultimate meaning of which is destined to expire along with the earthly objects he has spent his entire life lusting after in futility.

If that were not enough, the unbridled pursuit of the objects of earthly eros also implies an anti-social tendency. The earthly lover, after all, takes an interest in his beloved only so long as the latter satisfies the desires of the former, rather than the reverse. Despite appearances, the lover's eros is not oriented toward the good of his beloved, nor is it even effectively oriented toward his supposed beloved himself. Indeed, the truest object of the earthly lover's want is his own self-satisfaction and immediate pleasure. Thus in an important way the earthly-erotic relationship between the lover and his beloved reduces to terms that need only take account of the lover himself and his own - apparent - benefit. The essence of an earthly-oriented eros is therefore utterly narcissistic, and this in the fullest sense of the term. For when we read Socrates' repeated cautions in the Republic against the power of false images to deceive together with his claim that the deceptions of earthly objects are easy enough to fabricate "if you are

\footnotetext{
* It bears noting that in Pausanias' particular formulation it may appear that the very possibility of goodness in the lover's erotic longing for his beloved depends entirely upon the immortality of the soul: if the soul is not immortal, and therefore does not endure forever after its mortal and material form expires, then the otherwise meaningful distinction Pausanias has introduced between the earthly and the heavenly is thus reduced to a mere phantom of the good. Mercifully, my task here is not to decide the question of the soul's immortality, nor even to prove the existence of the Forms, but only to observe that there is nevertheless a meaningful distinction between a love of the material and a love of the Essential and that regardless of whether the soul is immortal or not, or whether the Forms exist or not, or even whether the Essential is eternal or not - that distinction carries with it moral, political and, most of all, economic implications. Therefore whether a given person's erotic love for one other particular person (as opposed to, i.e., the Form of Humanity, whatever that might mean) can indeed be defended in terms of the heavenly remains an interesting moral question, but its answer, whatever it may be, does not in any way affect the course of the present argument.
} 
willing to take a mirror and carry it around everywhere," ${ }^{, 23}$ we might well find the image of the mythical Narcissus staring us in the face.

In Ovid's famous telling of the myth, the young and beautiful Narcissus catches a glimpse of himself in the mirror-like stillness of a pool of water. As he reaches out into the pool to drink and

strives to satisfy one thirst, another is born; drinking, he's overcome by the beauty of the things that he sees; he falls in love with an immaterial hope, a shadow that he wrongly takes for substance. ${ }^{24}$

Ovid's tale cuts to the heart of the political economy of the Cave, or at least as it must operate before the return of the philosopher-kings. For Narcissus perfectly captures the nature of the prisoners, restrained in their ignorance by the bonds of their material existence, looking with lust upon the false images of shadows cast upon the Cave's darkened walls, shadows that each prisoner "wrongly takes for substance". Having satisfied their thirst for the necessities of life while yet remaining ignorant of the infinitely superior beauty of the immaterial Good, the prisoners must inevitably fall into conflict with each other over their competing desires to possess the fleetingly beautiful objects that fill their prison. ${ }^{25}$ With no little irony the objects of their want are mere material things that, for that very reason, can only ever be an "immaterial hope" for their desire to achieve erotic union with the truly beautiful. In his pursuit of precisely that end, Narcissus himself repeatedly reaches out for that which "he glimpses but cannot embrace," only to see the illusion momentarily vanish before his very eyes. ${ }^{26}$ Man's longing for wholeness, when pursued by means of the material, is similarly illusory for it can only ever be transient and thus, for that reason, as Pausanias observes, eternally 
unsatisfying. Narcissus in particular, and more generally the psycho-metaphysical phenomenon that he personifies, represents the epitome and logical endpoint of a moral outlook grounded in an exclusively earthly-oriented eros.

What makes the narcissism of the Cave inherently anti-social is that the widespread love for the material out of which it emerges must render all higher principles of honour, justice, and virtue in general completely subservient to itself. At stake is no less than the very possibility of politics. For the earthly lover condemns himself to a life of constant movement akin to that endured by the homosexuals we find in the seventh circle of Dante's Inferno, and, very much like Dante's poor souls, his erotic inconstancy makes it impossible for him to establish any lasting bonds of affection between himself and his fellow human beings. ${ }^{27}$ An earthly eros, taken by itself, alienates man from man. When a man loves not wisdom or justice, but pleasure and consumption, he places himself not in community with other men but in direct opposition to them. The economist who first invented the term "rival good" to describe the objects of the narcissist's affections was strikingly, if perhaps unintentionally, morally and politically insightful. For to the narcissist others become not potential partners in the pursuit of human greatness but necessary rivals - enemies - in his unrestrained efforts to acquire and consume as much as he can of what must always be a finite supply of material goods. Narcissism inevitably breeds faction and conflict between men.

Much like Socrates in his conversation with Glaucon midway through Book II of the Republic, "we have in [our] turn found the origin of war." ${ }^{28}$ War had of course already been identified earlier in the dialogue as the second of the two basic threats against which the city must be prepared to defend itself, ${ }^{29}$ but it is here and now, in the 
eroticized city, that we find its cause to be a fundamentally moral-economic one. An earthly-oriented eros must by its very nature become insatiably acquisitive because it is driven by the continual desire for erotic union with the material, which it may achieve only temporarily in the fleeting experiences of ever-greater consumption. Glaucon himself accepts the necessity of such a tendency, for which reason he agrees that his newly reformed "Feverish City" must inevitably be drawn into armed conflict with its neighbours. War therefore springs from a kind of poverty, but one of a different order than that in which the city finds its origin. It is rooted not in necessity but in its opposite excess - and thus points to the insufficiency not of the body but of its opposite as well the soul. The scourge of war is born not from the pursuit of necessity but from an erotic desire for earthly things at all costs. In a peculiar inversion of Greek tradition, Plato reveals the war-god Ares to be the offspring of Eros rather than the other way around. ${ }^{30}$

That man's erotic longing for completion can never be satisfied by earthly things means it is a necessary threat to the city's preservation, despite the fact that an earthly eros emerges from the city's very founding. This is true first of all because it impels the city toward war with its neighbours, as we have already discussed, but also, and less obviously, because the same drive must bring the city into conflict with itself. Somewhat surprisingly, Pausanias proves to be remarkably insightful regarding the political implications of the erotic distinction he introduces in the Symposium. In his speech he argues that tyrants "require that their subjects should be weak in spirit, and that there should be no strong bond of friendship or society among them, which [heavenly] love, above all other motives, is likely to inspire."31 Not only is the tyrant's own soul 
characterized by an inwardly-oriented eros, but his tyrannical rule also depends critically upon the same character prevailing within his city. Like Ovid's Narcissus, the tyrant seeks and is the one that he is seeking;

kindles the flame and is consumed by it $^{32}$

- himself along with the city he dominates. When the earthly-oriented soul acquires political power, then, as it inevitably will seek to do, the acquisitive instinct of eros is in that moment transformed into an appropriative impulse which thereby undermines the original economic foundation of the city, built as it is upon necessity, exchange, and the promise of mutual material benefit for all. To invert Von Clausewitz's famous dictum, tyrannical politics is war by other means. To ground the political order upon the materialism of earthly eros alone would be to kindle the flame of narcissism within the city and thus to guarantee that it will inevitably be consumed in the great inferno called tyranny.

There is therefore a crucial tension between Necessity and Love that Agathon fails to articulate in his speech when he draws the distinction between the two. The very force that brings the city into being in the first place in turn gives birth to a countervailing force that subsequently threatens to bring it to the brink of destruction. The Platonic Aristophanes aptly captures the potential for tragedy more precisely, though more subtly, in his telling of primordial man's fate after Zeus inflicts his divine retribution upon him. Men's bodies and souls having been torn in two, "each one longed for its own other half, and so they would throw their arms about each other, weaving themselves together, wanting to grow together. In that condition they would die from hunger and general idleness, because they would not do anything apart from each other." 33 More than perhaps anywhere else in the Symposium it is here that we see most clearly the face of 
Narcissus looking back at us through the ripples of Plato's text. For much like Aristophanes' primordial man, Narcissus seeks an erotic union with what he takes to be his other half - himself. And yet in both cases the apparent object of man's erotic desire proves indeed to be nothing more than an apparition. Just as Narcissus repeatedly reaches out into the water in a desperate and futile effort to embrace himself, primordial man, too, falls into a continuous embrace with the merely physical part of his other half. But the want of union within the soul, which is the cause of all erotic desire, cannot be had by such material means, by such merely earthly means. Hence men in both cases, literally captivated by the apparent beauty of their own shadows, fall into self-neglect and starvation. Narcissistic man, as Ovid puts it, "perishes by his own eyes."34

So, it seems, must the Feverish City and the erotic man - men like Glaucon who would just as soon have their city with "relishes" or not at all, men who, in their otherwise noble pursuit of human greatness, nevertheless threaten to tilt the city toward tyranny and its own annihilation. Beneath the comic tragedy - or perhaps the tragic comedy - of Aristophanes' speech, then, we cannot fail to notice a broad likeness to the Socratic speeches we find in both the Symposium and the Republic referencing the founding of the city and the emergence of tyranny. There is in particular a clear correspondence between Apollo's healing of man's physical wounds incurred by the wrath of god and Socrates' original founding of the city in speech, in partnership with Adeimantus, upon the economics of man's many material necessities. For Socrates, just like the divine charioteer of the sun, turns man's "face and half [his] neck towards the wound, so that each person would see that he'd been cut, ${ }^{, 35}$ thus compelling each man, in other words, to reflect on his condition as but a single being who will forever be 
insufficient unto himself. Yet the turning of man's attention toward the alleviation of his own necessities must, fittingly of its own necessity, turn man's gaze away from the heavens so that his works may be firmly grounded within the realm of the earthly. Beauty beckons one way, necessity another. Tragedy of tragedies! saith man, all is tragedy. ${ }^{36}$

The problem of such a moral bifurcation of Necessity and Love, the earthly and the heavenly, never arises for Aristophanes' primordial man, of course. Because primordial man was created with two faces, each looking in opposite directions, one is thus able to look upon the heavenly beauty while the other is able to pay mind to the realm of earthly necessities. Zeus's punishment, his tearing of man's unified nature asunder, compels man to choose between the beautiful and the necessary, and Apollo's ostensible healing, which reorients man's newly-singular gaze exclusively toward the material, nevertheless leaves man's genitals turned in the opposite direction. The misalignment between the two is the crucial detail in the story of man's would-be healing at the hands of Apollo. It implies of course that while the true object of man's eros remains in the heavenly realm, now, with his gaze turned toward the founding of the city and its material prosperity, he will inevitably seek to quell the pangs of eros that he feels in his soul by means of the objects that he finds within the earthly realm. His erotic desires come to be defined in terms of the impulse to acquire the always-inadequate material objects of his senses. Far from healing humankind, therefore, Apollo ironically completes man's transformation into a fallen, tyrannical disposition. Socrates' initial founding of the city in the Republic, because it gives birth to men's erotic desires under the aegis of Glaucon's demands for its reformation, does likewise. Again we find in the Symposium a clever playwright dressing up the human players in his speech with the 
masks of gods - only this time we find to our astonishment that the man in the golden mask is none other than Socrates himself. ${ }^{37}$

The powerful underlying subtext of the Platonic Aristophanes' myth of primordial man and his narcissistic tendencies, particularly when read alongside the Republic, points to the essence of the Platonic criticism of tyranny. That criticism is political, to be sure, because the tyrant fashions the city after his own ill-gotten soul; it is moral, necessarily, because the tyrant separates himself from the Good; yet it is also economic, fundamentally if not ultimately, because the tyrant produces nothing and yet consumes everything. The greatest of the tyrant's evils, if not also the source of all others within him, is his utter sterility, which makes him the very antithesis of civilization itself. In Christian terms he disobeys god's very first commandment, going forth not to multiply but instead to reduce. ${ }^{38}$ It is not his misdirected eros as such but, more precisely, the sterility such misdirection entails that is responsible for his necessary undermining of the foundation of the city, which is itself "brought forth" via the procreative union of Penia and Poros. The contrast between the two cases is particularly instructive. Whereas Penia in her obedience to the Prime Commandment seeks to alleviate her poverty by going forth and multiplying, the tyrant, in opposition to it, seeks to alleviate his own poverty by multiplying that of others.

It makes perfect political, moral, and especially economic sense, then, that the effective sterility that results from Apollo's ostensible healing of primordial man, and thus also the inevitable bifurcation of Necessity and Love that it implies, is a punishment so severe and so tragic that even almighty Zeus himself cannot abide it. In Aristophanes' myth, Zeus intervenes to bring Apollo's imperfect - shall we say insufficient? - healing 
of humankind to completion. Whereas human beings had hitherto "cast seed and made children, not in one another, but in the ground, like cicadas," Zeus moves to recast human nature by turning the genitals of each human being around from the rear to the front so that "he invented interior reproduction, by the man in the woman." 39 In so doing, he reconsecrates the formerly sterile and tortured erotic embraces of his fractured and broken children with the power of procreation. Zeus' Great Healing aims to correct not men's bodies, as Apollo's healing had done, but instead their very souls. In his turningaround of man's genitals Zeus brings man's eros into alignment with his gaze, thus making possible, though far from inevitable, the mutual pursuit of the objects most proper to each. Man's divine redemption comes in the form of the promise that he might fulfill the demands of Necessity no longer instead of, but rather by means of, his pursuit of Love.

Still, even after the Great Healing man has but one face and one set of genitals. He remains, like the founders of the Austere City, insufficient because sterile unto himself. As a solitary individual he would, as ever, be compelled to choose between Necessity and Love, but as a citizen joined to other men he need not be, for Necessity can be rejoined to Love through human community. As Socrates observes at the founding of the city, simple sense dictates that each citizen make the fruits of his labours available to others in common, since, were each man to work only for himself as Necessity compels him to do before the founding of the city, the very first and most fundamental purpose of the city would be made moot and irrelevant. In other words, the real value of the agora and the exchange of economic goods that it facilitates can only be realized when it is premised upon some form of a division of labour. Socrates summarizes his criterion for this 
division with the slogan "one man, one art", and he justifies it on the grounds that "each thing becomes more plentiful, finer, and easier, when one man, exempt from other tasks, does one thing according to nature." 40

These last few words are crucial. Whereas in her distribution of talents among humanity nature herself inclines men toward certain arts more than others, she also implicitly inclines each and every one toward the specific virtues that are associated with the art (techne) most proper to himself. The one-man-one-art criterion, then, in addition to being the organizing principle for the city's economic activity, also more subtly points to the city's proper moral and political ordering. It is this criterion, after all, that lays the groundwork for the justification of the city's rule by the Guardian class. ${ }^{41}$ The distinctive form of the division of labour that the one-man-one-art criterion implies therefore works above all to fit the citizenry as a whole to receive the virtues. For these reasons the criterion itself, along with the broader consequences it implies, is best described not merely as an economic criterion, as Socrates himself initially presents it, but rather more comprehensively as the VIRTUE PRINCIPLE.

Virtue manifests in artistry because the arts in their nature reinforce the outwardly-oriented erotic relationship of the lover to the beloved. In his debate with Thrasymachus concerning the art of ruling in the "precise sense" 42 - the ironic conceptual precursor to Socrates' own justification for the virtuous division of labour - Socrates observes that "the man who is to do anything fine by art never does what is best for himself nor does he command it, insofar as he is commanding by art, but rather what is best for the man who is ruled."43 The art of ruling, like all other arts, seeks the advantage and benefit of its object, the ruled, rather than its practitioner, the ruler. Yet this cannot be 
done, as Thrasymachus himself so ably though unintentionally demonstrates in his arguments in Book I of the Republic, by looking merely to the materiality of the objects of one's art. For man, with his gaze fixed solely upon the material, consumes, rather than preserves, the objects of his unlimited earthly desires. It is for this reason that the labours of the city must be divided not arbitrarily but instead according to the different individual natures of each citizen - that is, according to the Virtue Principle. A man who has no erotic attraction to the piano, for instance, will always make a poor pianist, no matter how good his training, for the simple reason that he is deaf to the beauty inherent in his instrument. Feeling not his want of knowledge in music, to recall Socrates' Diotima, he will never desire to seek its good; or, to negate St. Matthew, never seeking, the unerotic man will never find. ${ }^{44}$

However, when the city's labours are divided in line with the Virtue Principle, every citizen will not only desire to know the good proper to the object of his art, but the freedom from the necessities of other tasks that that division grants to all citizens allows each the opportunity actually to pursue it. Near the climax of his Symposium speech and its culmination in the idea of Diotima's Ladder, Socrates argues that every man's appreciation for the beautiful must always begin with its mere material particulars. There is beauty everywhere and in everything, but man must first come to notice it in individual, concrete instances. But, as Socrates further argues, "if the leader" - meaning eros - "leads aright, ... [man] should realize that the beauty of any one body is brother to the beauty of any other." ${ }^{45}$ Once man focuses his gaze, prudently and under the direction of reason, upon a single class of objects that he desires - which in Socrates' argument is framed in terms of the physical human body but just as easily applies to all other classes 
of objects such as pianos, or shoes, or houses - he will inevitably be led to conclude that each of the material particulars of a given class exhibits beauty in the same general way. The beautiful, although it is made apparent in particular objects, can nevertheless be abstracted from those objects; man realizes that there is such a thing as Beauty itself. As such, all material objects are but mere incarnations of that which, being the source of their apparent beauty, is therefore more perfectly beautiful, namely the Form in which each of the particulars participates. ${ }^{\dagger}$ Thus, when at last the lover comes to see that the true object of his erotic longing resides with the Form and not with any particular instantiation of it, he will realize "that this wild gaping after just one body is a small thing and [he will] despise it." ${ }^{46}$ His love, to put it more simply, will be for the heavenly rather than the earthly.

The division of labour by means of the Virtue Principle thus serves a decidedly moral function in that it permits man to focus his eros upon a single class of objects, in the same way that a magnifying glass focuses the sun's diffuse and scattered rays into a concentrated disc of light. In precisely such a fashion are the craftsmen - despite their metaphysical captivity and their ignorance of the beauty of wisdom - able to gather and focus the faint and nearly imperceptible light of the Good that inevitably strays into their remote corner of the Cave, thereby to penetrate, if only marginally, beyond the world of phantoms, to offer a fleeting glimpse of goodness in a realm wracked by illusion and the great potential for evil. ${ }^{\ddagger}$ While none of the prisoners will ever have a direct view of the

\footnotetext{
$\dagger$ Most beautiful of all, of course, would be the Form of the Good. But since the craftsmen, being unphilosophic by nature, will never be able to muster a sufficient erotic drive to move beyond the Form that is proper to their particular art, they will therefore never be able to gaze upon the Good itself. Technically, they will mistake the Form that governs their art to be Beauty itself.

$\$$ Just how does the light of the Good make its way into the Cave? There are at least two possibilities. The first is that the subterranean passage leading out into the realm of the intelligible is of such a path and
} 
Good itself, which must remain obscured to the many so long as they are unable to practise philosophy, each will nevertheless have an indirect view of the Good in the form of some particular type of good that he desires. Because of the great proliferation of arts that any division of labour necessitates, and the attendant proliferation of virtues that occurs in tandem with that division when it is conducted specifically in accordance with the Virtue Principle, the many as a whole will collectively possess an unobscured view of the Cave and its entire contents as fully illuminated. The Sun, despite its absence in the Cave, may nevertheless shine its light there, and brightly; and the prisoners, despite lacking wisdom themselves, may nevertheless be made to act, perhaps, in a way that is at least not inconsistent with its actual possession. ${ }^{47}$

The great achievement of the steady, outwardly reorientation of each citizen's eros toward the heavenly realm by means of his practising the art most suited to his nature serves a further moral-economic function: it moderates man's narcissistic and otherwise unrestrained drive to consume the city's scarce material goods. In the craftsman's recognition of the inferior beauty of his art's material particulars, he will no longer desire the physical union of his body with such "small things" but will desire instead the metaphysical union of his soul with the Form itself. The erotic impulse at work here is precisely the same as that which animates the sterility-stricken primordial

trajectory that some sunlight passes naturally, at least sometimes, into the deepest recesses of the Cave. Unless we accept that man in his pre-social condition has no knowledge of truth at all, and, even more, has no opportunity of ever obtaining it so long as he remains within his uncivilized state, then this would seem to be the likeliest possibility. The second possibility, however, is that the sunlight is brought back into the Cave by the philosopher. Although the mechanics of just how this would work within the allegory itself are unclear, the highly suggestive correspondence in Aristophanes' speech in the Symposium between Socrates and the god Apollo, who according to tradition drives the sun across the sky in his heavenly chariot, seems to militate in favour of this possibility. Either way, Socrates' apparently deliberately ambiguous description of the structure of the Cave in Book VII of the Republic seems to offer us no clear preference between these possibilities, and, regardless of which one we might ultimately decide to favour, one of the ongoing moral and political problems for the city remains how the prisoners can be made to distinguish between the sunlight - truth - and the light emanating from the fires - false opinion - that burn far behind and above them. 
players in Aristophanes' speech as well as the tyrant's narcissistic obsession with consumption and domination. Only now, having been transposed to the heavenly realm, the erotic impulse now, too, mirrors the inversion of the body to the soul and the material to the immaterial. As the antithesis of both sterility and consumption, heavenly eros is in its essential nature procreative. Socrates argues via Diotima in his speech in the Symposium that "all of us are pregnant... both in body and in soul, and, as soon as we come to a certain age, we naturally desire to give birth." 48 The allegory is one that appears frequently throughout Plato's dialogues. In the Republic and the Symposium specifically, however, Socrates employs the allegory to mean that the soul's erotic union with the Forms brings forth, in political terms, justice; in moral terms, virtue; and in economic terms, wealth.

Yet one cannot help but notice, particularly when we consider the extremely rigid social-sexual conventions that were characteristic of ancient Greek society, that Socrates' allegory in fact subverts the normative gender roles of the lover and the beloved, colouring each with a tint of the androgynous. For although the idea of pregnancy obviously implies the feminine, it is neither philosophically plausible nor even logically possible for either the lover or the beloved to fully assume a female role in the divine intercourse by which the soul of the artisan is joined to the Form that governs his art. In his erotic pursuit of the beautiful the artisan plays the role of the aggressive and dominating male lover insofar as his eros must penetrate beyond the materiality of the objects of his love in order that he may come to know their universal Form. Yet he must also adopt the role of the passive feminine beloved, submitting himself before the superior intelligence of the Form in order that he may be penetrated by the Idea and grow 
pregnant with it in his soul, ultimately to give birth to the knowledge that makes the practise of his art possible. The basic metaphysical mechanics of divine intercourse therefore presupposes two male participants, both of whom alternate between dominant and passive roles, for which reason Pausanias is correct to argue in his speech that heavenly eros is born of that in which "the female has no part" and that those who are inspired by it are impelled to "turn to the male, delighting in the more valiant and intelligent nature. ${ }^{\prime 49}$ Being so dominated by the idea of masculinity, heavenly eros therefore takes as its model the pederastic relationship between the knowledgeable older mentor and his youthful protégé, even while, at the same time, it inverts the relationship's traditional rituals of courtship and redirects its erotic vector entirely away from the body and toward the immaterial.

Aristophanes, too, alludes to very much the same kind of androgynous tint in human nature with his own speech when he suggests the masculine nature of the heavenly Forms and the feminine nature of earthly objects, including the human body. Arguing that "the male [gender] was originally an offspring of the sun, the female of the earth," ${ }^{50}$ Aristophanes draws an unmistakable reference to Socrates' allegorizing of the Good as the Sun in Book VI of the Republic, ${ }^{51}$ thus implicating his own myth within the broader imagery of the Cave. As a result, the light of truth comes to assume a phallic dimension in its penetration of the Cave's darkness, as in its penetration of the mind's ignorance; and the Cave itself, in its own turn, assumes in its representation of the earthly a necessary association with the female as a kind of womb, out of which the philosopher ultimately emerges. Thus does Aristophanes' myth reaffirm the moral dimension of the divine pederasty, specifically between the philosopher and the Good but also in more 
general terms between the artisan and the Form that governs his art. Inasmuch as the moral dimension makes truth a necessary element of one's practise of any art, man must first become pregnant in his soul, there to give birth to knowledge, before he may become pregnant in his body, there to give birth to material wealth.

In contrast to Pausanias' speech, then, with its less developed conception of gender, Aristophanes' myth suggests a specific set of moral conditions that govern economic production. Whereas the universal immaterial Idea both precedes and dominates the generation of all material particulars, in the domain of economics man becomes the metaphysical bridge through which the immaterial Form penetrates to the earthly material of its own particulars. It is man's androgynous nature alone - divided as it is between the soul and the body, the heavenly and the earthly, the male and the female - that allows him to fulfill that function. How great is the imperative, then, that men endeavour to realize as fully as possible their proper natures through the arts, the practise of which represents precisely the union of the male and the female, and which union eros, when guided by reason, always impulsively seeks to achieve. It is this, and only this, that allows the male-dominated soul of the lover to bring forth from his female-dominated body, to become, to imitate the Greek, the "maker" (poion).

But although man makes himself the maker through his erotic pursuit of the beautiful he is not himself, crucially, the cause of generation in any of the things that he makes. Man's nature may be androgynous, but it is not hermaphroditic. Aristophanes hints at the importance of the distinction in his myth of primordial man who, after the Great Healing, goes forth to participate in the new form of procreation caused " $b y$ the man in the woman." ${ }^{, 52}$ Thus it is the Good, as Socrates himself argues in the Republic, 
that "not only provides what is seen with the power of being seen, but also with generation, growth, and nourishment although it itself isn't generation. ${ }^{, 53}$ Inasmuch as it is both the penetrative male and implies the Beautiful, the Good acts as the formal cause of generation in that it stirs the erotic longing in men's souls and thereby attracts them into union with the Forms. To make the point still more carefully and with the utmost precision, the Good is the formal cause of all efficient causes in that it supplies each efficient cause with the final end proper to the nature it seeks to realize. As such, the earthly maker who, in her distinctly female role becomes pregnant in her body, must engage in an earthly sort of economic intercourse not directly with the Forms themselves, which are accessible only to the distinctly male part of the soul by means of the erotic practise of divine pederasty, but rather with the earthly, that is to say human, agents who are the knowledge-incarnate that is the offspring of man's divine intercourse with the Forms. Man himself becomes the Idea made flesh. All economic production therefore entails the erotic embrace of these two participants: the male who always dominates and the female who always submits, for the earthly female maker is but the material vessel of the earthly masculine agent who impregnates her materially with the immaterial Idea.

The human artisan thus bears and gives birth to the products of her art even though she does not and cannot embody the specifically generative, or formal, cause inherent in her art's own proper practise, which is instead given by the masculine partner who dominates. The pianist, for example, as the masculine lover of the piano, looks to the Form of the Universal Piano in order to grasp and realize the final end of his beloved instrument, which is to make music. His pederastic relationship with the Form provides him with the necessary knowledge by which he becomes technically proficient in his 
pianism. And yet the proficient pianist gives birth to her music only by assuming the role of the female beloved, for her music is given not by herself but by the masculine composer who writes the music that the pianist then channels by means of her artistry through her instrument, thus giving it earthly form. The great significance of the distinction - and it is very great indeed - is that economic production cannot occur in the absence of the artisan being ruled by some greater good beyond her own art, and therefore neither can it occur in the absence of the ultimate Good from which all Truth radiates. That is to say that, in the final analysis, the proper practise of every art is entirely dependent upon the proper practise of that one ultimate and singular art that seeks erotic union with none other than the Good itself - philosophy. For in the darkened shadow world of the Cave, erotic yet unphilosophic men do not become makers but remain forever sterile, insufficient creatures.

As a result, economic production can neither occur nor can it properly be understood in the absence of an integrated mode of exchange that serves to link each of the arts to the practise of philosophy. The virtuous division of labour, while having proven to be effective in directing the desires of men toward the attainment of knowledge concerning their proper virtues, must therefore yet fail to supply all of the material preconditions necessary for achieving those virtues in actual practise. Contrary to what Socrates rather disingenuously suggests to Thrasymachus in Book I of the Republic, each of the arts is, in fact, in need of "some supplementary virtue". ${ }^{54}$ Because no art looks to the good of its own practitioner, no art possesses the power to provide for the material preconditions that are necessary for its own practise. Indeed, this is the very argument that Thrasymachus attempts to formulate, though he does so unsuccessfully, when he 
argues that no shepherd looks to the benefit of his sheep as ends that are good in themselves but rather and only as means to his own benefit as an all-too-material human being. ${ }^{55}$ The point he wants to make is nearly identical to the one Socrates himself later introduces at the founding of the city: that no man is sufficient unto himself. Because of this material fact, no mere mortal man can ever practise any art purely for the sake of the good of another - unless, that is, the alleviation of his own material insufficiencies can be made to coincide with that practise. The Virtue Principle thus requires its own "supplementary" principle. Surely not without a certain sense of trepidation, we now find that man's nature once again very much begins to resemble that of his only partially healed primordial self in Aristophanes' myth.

Notwithstanding the entirely valid spirit of his argument, however, Thrasymachus does still err on the crucial point of precision upon which he had ironically insisted the debate be conducted. For it is not, importantly, the nature of the arts themselves that is defective, as Socrates correctly though misleadingly counters, but rather the nature of the artist: it is the practitioner himself who is defective. "The art of medicine has now been discovered because a body is defective [poneros]," says Socrates, gleefully taunting Thrasymachus with his own point before demolishing it on an apparent technicality, "and it won't do for it to be like that. The art was devised for the purpose of providing what is advantageous for a body." ${ }^{56}$ Yet even in his disingenuity Socrates cleverly prepares the ground for the more earnest debate that follows his exchange with Thrasymachus beginning with Book II of the Republic. In particular his use of the idiomatic Greek term poneros, which could be translated with equal justice as either "bad" or "vicious", 57 suggests precisely the kind of moral arguments that he will later make about the even 
greater defects of the human soul. The evident implication is that any statesman seeking to cure the insufficiencies of the body separately from, or, even worse, before or instead of, those of the soul will necessarily fail to achieve the ends that are most proper to his own art, which is the establishment of a just and stable political order. For vicious men who have already been made sufficient in their bodies can have no further inclination - or perhaps we ought rather to say "incentive" - whether politically, or morally, or economically, to become virtuous. Pace Diotima, feeling no want in their bodies, they may never, perhaps, feel any want in their souls.

Not the arts themselves, then, but more precisely the practise of the arts must be made to harmonize with the nobler and supremely necessary ends of philosophy, which are none other than wisdom and justice. To do so no doubt requires the careful coordination of the otherwise separate ends sought by each individual practitioner of the various arts. "For harmony is symphony, and symphony is an agreement," observes the noble doctor Eryximachus in his speech in the Symposium, while only barely maintaining the already thin veil over his more fundamentally political point, "but there cannot be an agreement of disagreements so long as they disagree; for that which disagrees cannot harmonize." ${ }^{58}$ Yet man's material condition may yet prove to be the leading note resolving men into a just consonance with each other, for man still is, to recall Socrates' words at the founding of the city, in need of much. No matter how great is his desire to live gazing in perpetuity upon the heavens "without food or drink, if that were possible," ${ }^{59}$ man's soul, despite all the strength of his desires to the contrary, is nevertheless incarnate. And although Socrates, while rightly noting that nothing of the "Beautiful City" (Callipolis) can ever exist in the absence of the Good, nevertheless errs 
himself in failing to specify the exact material conditions from which the Good is to be reached, it still remains that the political and moral imperatives upon which the philosopher-king must act are in their essence inextricably tied to the erotic nature of economics because the very foundation of the city - any city - is tied to the same as well.

So too must be the nature of economic exchange between men, that marvellous system which holds out the great promise that the disparate goals of the vast multitude of arts might be brought into equilibrium as so many discordant notes brought to a grand and harmonious final cadence. "Our ancestor Asclepius first established medicine as a profession," Eryximachus declares, "when he learned how to produce concord and love between such opposites." ${ }^{\prime 60}$ The parallel he draws between music and medicine is entirely all too fitting. For in the philosopher-king's endeavour to harmonize the city's triad of political, moral, and economic ends, he undertakes a virtuous division of labour in the great spirit of Apollo, signalling the initial healing of mankind in his turning-around of the prisoners in the Cave to reorient their gaze toward the heavenly light of Truth. Not only does he thereby allow the prisoners to contemplate what beauty they can and to seek what virtues they must, ${ }^{61}$ but, even more importantly for their mutual interest and collective self-sufficiency, he also infuses them with the necessary knowledge by which they are to become makers. And so, too, is it the philosopher-king who, like none other than almighty Zeus himself, must also undertake a final Great Healing of his own: he must turn around the genitals of human beings in order that they may be oriented toward each other, thus to invent a metaphysical form of erotic exchange and material production caused by the Idea in the artisan. Only thence do men bring forth into the earthly realm the infinite material diversity of the beautiful and the good. 
Such inventiveness on the part of man is surely an act of impiety if not outright subversion. What sacrilege! What outrage! Yet the philosopher-king's need to heal the many is as urgent as Zeus' healing of Aristophanes' primordial man, whose condition is broken, tortured, desperate, sterile, and starving. For man cannot long live in his isolated condition within a darkened Cave: although the many ignorant know not the difference, they cannot with their bodies drink of its darkness nor feed upon its shadows. Inasmuch as the philosopher-king seeks man's political liberation and moral redemption he cannot ignore the erotic economics upon which the city comes into being and through which its continuing existence is assured. Thus not just to free man of his necessities, not only to allow him to gaze upon the beautiful, nor even to deliver him unto wisdom - nay, not even to redeem his very soul. The stakes are far higher: to save the fabric of man's being from the abyss of annihilation. 


\section{The Moral Value of Property}

The political argument of the Republic holds that the well-ordered city must ultimately be rooted in what is an essentially moral community. As such, the pursuit of virtue becomes the dominant uniting interest of the city's various parts. In order for this to be the case, however, there must be a shared conception of virtue that allows for the specialization of tasks, otherwise the city will fail to achieve a proper alignment among the diversity of interests among and between its various parts. Since virtue is a particular kind of knowledge that implies a highly specialized form of practical activity, and since all practical activity is necessarily constrained by the particularities of the material conditions in which it takes place, property must play an essential role in achieving virtue. In this regard, property is also essential to the overall harmonizing of interests under the ideal regime. This is true at all levels of the city. At the level of the individual citizen, the capacities of the body must be reconciled to the demands of the soul; at the level of the city's classes, the competing interests of individual members must be reconciled to a greater overall purpose; and at the level of the city, the different ends of each class must be reconciled to a single common pursuit that is ultimately defined by the Good. In all three cases, the moral value of property makes it instrumental, and therefore indispensable, to harmonizing the diversity of competing interests within the city. 
Consider first the role of property at the level of the individual citizen. As we have already demonstrated, the division of labour among the citizenry at the founding of the city in Book II is implicitly premised upon the notion that the the erotic desires of the soul are by nature highly specialized. The inherently specialized nature of the soul implies, in turn, a certain predisposition of talents that can be explained in terms of an erotic orientation toward particular kinds of goods. The immediate problem that the division of labour aims to resolve is the misalignment between the capacities of the body and the moral imperatives of the soul that would otherwise result outside the context of the well-ordered political community. To facilitate the realignment of these two halves of the individual citizen, Socrates mandates a division of labour that implicitly allocates to each citizen the kinds of property that are necessary to equip the body to act upon the desires of the soul in terms of the practical activity that is virtue. Property thus becomes the instrument through which the individual citizen is able to pursue the particular objects that are given by nature according to his or her erotic predispositions. If we consider the moral demands and requirements of a virtuous division of labour with reference to, as an example, the shipwright, then erotic predispositions that would direct his efforts toward the crafting of vessels necessarily requires a distribution of property that would allocate to him all of the necessary tools and raw materials for the practice of ship-building, such as hammers, saws, nails, and lumber. Only through the use of such property is the shipwright capable of fulfilling his inherent nature.

The very same principle applies analogously at the level of the city's classes. Here the Bronze class illustrates the point particularly well, since the essential role of property in forging what might be called class identity reveals a greater degree of complexity in 
the city's class structure that is otherwise absent among the ruling classes. Whereas the specialization of tasks in the city leads Socrates to assign to the Gold and Silver classes a single specific task each - respectively, ruling and war-making - Socrates instead assigns the Bronze class the much more general task of producing all of the city's material goods. This means that the Bronze class will not perform any single task collectively as a class, as is the case with the other two, but rather a variety of very different tasks. Unlike the Guardians, for instance, each of whom has an erotic predisposition toward the Good and will therefore perform the very same art in concert with the other members of the Gold class, each of the city's money-makers will perform different arts separately from the other members of their class. For this reason, there is an added layer of complexity in establishing class cohesion and unity among the Bronze class compared to what exists among any of the other classes, including the rulers.

Again, property bridges the gap. When property is used specifically as a means for economic production, it gives rise to a natural metaphysical asymmetry that draws the arts together. The production of property does not result in additional instances of the same kind of property that is used to produce it. Instead, it results in a greater variety of property overall. Consider again the example of the Shipwright. While the practise of his own art requires that he employ a distinctive set of tools, which he brings to bear upon a particular kind of raw material, the very nature of his art is that it produces something altogether from that with which it began. The shipwright does not produce more hammers and more saws, but rather ships. While obvious, the point is nevertheless significant because it means that the shipwright will be unable to practise his art except in the company of other artisans. That the blacksmith must supply him with hammers and saws, 
and that the logger must supply him with lumber, means that there is an inherent element of economic dependence these three arts and those who practise them. The necessity of production draws them together and thereby aligns what would otherwise be competing interests between the individual craftsmen when considered in isolation from each other. The particular goods of each cannot be achieved except insofar as they are pursued in concert with the other members of the same class.

Finally, property serves to harmonize the interests of the different classes because it aligns the interests of the ruled and the rulers toward a single common Good. Because virtue is a kind of activity that both depends on and results in specialized areas of expertise, its practice necessarily implies an element of knowledge in the strictest Platonic sense of the word. This is most obviously true in the case of the rulers, who devote themselves fully to the pursuit of wisdom entire; yet it is also true in the case of the Bronze class, albeit to a lesser extent. The nature of the metaphysics of artistry that we have already discussed implies that the successful practice of, for example, the shipwright's art implies the successful achievement of knowledge of some kind. The skilfulness of virtue both demands and requires that the shipwright wield his instruments with certain knowledge of their proper good, for otherwise he will be unable to reproduce on the earthly plane multiple material instances of the heavenly Idea of the Ship. Just as the philosophers undertake their fabled ascent to knowledge of the Form of the Good, so too does the shipwright undertake his own lesser ascent to knowledge of the Form of the Ship. In this way the economic organization of the city, and the distribution of property that it requires, proves essential to achieving the harmony of the city's diverse interests in the common the pursuit of truth. 


\section{Notes}

\section{EPIGRAPH}

Thesis epigraph quoted from John Milton, Paradise Lost V, 574-576; eds. William Kerrigan, John Rumrich, and Stephen M. Fallon (New York: Modern Library, 2007), p. 183.

\section{INTRODUCTION}

1. Plato, Republic IV, 419a; trans. Allan Bloom (New York: Basic Books, 1991), p. 97.

2. Plato, Republic IV, 420b; trans. Bloom, p. 98.

3. Plato, Republic II, 372a-b; trans. Bloom, p. 49.

4. Plato, Republic IV, 420b; trans. Bloom, p. 98.

5. Plato, Republic I, 347a; trans. Bloom, p. 24.

6. Plato, Republic VII, 521a; trans. Bloom, p. 199.

7. Plato, Republic VI, 441a; trans. Bloom, p. 120.

8. Plato, Republic VI, 441a; trans. Bloom, p. 120.

9. Plato, Republic IX, 581a-c; trans. Bloom, p. 262.

10. Plato, Republic II, 358b; trans. Bloom, p. 36.

11. Plato, Republic III, 416e; trans. Bloom, p. 96.

12. Plato, Republic VII, 521a; trans. Bloom, p. 199.

13. Plato, Republic V, 464a and ff.; trans. Bloom, p. 143.

14. Plato, Republic VIII, 550e; trans. Bloom, p. 228

15. Plato, Republic I, 344a; trans. Bloom, p. 22.

16. Plato, Republic III, 415a-417b; trans. Bloom, pp. 94-96.

17. Plato, Republic III, 416e; trans. Bloom, p. 96.

18. Plato, Republic II, 369b-372a; trans. Bloom, pp. 45-49.

19. Plato, Republic VI, 494a; trans. Bloom, p. 173. 
20. Plato, Republic IV, 431e-434c; trans. Bloom, pp. 110-113.

21. See, for example, Leo Strauss, “On Plato's Republic,” chap. 2 in The City and Man (Chicago: University of Chicago Press, 1964).

22. Plato, Republic II, 358b; trans. Bloom, p. 36.

23. Cf. Plato, Republic IV, 419a; trans. Bloom, p. 97.

24. Plato, Republic III, 415d; trans. Bloom, p. 95.

25. Plato, Republic I, 328c-331d; trans. Bloom, pp. 4-7.

26. Plato, Republic I, 331d; trans. Bloom, p. 7.

27. Plato, Republic X, 614b-621d; trans. Bloom, pp. 297-303.

\section{Chapter 1: The Scales of Justice}

Chapter One epigraph quoted from Virgil, Aeneid XII, 725-728; trans. John Dryden, ed. Charles W. Eliot, Vol. 13 of the Harvard Classics (New York: P. F. Collier \& Son, 1909), p. 420.

1. Leo Strauss, “On Plato's Republic,” chap. 2 in The City and Man (Chicago: University of Chicago Press, 1964), p. 62.

2. Thucydides, History of the Peloponnesian War, II.47; trans. Rex Warner (New York: Penguin, 1972), p. 152.

3. Mark Gifford, "Dramatic Dialectic in Republic Book I," Oxford Studies in Ancient Philosophy 20 (summer 2001): p. 61.

4. Gifford, "Dramatic Dialectic in Republic Book I," pp. 83, 94. See also: Julia Annas, An Introduction to Plato's Republic (Oxford: Clarendon Press, 1985), p. 18; Allan Bloom, The Republic of Plato, second edition (New York: Basic Books, 1991), p. 440 n. 3; Strauss, “On Plato’s Republic,” p. 63.

5. Debra Nails, “The Dramatic Date of Plato's Republic,” The Classical Journal 93, no. 4 (1998): p. 390.

6. Nails, “The Dramatic Date of Plato’s Republic,” esp. pp. 387-390.

7. Strauss, “On Plato’s Republic,” p. 63.

8. Plato, Apology, 42a; trans. G. M. A. Grube, in Plato: Complete Works, ed. John M. Cooper (Indianapolis: Hackett, 1997), p. 36.

9. Allan Bloom, "Interpretive Essay," in The Republic of Plato, second edition (New York: Basic Books, 1991), p. 307.

10. José Luis Calvo Martínez, "The Katábasis of the Hero," in Héros et héroïnes dans les myths et les cultes grecs: Actes du colloque organizé à l'Université de Valladolid, du 26 au 29 mai 1999 (Liège: Presses universitaires de Liège, 2000), http://books.openedition.org/pulg/747, paragraph 5.

11. Martínez, "The Katábasis of the Hero," paragraph 2.

12. Eric Voegelin, "The Republic," $\$ 2$; chap. 3 in vol. 16 of The Collected Works of Eric Voegelin, ed. Dante Germino (Columbia: University of Missouri Press, 2000), p. 107. 
13. See, for example, Planinc Zdravko, Plato through Homer: Poetry and Philosophy in the Cosmological Dialogues (Columbia: University of Missouri Press, 2003); Jacob Howland, The Republic: The Odyssey of Philosophy (Philadelphia: Paul Dry Books, 2004); Stanley Cavell, "Plato," chap. 17 in Cities of Words: Pedagogical Letters on a Register of the Moral Life (Cambridge, Massachusetts: Belknap Press, 2004); Radcliffe G. Edmonds III, Myths of the Underworld Journey: Plato, Aristophanes, and the "Orphic" Gold Tablets (Cambridge: Cambridge University Press, 2004); David K. O'Connor, "Rewriting the Poets in Plato's Characters," chap. 3 in The Cambridge Companion to Plato's Republic, ed. G. R. F. Ferrari (New York: Cambridge University Press, 2007).

14. Homer, Odyssey XXIII, 252-253; qtd. in Voegelin, “The Republic," §2, pp. 107-108.

15. Voegelin, “The Republic,” §2, p. 108.

16. Plato, Republic, 328c; trans. Allan Bloom (New York: Basic Books, 1991), p. 4.

17. Voegelin, "The Republic," §2, p. 105.

18. Voegelin, “The Republic," §2, p. 106.

19. Voegelin, "The Republic," §2, p. 105.

20. Voegelin, “The Republic," §2, p. 105.

21. Voegelin, “The Republic,” §1, pp. 102-103.

22. Voegelin, “The Republic,” §1, pp. 100-103.

23. Voegelin, "The Republic,” §1, pp. 103.

24. Martínez, "The Katábasis of the Hero," paragraph 1.

25. Plato, Republic X, 614b-621b; trans. Bloom, pp. 297-303.

26. Voegelin, “The Republic,” §1, p. 102.

27. Voegelin, "The Republic," §2, p. 106.

28. Plato, Republic I, 327a; trans. Bloom, p. 3.

29. Voegelin, “The Republic," §2, p. 108.

30. Voegelin, "The Republic," §2, p. 107.

31. Voegelin, "The Republic," §2, p. 108.

32. Voegelin, "The Republic," §2, p. 108.

33. Voegelin, “The Republic," §2, p. 114.

34. Voegelin, "The Republic," §2, p. 108.

35. Voegelin, “The Republic,” §2, p. 108; §1, p. 103.

36. Voegelin, “The Republic," §2, p. 108.

37. Voegelin, "The Republic," §2, p. 109.

38. Voegelin, "The Republic," §1, p. 103. 
39. Voegelin, “The Republic,” §2, p. 114.

40. Voegelin, “The Republic,” §1, p. 102.

41. Consider, for example, Socrates' remarks at Republic VII, 523b; trans. Bloom, p. 202: "Some objects of sensation do not summon the intellect to the activity of investigation because they seem to be adequately judged by sense, while others bid it in every way to undertake a consideration because sense seems to produce nothing healthy."

42. Voegelin, “The Republic," §2, pp. 114-115.

43. Voegelin, “The Republic,” §2, p. 106.

44. Plato, Republic X, 620c; trans. Bloom, p. 303.

45. Voegelin, “The Republic,” §2, p. 113.

\section{CHAPTER 2: CIVILIZATION AND BARBARISM}

Chapter Two epigraph quoted from Aeschylus, The Eumenides, lines 904-909; trans. Richmond Lattimore, in Aeschylus I: Oresteia, eds. David Grene and Richmond Lattimore, The Complete Greek Tragedies

(Chicago: University of Chicago Press, 1953), p. 167.

1. Plato, Republic X, 614b; trans. Allan Bloom, second edition (New York: Basic Books, 1991), p. 297.

2. Allan Bloom, The Republic of Plato, second edition (New York: Basic Books, 1991), p. 471 n. 13.

3. Bloom, The Republic of Plato, p. 471 n. 13.

4. Homer, Odyssey XII, 488; trans. Robert Fagles (New York: Penguin, 1996), p. 285.

5. Eric Voegelin, "The Republic," chap. 3 in vol. 16 of The Collected Works of Eric Voegelin, ed. Dante Germino (Columbia: University of Missouri Press, 2000), §2, p. 108.

6. Victor Davis Hanson, A War Like No Other: How the Athenians and Spartans Fought the Peloponnesian War (New York: Random House, 2006), p. 84.

7. Plato, Republic I, 327a; trans. Bloom, p. 3.

8. For example: Leo Strauss, "On Plato's Republic,” chap. 2 in The City and Man (Chicago: University of Chicago Press, 1964), p. 62.

9. Corinne Ondine Pache, "Barbarian Bond: Thracian Bendis among the Athenians," chap. 1 in Between Magic and Religion: Interdisciplinary Studies in Ancient Mediterranean Religion and Society, eds. Sulochana R. Asirvatham, Corinne Ondine Pache, and John Watrous (New York: Rowman \& Littlefield Publishers, 2001), p. 7.

10. Plato, Republic X, 614c; trans. Bloom, pp. 297-298.

11. Plato, Republic X, 614b-616a; trans. Bloom, pp. 297-299.

12. Voegelin, “The Republic,” §2, p. 107.

13. Plato, Republic X, 614b-616a; Republic I, 327a; trans. Bloom, pp. 297-299, 3.

14. Voegelin, “The Republic,” §2, p. 112. 
15. Voegelin, “The Republic," §2, p. 108.

16. Plato, Republic I, 331e-334d; trans. Bloom, pp. 7-11.

17. Plato, Republic I, 332a; trans. Bloom, p. 8.

18. Plato, Republic I, 334d; trans. Bloom, p. 11.

19. Plato, Republic I, 331e-336a; trans. Bloom, pp. 7-13.

20. Homer, Odyssey XV, 81; trans. Fagles, p. 321.

21. Robert Fagles, introduction to The Odyssey by Homer, trans. Robert Fagles (New York Penguin 1997), pp. 28-36.

22. Homer, Odyssey X, 1-83; trans. Fagles, pp. 230-233.

23. Homer, Odyssey IV, 642-698; trans. Fagles, pp. 142-144.

24. Homer, Iliad XVIII, lines 639-640, 646-650; trans. Robert Fagles (New York: Penguin, 1998), p. 485.

25. Homer, Odyssey IX, 44-70; trans. Fagles, pp. 212-213.

26. Homer, Odyssey IX, 59-62; trans. Fagles, p. 213.

27. Homer, Odyssey IX, 57-58; trans. Fagles, p. 213.

28. Homer, Odyssey IX, 45; trans. Fagles, p. 212.

29. Edwards, “Homer's Ethical Geography,” esp. pp. 28-48.

30. Plato, Republic V, 470a; trans. Bloom, p. 150.

31. Plato, Republic V, 470c; trans. Bloom, p. 150.

32. Plato, Republic V, 469e-471a; trans. Bloom, pp. 149-151.

33. Plato, Republic V, 470c; trans. Bloom, p. 150.

34. Aristotle, Politics II.4, 1262b5; trans. Benjamin Jowett, in The Complete Works of Aristotle: The Revised Oxford Translation, ed. Jonathan Barnes, vol. 2, Bollingen Series (Princeton: Princeton University Press, 1984), p. 2003.

35. Plato, Republic V, 469e-471a; trans. Bloom, pp. 149-151.

36. Pache, "Barbarian Bond," esp. pp. 4-6.

37. Peter Gainsford, "Formal Analysis of Recognition Scenes in the 'Odyssey'," The Journal of Hellenic Studies 123 (2003): pp. 41-59.

\section{CHAPTER 3: THE GREAT ForgetTing}

Chapter Three epigraph quoted from Hesiod, Theogony, 29-32; trans. Catherine M. Schlegel and Henry Weinfield, in Theogony and Works and Days (Ann Arbor: University of Michigan Press, 2010), p. 24.

1. Hesiod, Theogony, 37-38; trans. Schlegel and Weinfield, p. 24. 
2. Hesiod, Theogony, 915-916; trans. Schlegel and Weinfield, p. 51.

3. Job 1:15-17 (Authorized Version).

4. Plato, Republic X, 621c; trans. Allan Bloom, second edition (New York: Basic Books, 1992), p. 303.

5. Plato, Meno, 89a-d; trans. G.M.A. Grube, in Plato: Complete Works, ed. John M. Cooper (Indianapolis: Hackett, 1997), pp. 888-889.

6. R. E. Allen, "The Socratic Paradox," Journal of the History of Ideas 21, no. 2 (Spring 1960): pp. 256265; Gerasimos Santas, "The Socratic Paradoxes," The Philosophical Review 73, no. 2 (April 1964): pp. 147-164; Roslyn Weiss, The Socratic Paradox and Its Enemies (Chicago: University of Chicago Press, 2006).

7. See, for example, Plato's own Protagoras, trans. Lombardo and Karen Bell, in Plato: Complete Works, ed. John M. Cooper (Indianapolis: Hackett, 1997), pp. 746-790.

8. Aristotle, Nicomachean Ethics II.4, 1105b15; trans. W. D. Ross, revised by J. O. Urmson, in vol. 2 of The Complete Works of Aristotle: The Revised Oxford Translation, ed. Jonathan Barnes, Bollingen Series (Princeton: Princeton University Press, 1984), p. 1746.

9. Aristotle, Nicomachean Ethics VII.3, 1146b6-1147b19; trans. Ross, pp. 1811-1813.

10. Lawrence D. Houlgate, "Virtue Is Knowledge,” Monist 54, no. 1 (January 1970): p. 142.

11. Houlgate, "Virtue Is Knowledge," p. 143.

12. Heda Segvic, "No One Errs Willingly: The Meaning of Socratic Intellectualism," Oxford Studies in Ancient Philosophy XIX (Winter 2000): pp. 1-45.

13. Plato, Meno, 70b; trans. G. M. A. Grube, in Plato: Complete Works, ed. John M. Cooper (Indianapolis: Hackett, 1997) pp. 871-872.

14. Plato, Meno, 71c; trans. G. M. A. Grube, p. 872.

15. Plato, Meno, 71c; trans. G. M. A. Grube, p. 872.

16. Plato, Meno, $71 \mathrm{c}-\mathrm{d}$; trans. G. M. A. Grube, p. 872.

17. Plato, Meno, 89a-e; trans. G. M. A. Grube, pp. 888-889.

18. Lynn E. Rose, “Plato's Meno, 86-89," Journal of the History of Philosophy 8, no. 1 (January 1970): pp. 1-8; Harold Zyskind and R. Sternfeld, "Plato's 'Meno' 89c: 'Virtue Is Knowledge' a Hypothesis?" Phronesis 21, no. 2 (1976): pp. 130-134.

19. Plato, Meno, 86a-89e; trans. G. M. A. Grube, pp. 886-889.

20. Plato, Republic VII, 533c-d; trans. Bloom, p. 212.

21. Plato, Republic VII, 533d; trans. Bloom, p. 212.

22. Ovid, Metamorphoses VIII, 270-271; trans. Charles Martin (New York: Norton, 2004), p. 271.

23. Plato, Meno, 97a-98a; trans. G. M. A. Grube, p. 895.

24. Plato, Republic I, 339c-340b; trans. Bloom, pp. 16-17.

25. Plato, Republic I, 340c; trans. Bloom, p. 18. 
26. Plato, Republic I, 340d-342e; trans. Bloom, pp. 18-21.

27. Plato, Republic II, 370b; IV, 433b; trans. Bloom, pp. 47, 111.

28. Plato, Republic III, 416e; VII, 521d; trans. Bloom, pp. 95, 200.

29. Aristotle, Nicomachean Ethics I.8, 1098b30-1099a5; trans. Ross, p. 1736.

30. R. E. Allen, “The Socratic Paradox,” p. 257-258.

31. Plato, Meno, 86b; trans. G. M. A. Grube, p. 886.

32. Plato, Meno, 95c-96d; trans. G. M. A. Grube, pp. 893-894.

33. Plato, Meno, 74a; trans. G. M. A. Grube, p. 874.

34. Plato, Meno, 89e-96d; trans. G. M. A. Grube, pp. 889-894.

35. Plato, Meno, 90a-91b; 72a-75b; trans. G. M. A. Grube, pp. 889-890, 872-875.

36. Plato, Meno, 72a; trans. G. M. A. Grube, p. 872.

37. Ecclesiastes 3:1 (Authorized Version).

38. Ecclesiastes 1:11 (Authorized Version).

39. Plato, Meno, 80d; trans. G. M. A. Grube, p. 880.

40. Plato, Meno, 80e; trans. G. M. A. Grube, p. 880.

41. See, for instance, Republic III, 413d; VI, 486d; VII, 535c; trans. Bloom, pp. 92, 166, 214.

42. Plato, Meno, 93e; trans. G. M. A. Grube, p. 892.

43. Plato, Meno, 89b; trans. G. M. A. Grube, pp. 888-889.

44. Plato, Meno, 87d-89c; trans. G. M. A. Grube, pp. 887-889.

45. Plato, Republic VII, 519c; trans. Bloom, p. 198.

46. Plato, Republic VII, 518d; trans. Bloom, p. 197.

47. Plato, Republic VII, 519c; trans. Bloom, p. 198.

48. Plato, Republic III, 416d-417d; trans. Bloom, pp. 95-96.

49. Plato, Republic III, 415d; trans. Bloom, pp. 94-95.

50. Plato, Republic III, 416b; trans. Bloom, p. 95. (Emphasis added.)

51. Johann Wolfgang von Goethe, Faust, Part I, 1335-1336; trans. David Constantine (Toronto: Penguin, 2005), p. 46.

52. Plato, Republic III, 414d; trans. Bloom, p. 94.

53. Plato, Republic III, 415d; trans. Bloom, p. 94. 


\section{CHAPTER 4: REFOUNDING THE CitY}

Chapter Four epigraph quoted from Genesis 11:4-6 (Authorized Version).

1. Genesis 11:7-9.

2. Plato, Symposium, 190b-e; trans. Benjamin Jowett, revised by Hayden Pelliccia, in Selected Dialogues of Plato (New York: Modern Library, 2001), pp. 229-230.

3. See, for instance, Sophocles, Oedipus the King in The Three Theban Plays, trans. Robert Fagles (New York: Penguin, 1984); or Euripides, The Bacchae, trans. William Arrowsmith in Euripides V, ed. David Grene and Richmond Lattimore (Chicago: University of Chicago Press, 1968).

4. Plato, Republic II, 369b; trans. Allan Bloom, second edition (New York: Basic Books, 1991), p. 46.

5. Plato, Republic II, 369c; trans. Bloom, p. 46.

6. Plato, Republic II, 371b; trans. Bloom, p. 48.

7. Plato, Republic II, 371e-372a; trans. Bloom, p. 49.

8. See John Locke, Second Treatise of Government in Two Treatises of Government and A Letter Concerning Toleration, ed. Ian Shapiro (New Haven: Yale University Press, 2003), esp. ch. V, §§2551, pp. 111-121.

9. Plato, Republic II, 372c-373b; trans. Bloom, pp. 49-50.

10. Plato, Republic II, 372d; trans. Bloom, p. 49.

11. Socrates himself refers to Glaucon as an "erotic man" at Republic V, 474d; trans. Bloom, p. 154.

12. Plato, Republic II, 372c; trans. Bloom, p. 49.

13. Plato, Symposium, 178a; trans. Alexander Nehamas and Paul Woodruff, in Plato: Complete Works, ed. John M. Cooper (Indianapolis: Hackett, 1997), p. 463.

14. Plato, Symposium, 195c; trans. Nehamas and Woodruff, p. 478.

15. Plato, Symposium, 203b; trans. Nehamas and Woodruff, p. 486.

16. Plato, Republic II, 372b; trans. Bloom, p. 49.

17. Plato, Republic II, 372a; trans. Bloom, p. 49.

18. Plato, Symposium, 203e; trans. Nehamas and Woodruff, p. 486.

19. Plato, Republic VII, 517c; trans. Bloom, p. 196.

20. Hesiod, Works and Days, line 100; trans. Catherine M. Schlegel and Henry Weinfield, in Theogony and Works and Days (Ann Arbor: University of Michigan Press, 2010), p. 60.

21. Plato, Symposium, 204a; trans. Jowett, p. 250.

22. Plato, Symposium, 183e; trans. Jowett, pp. 220-221.

23. Plato, Republic X, 596d; trans. Bloom, p. 279. 
24. Ovid, Metamorphoses III, 533-537; trans. Charles Martin (New York: Norton, 2004), p. 107.

25. Plato, Republic VII, 521a; trans. Bloom, p. 199.

26. Ovid, Metamorphoses III, 551-557; trans. Martin, p. 107.

27. Dante, Inferno XV; trans. Hollander and Hollander, pp. 276-285.

28. Plato, Republic II, 373e; trans. Bloom, p. 50.

29. Plato, Republic II, 372b; trans. Bloom, p. 49.

30. Plato, Republic II, 372e-373e; trans. Bloom, pp. 49-50.

31. Plato, Symposium, 182c; trans. Jowett, pp. 218-219.

32. Ovid, Metamorphoses III, 549-550; trans. Martin, p. 107.

33. Plato, Symposium, 191a-b; trans. Nehamas and Woodruff, p. 474.

34. Ovid, Metamorphoses III, 567; trans. Martin, p. 108.

35. Plato, Symposium, 190e; trans. Nehamas and Woodruff, p. 474.

36. Plato, Symposium, 190e-191a; trans. Nehamas and Woodruff, p. 474.

37. Plato, Symposium, 189d-190a; trans. Nehamas and Woodruff, p. 473.

38. Genesis 1:28.

39. Plato, Symposium, 191c; trans. Nehamas and Woodruff, p. 474. (Emphasis in the original.)

40. Plato, Republic II, 370c; trans. Bloom, p. 47. (Emphasis added.)

41. Plato, Republic II, 374a; trans. Bloom, pp. 50-51.

42. Plato, Republic I, 342b; trans. Bloom, p. 20.

43. Plato, Republic I, 347a; trans. Bloom, p. 24.

44. Matthew 7:7.

45. Plato, Symposium, 210a-b; trans. Nehamas and Woodruff, p. 492.

46. Plato, Symposium, 210b; trans. Nehamas and Woodruff, p. 492.

47. Plato, Republic VII, 514a-517c; trans. Bloom, pp. 193-196.

48. Plato, Symposium, 206c; trans. Nehamas and Woodruff, p. 489.

49. Plato, Symposium 181c; trans. Jowett, p. 217.

50. Plato, Symposium, 190b; trans. Nehamas and Woodruff, p. 473.

51. Plato, Republic VI, 507d-509c; trans. Bloom, pp. 187-190.

52. Plato, Symposium, 191c; trans. Nehamas and Woodruff, p. 474. (Emphasis in the original.)

53. Plato, Republic VI, 509b; trans. Bloom, p. 189. 
54. Plato, Republic I, 342a; trans. Bloom, p. 19.

55. Plato, Republic I, 343a-344d; trans. Bloom, pp. 19-20.

56. Plato, Republic I, 341e; trans. Bloom, p. 19.

57. Bloom himself makes exactly this point: The Republic of Plato, second edition (New York: Basic Books, 1991), p. 445 n. 36.

58. Plato, Symposium, 187b; trans. Jowett, pp. 226-226.

59. Plato, Symposium, 211d; trans. Jowett, p. 260.

60. Plato, Symposium, 186e; trans. Nehamas and Woodruff, p. 470.

61. Plato, Republic VII, 532b-c; trans. Bloom, p. 211. 


\title{
Bibliography
}

\author{
Dialogues of Plato
}

Cooper, John M., ed. Plato: Complete Works. Indianapolis: Hackett, 1997.

Jowett, Benjamin, trans. Selected Dialogues of Plato. Revised by Hayden Pelliccia. New York: Modern Library, 2001.

Plato. Apology. Translated by G. M. A. Grube. In J. Cooper, 17-36.

—. Gorgias. Translated by Donald J. Zeyl. In J. Cooper, 791-869.

—. Meno. Translated by G. M. A. Grube. In J. Cooper, 870-897.

—. Phaedrus. Translated by Benjamin Jowett. In Jowett, 111-197.

—. Protagoras. Translated by Lombardo and Karen Bell. In J. Cooper, 746-790.

- Republic. Translated by Allan Bloom. Second edition. New York: Basic Books, 1991.

- Symposium. Translated by Alexander Nehamas and Paul Woodruff. In J. Cooper, 457-505.

—. Symposium. Translated by Benjamin Jowett. In Jowett, 199-277.

\section{OTHER SOURCES}

Aeschylus. The Eumenides. Translated by Richmond Lattimore. In Aeschylus I: Oresteia, edited by David Grene and Richmond Lattimore, 133-171. The Complete Greek Tragedies. Chicago: University of Chicago Press, 1953.

Allen, R. E. “The Socratic Paradox.” Journal of the History of Ideas 21, no. 2 (Spring 1960): 256-265. http://www.jstor.org/stable/2708198.

Annas, Julia. An Introduction to Plato's Republic. Oxford: Clarendon Press, 1985.

Aristotle. Economics. Translated by E. S. Forster and G. C. Armstrong. In Barnes, vol. 2, 2130-2151. 
. Nicomachean Ethics. Translated by W. D. Ross. Revised by J. O. Urmson. In Barnes, vol. 2, 1729-1867.

—. Politics. Translated by Benjamin Jowett. In Barnes, vol. 2, 1986-2129.

Ault, Bradley A. "Oikos and Oikonomia: Greek houses, households and the domestic economy." British School at Athens Studies 15 (2007): 259-265. http://www.jstor.org/stable/40960595.

Barnes, Jonathan, ed. The Complete Works of Aristotle: The Revised Oxford Translation. 2 vols. Bollingen Series. Princeton: Princeton University Press, 1984.

Berlin, Isaiah. "Does Political Theory Still Exist?" Chap. 3 in The Proper Study of Mankind, edited by Henry Hardy and Roger Hausheer. New York: Ferar, Straus and Giroux, 2000.

Bloom, Allan. The Republic of Plato. Second edition. New York: Basic Books, 1991.

_ _ "Response to Hall." Political Theory 5, no. 3 (August 1977): 315-330. http://www.jstor.org/stable/190644.

Burkholder, Peter J., Donald Jay Grout, and Claude V. Palisca. A History of Western Music. Seventh edition. New York: Norton, 2006.

Cavell, Stanley. "Plato." Chap. 17 in Cities of Words: Pedagogical Letters on a Register of the Moral Life. Cambridge, Massachusetts: Belknap Press, 2004.

Cooper, Barry and Jodi Bruhn. Voegelin Recollected: Conversations on a Life. Columbia: University of Missouri Press, 2008.

Dante. Inferno. Translated by Robert Hollander and Jean Hollander. New York: Anchor Books, 2002.

Edmonds, Radcliffe G. III. Myths of the Underworld Journey: Plato, Aristophanes, and the "Orphic" Gold Tablets. Cambridge: Cambridge University Press, 2004.

Edwards, Anthony. "Homer's Ethical Geography: Country and City in the Odyssey." Transactions of the American Philological Association 123 (1993): 27-78. http://www.jstor.org/stable/284323.

Euripides. The Bacchae. Translated by William Arrowsmith. In Euripides $V$, edited by David Grene and Richmond Lattimore, 141-222. Chicago: University of Chicago Press, 1968.

Finley, M. I. The Ancient Economy. 1973. Second edition. London: Hogarth Press, 1985.

Foley, Vernard. "The division of labor in Plato and Smith." History of Political Economy 6, no. 2 (summer 1974): 220-242. 
Gainsford, Peter. "Formal Analysis of Recognition Scenes in the 'Odyssey'." The Journal of Hellenic Studies 123 (2003): 41-59.

http://www.jstor.org/stable/3246259.

Gifford, Mark. "Dramatic Dialectic in Republic Book I." In Oxford Studies in Ancient Philosophy XX (summer 2001): 35-106.

Goethe, Johann Wolfgang von. Faust, Part I. Translated by David Constantine. Toronto: Penguin, 2005.

Hall, Dale. "The Republic and the 'Limits of Politics'." Political Theory 5, no. 3 (August 1977): 293-313. http://www.jstor.org/stable/190643.

Hanson, Victor Davis. A War Like No Other: How the Athenians and Spartans Fought the Peloponnesian War. New York: Random House, 2006.

Hesiod. Theogony and Works and Days. Translated by Catherine M. Schlegel and Henry Weinfield. Ann Arbor: University of Michigan Press, 2010.

Homer. The Iliad. Translated by Robert Fagles. New York: Penguin, 1998.

- The Odyssey. Translated with an introduction by Robert Fagles. New York: Penguin, 1997.

Houlgate, Lawrence D. "Virtue Is Knowledge.” Monist 54, no. 1 (January 1970): 142153. doi:10.5840/monist197054111.

Howland, Jacob. The Republic: The Odyssey of Philosophy. Philadelphia: Paul Dry Books, 2004.

Locke, John. Second Treatise of Government. In Two Treatises of Government and A Letter Concerning Toleration, edited by Ian Shapiro, 100-209. New Haven: Yale University Press, 2003.

Martínez, José Luis Calvo. "The Katábasis of the Hero.” In Héros et hérö̈nes dans les myths et les cultes grecs: Actes du colloque organizé à l'Université de Valladolid, du 26 au 29 mai 1999. Liège: Presses universitaires de Liège, 2000. http://books.openedition.org/pulg/747.

Migeotte, Léopold. The Economy of the Greek Cities: From the Archaic Period to the Early Roman Empire. Translated by Janet Lloyd. Berkeley: University of California Press, 2009.

Milton, John. Paradise Lost. Edited by William Kerrigan, John Rumrich, and Stephen M. Fallon. New York: Modern Library, 2007.

Nails, Debra. “The Dramatic Date of Plato's Republic.” The Classical Journal 93, no. 4 (1998): 383-396. http://www.jstor.org/stable/3298163. 
O’Connor, David K. "Rewriting the Poets in Plato's Characters.” Chap. 3 in The Cambridge Companion to Plato's Republic, edited by G. R. F. Ferrari. New York: Cambridge University Press, 2007.

Ovid. Metamorphoses. Translated by Charles Martin. New York: Norton, 2004.

Pache, Corinne Ondine. "Barbarian Bond: Thracian Bendis among the Athenians." Chap. 1 in Between Magic and Religion: Interdisciplinary Studies in Ancient Mediterranean Religion and Society, edited by Sulochana R. Asirvatham, Corinne Ondine Pache, and John Watrous. New York: Rowman \& Littlefield Publishers, 2001.

Pipes, Richard. Property and Freedom. New York: Knopf, 2007.

Polanyi, Karl. The Great Transformation. 1947. Boston, Mass.: Beacon Press, 2001.

Rose, Lynn E. “Plato’s Meno, 86-89.” Journal of the History of Philosophy 8, no. 1 (January 1970): 1-8.

Rosen, Stanley. Plato's Republic: A Study. New Haven: Yale University Press, 2005.

Santas, Gerasimos. "The Socratic Paradoxes." The Philosophical Review 73, no. 2 (April 1964): 147-164. http://www.jstor.org/stable/2183333.

Schofield, Malcolm. "Plato on the Economy." Chap. 4 in Saving the City: PhilosopherKings and Other Classical Paradigms. New York: Routledge, 2003.

Seery, John Evan. "Politics as Ironic Community: On the Themes of Descent and Return in Plato's Republic.” Political Theory 16, no. 2 (May 1988): 229-256. http://www.jstor.org/stable/191707.

Segvic, Heda. "No One Errs Willingly: The Meaning of Socratic Intellectualism." Oxford Studies in Ancient Philosophy XIX (winter 2000): 1-45.

Shakespeare, William. Hamlet. The Annotated Shakespeare. Edited by Burton Raffel. New Haven: Yale University Press, 2003.

- Romeo and Juliet. Edited by G. Blakemore Evans. Cambridge: Cambridge University Press, 1984.

Skinner, Quentin. “A reply to my critics.” Chap. 14 in Tully.

—. "Meaning and understanding in the history of ideas." Chap. 2 in Tully.

Smith, Adam. An Inquiry into the Nature and Causes of the Wealth of Nations. Edited by R. H. Campbell and A. S. Skinner. 2 vols. The Glasgow Edition of the Works and Correspondence of Adam Smith. Indianapolis: Liberty Fund, 1981. 
Sophocles. Oedipus the King. In The Three Theban Plays, translated by Robert Fagles, 129-251. New York: Penguin, 1984.

Strauss, Leo. “On Plato’s Republic.” Chap. 2 in The City and Man. Chicago: University of Chicago Press, 1964.

—. "Persecution and the Art of Writing." Chap. 2 in Persecution and the Art of Writing. Glencoe, Illinois: The Free Press, 1952.

—. "Plato." 1963. In An Introduction to Political Philosophy: Ten Essays, edited by Hilal Gilden, 167-245. Detroit: Wayne State University Press, 1989.

Thucydides. History of the Peloponnesian War. Translated by Rex Warner. New York: Penguin, 1972.

Tully, James, ed. Meaning and Context: Quentin Skinner and His Critics. Cambridge: Polity Press, 1998.

Virgil. The Aeneid. Translated by John Dryden. Edited by Charles W. Eliot. Vol. 13 of the Harvard Classics. New York: P. F. Collier \& Son, 1909.

Voegelin, Eric. "The Republic." Chap. 3 in vol. 16 of The Collected Works of Eric Voegelin, edited by Dante Germino. Columbia: University of Missouri Press, 2000 .

Welles, C. Bradford. “The Economic Background of Plato's Communism.” The Journal of Economic History 8 (supplement 1948): 101-114. http://www.jstor.org/stable/2113567.

Weinstein, Joshua I. “The Market in Plato's Republic.” Classical Philology 104, no. 4 (October 2009): 439-458. doi:10.1086/650979.

Weiss, Roslyn. The Socratic Paradox and Its Enemies. Chicago: University of Chicago Press, 2006.

Zdravko, Planinc. Plato through Homer: Poetry and Philosophy in the Cosmological Dialogues. Columbia: University of Missouri Press, 2003.

Zyskind, Harold and R. Sternfeld. 'Plato's 'Meno' 89c: 'Virtue Is Knowledge' a Hypothesis?" Phronesis 21, no. 2 (1976): 130-134.

http://www.jstor.org/stable/4181984. 